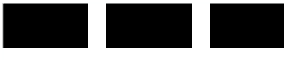 \\ DE
}

The WiLliam DAVIDSON INSTITUTE

AT THE UNIVERSITY OF MICHIGAN BUSINESS SCHOOL

Assessing Equilibrium Exchange Rates in CEE Acceding Countries: Can We Have DEER with BEER without FEER?

\author{
By: Balázs Égert
}

William Davidson Institute Working Paper Number 664

February 2004 


\section{Assessing Equilibrium Exchange Rates in CEE Acceding Countries: Can We Have DEER with BEER without FEER?}

Balázs Égert ${ }^{1}$

\section{Abstract}

The ambition of this paper is to provide a thorough overview of equilibrium exchange rates in the acceding countries of Central and Eastern Europe. Therefore, theoretical models of equilibrium exchange rates are reviewed first and presented in a structured way. Subsequently, the existing body of the empirical literature aimed at investigating real exchange rate determination and possible misalignments is analyzed in a systematic manner. Finally, an attempt is made to sum up where we stand at the moment and what the major shortcomings of the approaches currently used in the literature are.

JEL Codes: E31, F31, O11, P20

Keywords: Equilibrium Exchange Rate, BEER, DEER, FEER, NATREX, Balassa-Samuelson effect, tradable goods, regulated prices, transition economies

$1 \quad$ Foreign Research Division, Oesterreichische Nationalbank; MODEM, University of Paris X-Nanterre and the William Davidson Institute. E-mail: balazs.egert@oenb.at and begert@u-paris10.fr.

Earlier versions of this study were presented at the Annual Meeting of the French Economic Association (AFSE), 2003, and at seminars held at the European Commission and at The Vienna Institute for Comparative Economic Studies (WIIW).

The study benefited from comments and suggestions from Enrique Alberola, Peter Backé, Virginie Coudert, Mark DeBroeck, Rumen Dobrinsky, Péter Karádi, likka Korhonen, Dubravko Mihaljek, Renzo Orsi, Jörg Rahn, Martti Randveer, Katerina Šmídková, Jerome L. Stein, Balázs Vonnák and Cezary Wójcik. I am particularly indebted to Kirsten Lommatzsch and Thomas Reininger for their thorough remarks and suggestions. Many thanks go to Michaela Meth, Irene Mühldorf and Ingeborg Schuch for excellent language advice. 


\section{Introduction}

Recently, the much-heralded EU enlargement has focused considerable attention on how acceding countries should prepare for their subsequent euro area entry. In this context, one important issue at the center of policy debate is the introduction of an exchange rate mechanism, ERM II, which is consistent with the Maastricht criterion on exchange rate stability. Hence, the focus has swiftly shifted to the questions of how quickly and with which parity new Member States should join ERM II and subsequently the euro area. The latter question is closely related to the concept of the equilibrium real exchange rate, and the answer is bound to remain a challenge in the future.

This paper attempts to take stock of what is known about equilibrium real exchange rates in acceding countries by surveying the empirical literature. The roadmap of the paper is the following. Section 2 presents basic concepts and definitions of the exchange rate. Section 3 discusses the theoretical background and the operational toolbox of the equilibrium real exchange rate. Section 4 attempts to link the different approaches. Section 5 gives an overview of the empirical body of literature. Section 6 summarizes the findings. Finally, Section 7 provides concluding remarks.

\section{Basic Concepts and Definitions}

The real exchange rate can be defined in two different ways. The first definition, termed the "internal real exchange rate," refers to the ratio of nontradable prices to tradable prices

$$
Q^{\mathrm{internal}}=\frac{P^{N T}}{P^{T}}
$$

where $Q$ is the internal real exchange rate and $P^{N T}$ and $P^{T}$, respectively, stand for the price level of the nontradable and tradable sectors.

This definition is appropriate for small, open developing countries whose trade consists chiefly of commodities. The internal real exchange rate does not include the nominal exchange rate, as the latter is assumed to be either fixed or to be driven by commodity 
prices in world markets. This is the reason why estimating the equilibrium "internal real exchange rate" provides little guidance on the equilibrium nominal exchange rate.

What is more relevant to our purposes is, however, the macro definition of the real exchange rate, also labeled the "external real exchange rate," which is given as the nominal exchange rate multiplied by the foreign price level and divided by the domestic price level as follows:

$$
Q=\frac{E \cdot P^{*}}{P}
$$

In this case, the nominal exchange rate $(E)$ is expressed as units of domestic currencies per one unit of foreign currency. Thus, a rise in the exchange rate means a depreciation, while a drop indicates an appreciation. Note that this definition will be used throughout the whole paper. $P$ and $P^{*}$ denote the domestic and the foreign price levels. The real exchange rate $(Q)$ is the ratio of the foreign $\left(E P^{*}\right)$ and domestic price $(P)$ levels converted into the same unit of measure, i.e. domestic currency units. We will refer to the external real exchange rate as the real exchange rate in the remainder of this paper.

If the variables are expressed in indices, the real exchange rate shows the relative shift which has occurred between the foreign and domestic price levels over a given lapse of time.

The price level can be split into tradable and nontradable prices, which, after transforming variables into logarithms, can be written in the following way: ${ }^{2}$

$$
p=\alpha \cdot p^{T}+(1-\alpha) \cdot p^{N T}
$$

where $\alpha$ stands for the share of tradable goods in the consumer price basket and $(1-\alpha)$ represents the share of nontradable goods. Introducing equation (3) into equation (2), and making some manipulations, ${ }^{3}$ the real exchange rate can be decomposed into three components:.

\footnotetext{
${ }^{2}$ Small letters refer to logarithms hereafter.

${ }^{3}$ Introducing equation (3) into equation (2) yields equation (1'):
} 
- the nominal exchange rate (e)

- the ratio of foreign to domestic tradable prices $\left(p^{T} *-p^{T}\right)$

- the ratio of the domestic to the foreign relative price of nontradable goods:

$$
\begin{aligned}
& (1-\alpha)\left(p^{N T}-p^{T}\right)-\left(1-\alpha^{*}\right)\left(p^{N T} *-p^{T *}\right) \\
& q=\underbrace{e+p^{T} *-}_{\text {tradable sector }} p^{T}-(\underbrace{1-\alpha)\left(p^{N T}-p^{T}\right)-\left(1-\alpha^{*}\right)\left(p^{N T} *-p^{T}\right.}_{\text {the ratio of the domestic to the foreign }})) \\
& \text { relative price of nontradable goods }
\end{aligned}
$$

real exchange rate of the tradable sector

the internal real exchange rate

The first two components are actually the real exchange rate for tradable goods. It also becomes evident that the internal real exchange rate is part of the external real exchange rate.

\section{Theoretical Foundations of the Equilibrium Real Exchange Rate}

\subsection{Purchasing Power Parity}

There are several approaches to equilibrium real exchange rates. The first one, purchasing power parity (PPP), formalized in a string of papers by Cassel (1916a, b and 1918), tells us that the nominal exchange rate is the domestic price level divided by the foreign price level:

$$
E^{P P P}=\frac{P}{P^{*}}
$$

PPP is supposed to determine the long-term nominal exchange rate. But in the shorter run, the nominal exchange rate prevailing in the forex markets may deviate from that suggested by PPP. In this event, the extent of the deviation might be thought of as an

$$
q=e+\alpha^{*} \cdot p^{T} *+\left(1-\alpha^{*}\right) \cdot p^{N T} *-\left(\alpha \cdot p^{T}+(1-\alpha) \cdot p^{N T}\right)
$$

With $\alpha^{*} \cdot p^{T *}=p^{T} *-\left(1-\alpha^{*}\right) \cdot p^{T}$ and $-\alpha \cdot p^{T}=-p^{T}+(1-\alpha) \cdot p^{T}$, we obtain:

$$
q=e+p^{T} *-p^{T}-\left(1-\alpha^{*}\right) \cdot p^{T} *+\left(1-\alpha^{*}\right) \cdot p^{N T} *+(1-\alpha) \cdot p^{T}-(1-\alpha) \cdot p^{N T}
$$

The rearrangement of equation (2') then gives equation (4). 
over- or undervaluation of the home currency. This can be illustrated by introducing equation (5) into equation (2) ${ }^{4}$ :

$$
Q=\frac{E}{E^{P P P}}
$$

If the actual nominal exchange rate is higher than the one given by $\operatorname{PPP}\left(E>E^{P P P}\right)$, i.e. the real exchange rate is higher than 1 , the real and nominal exchange rates are undervalued whereas in the opposite case they are overvalued $\left(E<E^{P P P}\right)$. If $E=E^{P P P}$, the real exchange rate is equal to 1 and can be viewed as fairly valued in PPP terms.

The conjecture underlying PPP is that the Law of One Price (LOOP) holds for every good in the price basket. In accordance with LOOP, a given good should cost the same in the home and the foreign country when the price is expressed in the same currency $\left(P_{i}=E \cdot P_{i}^{*}\right)$. This is secured by the international good arbitrage mechanism, which impacts on prices and the nominal exchange rate so that LOOP holds at the end of the day. For good arbitrage to be effective, perfect competition must prevail both in home and foreign markets, there must be no trade barriers and capital movements must not be restricted.

There are a number of reasons why PPP might be misleading as a yardstick for assessing equilibrium real exchange rates, of which only the most important ones are enumerated below.

First, even though LOOP holds, if the composition and the weights of the price basket differ across countries, PPP is a flawed measurement, as it is akin to comparing apples with oranges and pears. Differences in the composition of the price basket can come from different consumer and production patterns: consumers may want to consume different goods or varying quantities of the same good and producers can manufacture different goods in different countries.

Note that this formula is sometimes also referred to as the Exchange Rate Deviation Index (ERDI). $Q$ is defined as units of local currency over one unit of foreign currency. 1/Q is the real exchange rate given as units of foreign currency to one unit of domestic currency, and is also labeled as the comparative or relative price level or the exchange rate gap. 
Second, LOOP may not work, which in turn leads to the failure of PPP, because perfect competition may not prevail: there are transport costs and differentiated products that may lead to pricing-to-market phenomena (Driver and Westaway, 2004; Haskel and Wolf, 2001).

Third and most importantly, the presence of nontradable goods in the price basket is bound to bring about a systematic deviation of the observed exchange rate from the exchange rate implied by PPP. This deviation is expected to be substantial especially when comparing countries at different stages of economic development. The reason for this is that nontradable prices in developing countries are far lower than in developed countries.

\subsection{Trend Appreciation in Transition Economies}

\subsubsection{Accounting for Market Nontradable Prices: The Balassa- Samuelson Effect}

\subsubsection{A Brief Description}

Consider two countries with the same nontradable price level (case 1) and that PPP holds for the open sector. The respective price levels are given by $P_{1}$ and $P^{*}$. Next, consider the case (case 2 ) based on the same foreign country ( $P^{*}$ is constant) and in which, all things being equal, nontradable prices in the home country are lower than in the foreign economy (overall price level $=P_{2}$ ) so that the domestic price level will be below that in case 1 . As a corollary, the PPP-based nominal exchange rate will be lower in case 2 than in case 1 . $\left(P_{2}<P_{1}\right.$, so that $\left.P_{2} / P^{*}<P_{1} / P^{*}\right)$. In both cases, the actual nominal exchange rate $(E)$ is given by PPP in the open sector. This means that the real exchange rate in the first case will equal 1 (the real exchange rate is in equilibrium) while it will be higher than 1 in the second case (in equation (6), the real exchange rate is undervalued). However, if the price level of nontradables in the home country converges towards nontradable prices in the foreign country so that the ratio $\left(P^{N T} / P^{T}\right)$ is roughly $\left(P^{N T} * / P^{T *}\right)$ in the long run, the real exchange rate will systematically 
appreciate, since it is higher than 1 at the outset and will tend to decrease to 1 over time.

The theoretical backdrop of this trend appreciation is elaborated in the BalassaSamuelson model (Balassa, 1964; Samuelson, 1964; henceforth referred to as the B-S effect). The model is based on an economy split into two sectors, producing tradable and nontradable goods. It is assumed that market forces are at work in both sectors. This has important implications, because in the public and other regulated sectors, wages and prices will not behave as described hereafter. First, PPP is assumed to be verified for the tradable sector. Hence, prices in this sector are given exogenously. Second, wages are linked to the level of productivity in the open sector. Third, wages tend to equalize across sectors so that the wage level in the closed sector is comparable to that in the open sector. Finally, prices in the sheltered sector depend on wages, i.e. on unit labor costs rather than on the level of productivity in this sector.

Let us now assume that the home country is the developing country with low productivity levels while the foreign country is the developed country with high productivity levels in the open sector. Prices for tradable goods are given by PPP in both countries. In the home country, low productivity in the open sector implies low wages in the same sector, which in turn implies low wages and low prices in the marketbased closed sector. By contrast, high productivity in the open sector implies high wages $^{5}$ in the same sector, which is reflected in high wages and high prices in the market-based closed sector. The true key to different market-driven nontradable prices and thus overall price levels should be sought in differing productivity levels.

If the home (developing) economy is able to catch up systematically with the foreign (developed) economy, productivity is expected to rise correspondingly in the open sector. When productivity improves faster in the open sector than in the market-based sheltered sector, market-determined nontradable prices are expected to rise because of the wage spillover from tradables to nontradables. This in turn gives rise to an increase in the overall price level. If the home country's productivity differential between the open

\footnotetext{
${ }^{5}$ Higher productivity means that more goods can be produced using the same amount of inputs, i.e. labor and capital, so that the inputs' remuneration can be increased (i.e. higher wages) without putting competitiveness at risk (as prices are determined by PPP).
} 
and the market-based sheltered sector exceeds that of the foreign country, the price level will rise faster in the home country, implying a positive inflation differential. This in turn will be reflected in the appreciation of the home country's real exchange rate.

It is worth pausing to summarize the propositions of the B-S model:

1) Different productivity levels imply, via differences in market-based nontradable prices, different price levels expressed in the same currency;

2) The real and nominal exchange rate of low-productivity (typically developing) countries seem undervalued in PPP terms;

3) If productivity growth is higher in the open sector than in the sheltered sector, nontradable prices and thus the overall price level will rise (also referred to as structural inflation); and

4) Higher growth of the productivity differential in the home country than in the foreign country is reflected in faster increases in the price level, leading to the real appreciation of the home currency (convergence towards PPP).

However, these propositions hinge on the following assumptions:

1) Wages are linked to productivity in the open sector;

2) Wages tend to equalize across sectors; and

3) PPP holds for the open sector.

The last assumption has important implications: The entire appreciation of the real exchange rate deflated by the consumer price index (as a proxy for overall inflation) comes from increases in nontradable prices, and this can be fully ascribed to the B-S effect (the appreciation of the CPI-based real exchange rate). By contrast, in the event that PPP is not verified for the open sector and, say, the real exchange rate based on producer prices (as a proxy for tradable prices) also appreciates, the B-S effect can explain only the difference between the CPI- and the PPI-deflated real exchange rate.

\subsubsection{Formal Derivation}

It is possible to formally derive the relationship between productivity in the tradable sector relative to that in the nontradable sector (henceforth referred to as dual productivity) and the price of nontradable goods relative to that of tradable goods 
(henceforth referred to as the relative price of nontradable goods). Based on a twosector neoclassical framework with perfect capital mobility and with the interest rate assumed exogenous, we obtain the following relationship:

$$
\hat{p}^{N T}-\hat{p}^{T}=\frac{\delta}{\gamma} \hat{a}^{T}-\hat{a}^{N T}
$$

where circumflexes $\left({ }^{\wedge}\right)$ stand for growth rates, $\delta$ and $\gamma$ denote the share of labor in the sheltered and open sectors, respectively. $\hat{p}^{N T}-\hat{p}^{T}$ represents the growth rate of the relative price of nontradable goods and $\hat{a}^{T}-\hat{a}^{N T}$ is the growth rate of dual total factor productivity. ${ }^{6}$ The transformation of equation (4) into growth rates combined with equation (7) yields equation (8) if the share of tradables in the consumer price basket is the same in the home and foreign economies $\left(\alpha=\alpha^{*}\right)$ :

$$
\hat{q}=\hat{e}+\hat{p}^{T *}-\hat{p}^{T}-(1-\alpha)\left(\left(\frac{\delta}{\gamma} \hat{a}^{T}-\hat{a}^{N T}\right)-\left(\frac{\delta^{*}}{\gamma^{*}} \hat{a}^{T} *-\hat{a}^{N T}\right)\right)
$$

where the growth rate of the real exchange rate equals the rate of growth of the real exchange rate for the open sector, and, most importantly, the difference between the growth rates of dual total factor productivity at home and abroad.

\footnotetext{
${ }^{6}$ The supply side of the two sectors is modeled by means of two different, constant-returns-to-scale Cobb-Douglas production functions: $Y^{T}=A^{T}\left(L^{T}\right)^{\gamma}\left(K^{T}\right)^{(1-\gamma)}$ and $Y^{N T}=A^{N T}\left(L^{N T}\right)^{\delta}\left(K^{N T}\right)^{(1-\delta)}$ where $A^{T}, A^{N T}, L^{T}, L^{N T}, K^{T}$ and $K^{N T}$ represent the level of total factor productivity, labor and capital in the open and closed sectors, respectively. Because of profit maximization, interest rates $(i)$ and nominal wages $(w)$ in both sectors equal the marginal products $d Y^{T} / d K^{T}, d Y^{N T} / d K^{N T} d Y^{T} / d L^{T}$ and $d Y^{N T} / d L^{N T}$,respectively:

$$
\begin{aligned}
& i^{T}=\log (1-\gamma)+a^{T}-\gamma\left(k^{T}-l^{T}\right) \\
& i^{N T}=\left(p^{N T}-p^{T}\right)+\log (1-\delta)+a^{N T}-\delta\left(k^{N T}-l^{N T}\right) \\
& w^{T}=\log (\gamma)+a^{T}+(1-\gamma)\left(k^{T}-l^{T}\right) \\
& w^{N T}=\left(p^{N T}-p^{T}\right)+\log (\delta)+a^{N T}+(1-\delta)\left(k^{N T}-l^{N T}\right)
\end{aligned}
$$

Equations $\left(3^{\prime}\right)$ to $\left(6^{\prime}\right)$ are expressed in logarithmic terms. Tradable prices are exogenous because of perfect competition in the open sector. Given that capital is assumed to be fixed in the short run, the first order conditions (FOC) in the open sector determine the capital-labor ratio and the nominal wage. Wage equalization across sectors implies that this wage level is exogenous in the sheltered sector. In turn, the FOC in the sheltered sector give the capital-labor ratio in the sheltered sector and the price of nontradables relative to that of tradables. To obtain equation (7), equations ( $\left.3^{\prime}\right)$ to (6') are totally differentiated and rearranged (for a step-by-step derivation, see Ėgert, 2003).
} 
However, it may be more convenient to derive the above developed relationships in levels (as opposed to growth rates) and on the basis of average labor productivity (as opposed to total factor productivity): ${ }^{7}$

$$
\frac{P^{N T}}{P^{T}}=\frac{\gamma}{\delta} \cdot \frac{Y^{T} / L^{T}}{Y^{N T} / L^{N T}}
$$

where $\mathrm{Y}$ and $\mathrm{L}$ denote output and labor and $Y / L$ is the average labor productivity. Transforming equation (9) into logarithms leads to:

$$
p^{N T}-p^{T}=\text { const }+\left(a^{T}-a^{N T}\right)
$$

where const is a constant term containing $\log (\gamma)$ and $\log (\delta)$. Applying equation (10) to equation (4) gives equation (11), provided $\alpha=\alpha^{*}$ :

$$
q=\text { const }+\left(e+p^{T} *-p^{T}\right)-(1-\alpha)\left(\left(a^{T}-a^{N T}\right)-\left(a^{T} *-a^{N T} *\right)\right)
$$

where the real exchange rate is linked to the difference between dual average labor productivity at home and abroad (henceforth referred to as the dual productivity differential). Note that the constant term now contains $\log (\gamma), \log (\delta), \log \left(\gamma^{*}\right)$ and $\log \left(\delta^{*}\right)$ multiplied by $(1-\alpha)$.

Such a derivation has two advantages. First, sectoral average labor productivity can be used on its own right and not as a proxy for sectoral total factor productivity. ${ }^{8}$ In

7 Given that the marginal productivity of labor is equal between the open and closed sectors, equations $\left(3^{\prime}\right)$ and $\left(4^{\prime}\right)$ can be equated based on which the relative price of nontradables can be expressed as follows: $\frac{P^{N T}}{P^{T}}=\frac{\partial Y^{T} / \partial L^{T}}{\partial Y^{N T} / \partial L^{N T}}$. A well-known feature of Cobb-Douglas production functions is that marginal productivity equals average productivity: $\frac{\partial Y^{T}}{\partial L^{T}}=A^{T} \gamma\left(\frac{K^{T}}{L^{T}}\right)^{(1-\gamma)}=\gamma \frac{Y^{T}}{L^{T}}$ and $\frac{\partial Y^{N T}}{\partial L^{N T}}=A^{N T} \delta\left(\frac{K^{N T}}{L^{N T}}\right)^{(1-\delta)}=\delta \frac{Y^{N T}}{Y^{N T}}$, which yields equation (9).

${ }^{8}$ In equations (7) and (8), total factor productivity can be approximated by average labor productivity, which may, however, be a biased proxy. Labor productivity (LP) can be decomposed into (1) the capital-labor ratio, i.e. capital intensity $(\mathrm{Cl})$ and into (2) TFP ( $\mathrm{LP}=\mathrm{Cl}+\mathrm{TFP})$. Therefore, the level of labor productivity might be systematically higher or lower than TFP, with capital intensity working as a "leverage." In the event that capital intensity changes over time, the evolution of labor productivity will differ from that of TFP. Needless to add that if capital intensity differs across countries, labor productivity as a proxy for TFP will induce an additional bias when productivity developments are 
addition, the terms $\gamma$ and $\delta$ are passed into the constant term. Second, the level relationship makes it possible to use the cointegration technique to estimate the longrun relationship between the real exchange rate and the dual productivity differential. ${ }^{9}$

According to the B-S model set out here, changes in dual productivity leads to changes in the relative price of non-tradable, which, through increased overall inflation leads to the appreciation of the real exchange rate. Because PPP holds for the open sector, competitiveness is not affected by the real appreciation. It is often argued in the literature that there is an equivalence between this type of appreciation (with fixed nominal exchange rates) and a real appreciation caused by the nominal exchange rate. If the appreciation of the nominal exchange rate proportionally decreases the price of tradables, PPP holds for the open sector, leaving competitiveness unaffected. The real exchange rate of the closed sector appreciates, implying the appreciation of the overall real exchange rate. However, two problems arise: (1) the B-S model does not contain any straitforward mechanism explaining nominal appreciation, and (2) if nominal appreciation occurs for any other reason, because the exchange rate pass-through is usually lower than unity, competitiveness in the open sector would deteriorate.

\subsubsection{Possible Extensions}

The standard simple B-S framework can be extended as follows:

1) Along the lines proposed by Bergstrand (1991), the model can be augmented with demand-side variables, i.e. private consumption. It is argued that because of the high income elasticity of demand for nontradable goods, an increase in dual productivity accompanied by increasing disposable income per capita may result, in the long run, in rising consumption, which falls to an increasing extent on nontradable goods. Thus, demand-side pressure in the sheltered sector yields higher nontradable prices.

compared across countries. Therefore, it would be preferable to use equations (10) and (11) where average labor productivity can be used directly.

${ }^{9}$ A specification in growth rates such as in equations (7) and (8) would imply that the cointegration technique (extensively used in the literature: see table $5 a$ ), which is meant to link variables that are nonstationary in levels but stationary in first differences, could not be applied because the growth rates may already render the series stationary. 
2) The standard B-S effect rests on a two-sector, two-input small, open economy model. According to Fischer (2002), a three-sector four-input model makes it possible to show that investment demand can also lead to a rise in the price of nontradable goods.

3) Holub and Čihak (2003) formally introduce tradable and nontradable capital alongside the risk premium to the model and show that the following factors can bring about a rise in relative prices: (1) a decrease in the risk premium, (2) an increase in nontradable capital per capita, (3) a rise of employment in the nontradable sector relative to total employment.

\subsubsection{The Real Exchange Rate in the Open Sector: The Role of Tradable Prices and the Nominal Exchange Rate}

Lommatzsch and Tober (2002b) and Égert et al. (2003), among others, documented that in selected transition economies, not only the CPI-based real exchange rate but also the PPI-deflated real exchange rate witnessed a certain trend appreciation from the early 1990s onwards and that the CPI- and PPI-based real exchange rates moved fairly closely together. ${ }^{10}$ Clearly, the traditional B-S effect cannot explain the appreciation of the real exchange rate deflated by the PPI (as a proxy for tradable prices) because its impact passes through the nontradable price channel. Indeed, the B-S effect that posits PPP to hold for tradable goods is meant to explain possible differences between changes in the overall inflation-based (CPI) and the tradable price-deflated (PPI) exchange rates.

1) The real exchange rate based on tradable prices may appreciate in the event of a substantial initial undervaluation at the onset of the systemic transformation process. Hence, the appreciation of the PPI- and CPI-based real exchange rates may reflect an adjustment towards equilibrium as proposed in Halpern and Wyplosz (1997) and in Krajnyák and Zettelmeyer (1998).

2) However, the source of the appreciation of the tradable price-based real exchange rate may be more closely related to the transformation process. At the

\footnotetext{
${ }^{10}$ Ito et al. (1997) and Lee and Tang (2003) provide evidence in favor of a tradable price-based real appreciation for Asian countries and for selected OECD countries, respectively.
} 
beginning of transition, both domestic and foreign consumers tend to prefer foreign goods. However, with economic restructuring that entails productivity increases in the tradable sector, the home economy becomes capable of producing a growing number of goods of better quality. This is why the preference of domestic and foreign consumers shifts towards home goods. An increasing reputation and home bias allow higher prices to be set for the goods produced in the home economy both in the foreign and the domestic markets. Also, an improving export performance based on the aforementioned factors may lead to the appreciation of the nominal exchange rate (see Égert and Lommatzsch, 2003).

Thus, productivity gains could operate not just via nontradable prices, but also via the tradable price and the nominal exchange rate channels. If rises in tradable prices fueled by productivity advances are faster in the home economy than in the foreign one, the resulting positive inflation differential in tradable prices causes the real exchange rate based on tradable prices to appreciate. Similarly, the appreciation of the nominal exchange rate also leads to an appreciation of the tradable price-based real exchange rate.

3) Another kind of appreciation of the real exchange rate deflated by means of tradable prices can stem from the appreciation of the nominal exchange rate that is based on expected future productivity gains. Capital inflows related to productive foreign investment may trigger future productivity gains and an increase in future export revenues that could counterbalance today's deterioration of the current account. Most importantly, this kind of nominal appreciation will be an ex post equilibrium phenomenon only if productivity advances materialize and export revenues actually increase. In the opposite case, i.e. in the event that productivity gains do not materialize, an expectation-driven nominal appreciation, viewed ex ante as an equilibrium phenomenon, may lead to an ex post overvaluation of the real exchange rate.

4) Another source of possible equilibrium appreciation of the tradable price-based real exchange rate may be the nontradable component of tradable goods. The price of tradable goods increases through their service component, the rise of which is driven by the traditional B-S effect. 
5) There is a more general problem. Inflation measures, usually the CPI, are likely to overstate the "true" rate of inflation. The four sources of an upward inflation bias are as follows: (1) consumer substitution, (2) outlet substitution, (3) quality improvements, and (4) new goods bias (Boskin et al., 1996; Gordon, 2000). ${ }^{11}$ Transition economies are even more prone to this bias than well-established market economies. Hanousek and Filer (2001a, 2001b) argue that in the Czech Republic, the bias due to quality changes may reach $50 \%$ of the CPI reported for food and goods and that the bias coming from the other sources are comparable to that measured for the U.S. economy and other industrialized countries. Although estimates are not available for other acceding countries and for the PPI, the quality issue may also be very important in this case. Hence, the measured appreciation of the real exchange rate may be larger than the one based on unbiased inflation measures.

\subsubsection{The Role of Regulated Prices}

The trend appreciation of the real exchange rate as described in the B-S model and changes in tradable prices are based on sectors and prices governed by market forces. Nevertheless, administered and regulated prices, ${ }^{12}$ which are composed mainly of services, represent a large portion of overall inflation, i.e. the consumer price index, especially in transition economies. Increases in these prices are usually the highest and are not related to productivity increases. ${ }^{13}$

\footnotetext{
${ }^{11}$ Consumer substitution: changes in consumption patterns towards items with low price increases are not taken into account in the CPI. Outlet substitution: weights attributed in the CPI to different channels of distribution do not coincide with the observed patterns. The excessive weight of expensive traditional outlets at the expense of cheaper hypermarkets cause true CPI inflation to be overstated. Quality improvements: changes in prices due to quality changes are misconceived as price inflation. New goods bias: new goods are introduced into the CPI basket only with a delay.

12 The terms administered and regulated prices will be used interchangeably in the remainder of the paper.

${ }^{13}$ Prices of regulated services including public transport, communication, energy and water supply were left largely unchanged at the outset of transition. In setting the price of regulated items, only operational costs were considered initially because the capital stock of the sectors concerned was inherited from the communist era and because of political considerations. Later on, also capital maintenance costs were considered to account for wear and tear. However, once general price liberalization was over, the progressive replacement of the capital stock at market prices, partly through privatization, led to huge increases in regulated prices because the cost of capital had to be taken into account as well (see Zavoico, 1995). This was all the more important as the regulated sectors tend to be very capital intensive. It appears that the adjustment of regulated prices is, however, not over yet. First, prices may still be below cost recovery in some cases. Second,
} 
Because regulated items can be inputs for tradable and market nontradable goods, an increase in regulated prices may affect tradable goods' competitiveness directly and indirectly through the market-based nontradable component of tradable goods.

Yet, increases in regulated prices may not affect competitiveness and may also partly be viewed as an equilibrium phenomenon for two reasons. First, regulated prices were left unchanged at the onset of the transition period when other prices were set free. Therefore, a large increase in regulated prices may reflect a late catching-up with other prices, mainly with market services. It appears that this adjustment process has not finished yet, because the current prices of regulated services often do not allow cost recovery. Second, regulated prices may impact on tradable goods that do not enter international competition.

Chart 1 summarizes the elements of the trend appreciation of the equilibrium real exchange rate in transition economies.

governments still provide direct and indirect subsidies, which may be cut because of efforts to consolidate public finances and because of the need to comply with competition rules in the acquis communautaire. Finally, the need for additional capital investment to meet the quality of services required by EU standards may also imply further price increases (Égert, 2003). To dampen price increases, efficiency can be improved via privatization and market liberalization. In the case of industries where true market competition is not possible, an appropriate price regulatory framework should be implemented, as was the case in England and Wales (Saal and Parker, 2001). 
Chart 1 Elements of the Appreciation of the Equilibrium Real Exchange Rate

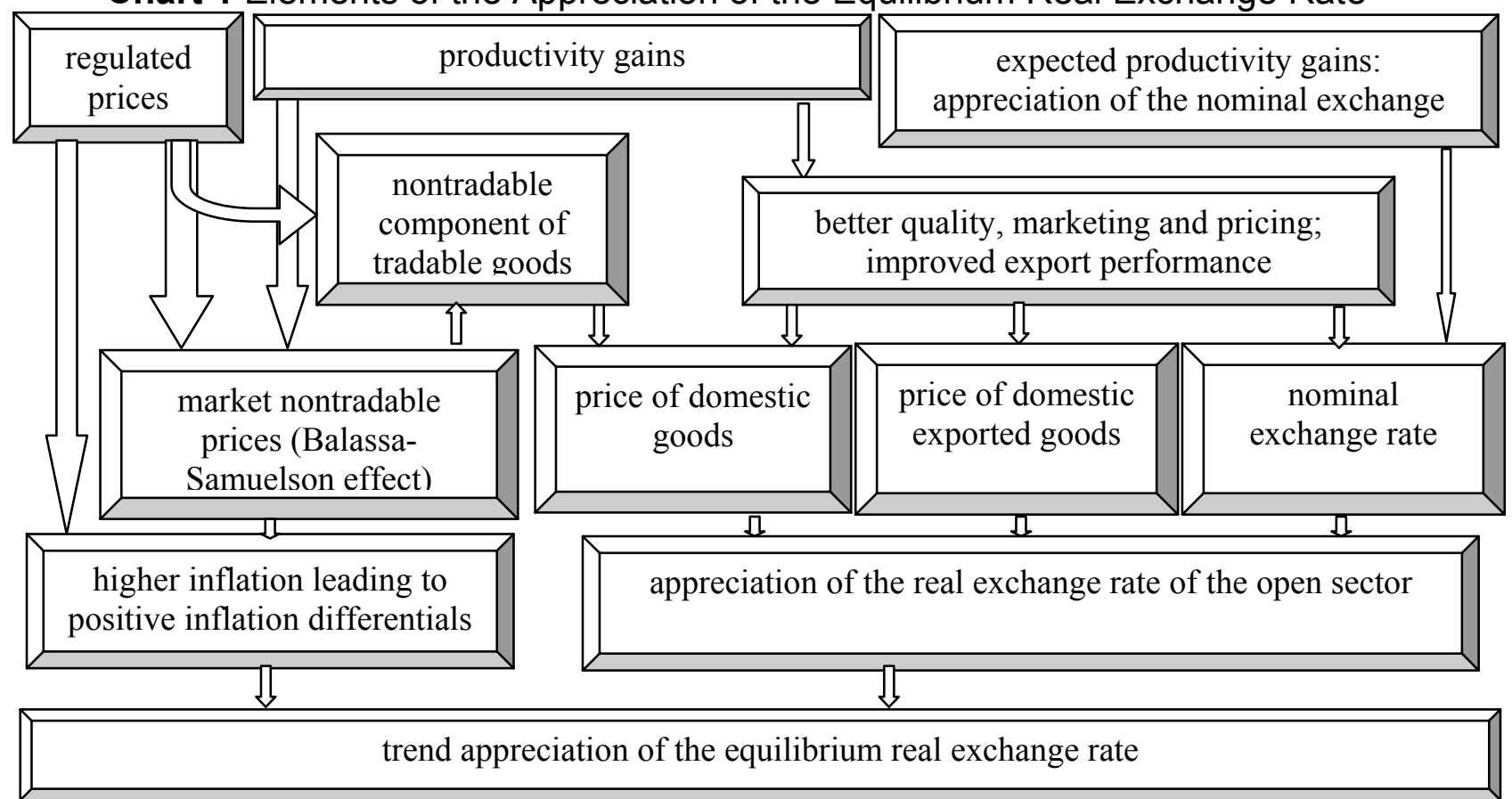

Source: Author.

\subsection{The Fundamental Equilibrium Exchange Rate (FEER)}

For small, open economies, it would be more straightforward to define the equilibrium real exchange rate in terms of a sustainable external position, i.e. a sustainable current account and sustainable external debt. The theoretical framework to the trend appreciation vaguely takes account of external sustainability by underscoring that the appreciation of the real exchange rate comes only from market nontradable price increases and that PPP is ensured for the open sector, thus securing the competitiveness of exports. However, it is easy to see that other factors besides productivity growth can play an essential role in current account and external debt sustainability, such as the real interest rate, fiscal policy or determinants of savings and investments.

The notion of the external sustainability-based equilibrium real exchange rate was first advocated by Nurkse (1945), and then elaborated by Artus (1978). Nevertheless, the concept gained popularity with a series of publications by Williamson $(1985,1994)$ that gave a fillip to theoretical and empirical research related to equilibrium real exchange rates. Williamson coined the expression Fundamental Equilibrium Exchange Rate 
(FEER) for the sustainable external account-based equilibrium real exchange rate. In accordance with Williamson's definition, FEER is a real effective exchange rate that simultaneously secures internal and external balances for a given number of countries at the same time. Internal balance is defined as the nonaccelerating inflation rate of unemployment (NAIRU). Put differently, internal balance is reached when the economy functions at full capacity accompanied by low inflation. External balance is achieved when the balance of payments is in a sustainable position over a medium-term horizon, ensuring external debt sustainability. ${ }^{14}$

When it comes to making FEER operational, there are two main questions to be answered. The first one is related to the determination of the potential output growth associated with low inflation. Two major avenues are open: Either historical GDP growth can be statistically decomposed into trend and cyclical components, e.g. using the Hodrick-Prescott (HP) filter or the Beveridge-Nelson decomposition, or economic theory can be used to determine the magnitude of potential growth. The second question to be addressed concerns the notion of what a sustainable current account is. First, a current account deficit can be considered sustainable if it is covered by long-term capital inflows and if it stabilizes the external debt-to-GDP ratio at a given level. It remains an open question, though, what the optimal level of this ratio is. Second, the current account can be viewed in terms of saving-investment balances $(C A=S-I)$. Accordingly, econometric models are estimated by regressing saving and investment on an array of explanatory variables, such as population growth, the fiscal position or openness $\left(I=I\left(\bar{Z}_{1}\right), S=S\left(\bar{Z}_{2}\right) \text {, where } \bar{Z}_{1}, \bar{Z}_{2} \text { stand for vectors of explanatory variables }\right)^{15}$. Fitted values for investment and saving are then used to derive medium-term values of the current account. This approach is also dubbed the Macroeconomic Balance Approach.

FEER has a close relative called Desired Equilibrium Exchange Rate (DEER). The difference between these related concepts is that in the case of DEER, external equilibrium is defined in terms of optimal policy. In other words, the current account

\footnotetext{
${ }^{14}$ Bayoumi et al. (1994) define a horizon from four up to six years.

${ }^{15}$ For more details, see e.g. Isard et al. (2001).
} 
target and the subsequent foreign debt should be in line with what policymakers deem optimal.

Turning our attention to how to derive the fundamental or desired equilibrium exchange rates, the following steps can be pinned down:

1) Determining the targeted current account position;

2) Estimating the elasticity of the current account to domestic and foreign output and to the real effective exchange rate $\left(C A=f\left(Y, Y^{*}, R E E R\right)\right)$;

3) Working out the change in the real effective exchange rate (REER) that would place domestic and foreign output on their potential path and that would achieve the targeted current account. However, the simultaneous achievement of this triple goal is hardly possible. Therefore, it is normally assumed that internal balance both in the home and foreign economies is reached without the help of the real effective exchange rate;

4) Seeking the change in the real effective exchange rate that would make the current account, adjusted for internal balances (i.e. the current account that would prevail at potential output), move to its target value. The change in the real effective exchange rate is tantamount to the total misalignment; and

5) Calculating the bilateral equilibrium nominal exchange rates. The current nominal effective exchange rate needs to be adjusted with the required change in the real effective exchange rate, and subsequently the bilateral nominal exchange rates are to be extracted.

\subsection{The Natural Real Exchange Rate (NATREX)}

Developed in a series of papers by Stein (1994, 1995 and 2002), the NATural Rate of EXchange (NATREX) approach distinguishes equilibrium real exchange rates at two horizons, a medium-run and a long-run equilibrium real exchange rate. In the medium run, the real exchange rate can be viewed at equilibrium when internal and external balances are achieved simultaneously, very much like in the FEER approach. The definition of internal balance is slightly different, because it is not defined in terms of NAIRU but rather at full capacity utilization, whereas external balance implies current account sustainability, such as: 


$$
C A-(S-I)=0
$$

That is, the current account corresponds to net exports $(N X)$ minus net income payments/inflows related to foreign debt/assets, i.e. net factor income ( $\left.C A=N X-i^{*} \cdot F D E B T\right)$ should be equal to long-term net capital inflows determined by saving and investment decisions.

Let us now consider the investment and consumption functions and the determinants of the trade balance that are connected via the national account identity as in equation (16):

$$
\begin{aligned}
& \frac{I}{Y}=f\left(\stackrel{+}{a}, \frac{\bar{K}}{Y}, \bar{r}, \stackrel{+}{Q}\right) \\
& \frac{C}{Y}=f\left(\frac{+}{Y}, \frac{F D \bar{E} B T}{Y}, \bar{Z}\right) \\
& \frac{N X}{Y}=f\left(\stackrel{+}{Q}, \frac{\bar{D}}{Y}, \frac{\stackrel{+}{D^{*}}}{Y}, T \stackrel{+/-}{T O}\right) \\
& \frac{I}{Y}+\frac{C}{Y}+\frac{N X}{Y}=1
\end{aligned}
$$

Investment $(I)$, consumption $(C)$, capital stock $(K)$, foreign debt $(F D E B T)$, the trade balance $(N X)$ and domestic and foreign demand $\left(D, D^{*}\right)$ are expressed in GDP terms $(Y)$. Investment increases with a rise in the rate of growth of total factor productivity $(a)$ and the depreciation of the real exchange rate $(Q)$ and decreases when capital stock and the real interest rate increase. Consumption, including both private and public consumption, is positively related to wealth, defined as capital stock $(K)$ minus foreign debt (FDEBT): therefore, it is a positive function of capital and depends negatively on foreign debt. $\bar{Z}$ denotes a vector of exogenous variables, the most important of which is the social thrift parameter that stands for the social (private and public) propensity to save. Finally, the trade balance improves with the depreciation of the real exchange rate. Furthermore, the trade balance is negatively related to domestic demand, whereas it bears a positive sign with foreign demand. Substituting equation (13) - (15) into 
equation (16) and solving it for the real exchange rate $(Q)$ yields the medium-term equilibrium real exchange rate. In practice, equations (13) - (15) are estimated by means of econometric techniques and the estimated medium-term NATREX is given by applying the estimated parameters to the solution of the system. ${ }^{16}$

In the NATREX model, a change in foreign debt and in the capital stock $(K)$ feed back into the macroeconomic balance. For instance, an increase in foreign debt resulting from a deteriorating current account position decreases wealth $(K-F D E B T)$, and this leads to a fall in consumption. As a consequence, import demand drops and the real exchange rate depreciates, which in turn ameliorates the current account and decreases foreign debt. This is indeed a feedback mechanism that stabilizes foreign debt.

What the NATREX approach indeed adds to FEER is that it also considers the stock of capital and the stock of net foreign debt in the long run and that it describes the path of the real exchange rate from medium-term equilibrium towards long-term equilibrium. Whilst the medium-term NATREX is obtained based on current values of the capital stock and foreign debt, the long-term equilibrium is derived when the stock of capital and the stock of foreign debt are stabilized at their steady-state levels, given respectively in equations (17) and (18):

$$
\begin{aligned}
& \frac{K}{Y}=\frac{1+g}{\delta+g} \cdot \frac{I}{Y} \\
& \frac{F D E B T}{Y}=\frac{1+g}{g} \cdot \frac{C A}{Y}
\end{aligned}
$$

where $\delta$ denotes the rate of depreciation of the capital stock and $g$ stands for the growth rate of GDP.

To illustrate the difference between the medium- and long-run real exchange rates, Stein (1995) considers two cases: (1) the propensity to save decreases and (2)

${ }^{16}$ Equations (13) to (15) are normalized using actual output, which implies that the medium-run NATREX is the exchange rate that brings investment, consumption and net exports such as estimated in equations (13) to (15) in line with observed output (equation (16)). However, if equations (13) to (15) were normalized using potential output, the medium-term NATREX would be given as the exchange rate that equalizes medium-term aggregate demand with potential output (Karádi, 2003). 
productivity rises. In both cases, the medium-term NATREX appreciates. In the first case, a decrease in savings implies an increase in consumption, and this leads to a worsening of the current account and the foreign debt. In the second case, a productivity shock occurs that leads to a rise in investment. Similarly to the first case, this implies a larger current account deficit and thus an increase in the foreign debt. The resulting capital inflows cause the real exchange rate to appreciate, which restores the internal and external balances.

However, in the first case, the real exchange rate depreciates in the long run because increased foreign debt causes interest payments to rise. Indeed, the real exchange rate depreciates to improve the trade balance required to service the debt.

Contrary to a drop in the propensity to save, an increase in productivity may bring about an appreciation of the real exchange rate in the long run. Not only foreign debt rises in the medium term, so does capital stock. In turn, productivity increases further, and higher GDP growth results in higher savings. Given this development, foreign debt decreases and the real exchange rate appreciates in the long run to counterbalance the improving current account. At the same time, however, higher capital stock implies higher imports, which may offset some of the appreciation of the real exchange rate.

Recent attempts to estimate the structural form of the NATREX model include Detken et al. (2002) for the euro area and Karádi (2003) for Hungary. However, it is common practice to estimate a reduced-form equation of the model that includes the exogenous variables of the model. In this case, the estimation method is tantamount to the BEER approach presented below.

\subsection{The Behavioral Equilibrium Exchange Rate (BEER)}

The theoretical underpinning of the BEER approach as proposed by MacDonald (1997) and Clark and MacDonald (1998) rests on the uncovered interest rate parity (UIP):

$$
E_{t}\left(e_{t+1}\right)-e_{t}=i_{t}-i_{t}^{*}
$$

where $E_{t}\left(e_{t+1}\right)$ denotes the expected value of the nominal exchange rate in period $t$ for period $t+1$, and $e_{t}, i_{t}, i_{t}^{*}$ stand for the current value of the nominal exchange rate and 
the domestic and foreign interest rates ${ }^{17}$. After subtracting the expected inflation differential $\left(\left(E_{t}\left(p_{t+1}\right)-p_{t}\right)-\left(E_{t}\left(p_{t+1}^{*}\right)-p_{t}^{*}\right)=E_{t}\left(\Delta p_{t+1}\right)-E_{t}\left(\Delta p_{t+1}^{*}\right)\right)$ from both sides of equation (19), we obtain the real interest parity:

$$
E_{t}\left(q_{t+1}\right)-q_{t}=r_{t}-r_{t}^{*}
$$

where $r_{t}=i_{t}-E_{t}\left(\Delta p_{t+1}\right), r_{t}^{*}=i_{t}^{*}-E_{t}\left(\Delta p_{t+1}^{*}\right)$ represent the domestic and foreign ex ante real interest rates, $E_{t}\left(q_{t+1}\right)$ stands for the expected real exchange rate in $t$ for $t+1$, and $q_{t}$ is the observed real exchange rate in period t. Rearranging equation (20), we obtain that the observed real exchange rate is a function of the expected value of the real exchange rate in $t$ for $t+1$ and the ex ante real interest differential.

$$
q_{t}=E_{t}\left(q_{t+1}\right)-\left(r_{t}-r_{t}^{*}\right)
$$

$E_{t}\left(q_{t+1}\right)$ can be assumed to be the outcome of the expected values of the fundamentals, so that

$$
q_{t}=E_{t}\left(\bar{x}_{t+1}\right)-\left(r_{t}-r_{t}^{*}\right)
$$

where $\bar{x}$ is the vector of fundamentals. In practical terms, the real exchange rate can be written as the function of long- and medium-term $(x)$ fundamentals and short-term variables $(\mathrm{z})$ :

$$
q_{t}=q_{t}\left(\bar{x}_{t}, \bar{z}_{t}\right)
$$

Nevertheless, BEER can be considered rather as a statistical approach. The reason for this is that all econometric estimates aimed at estimating single equation-type relationships between the real exchange rate and the fundamentals can be classified as falling into the BEER approach. Hence, testing reduced-form equations of different theoretical models is akin to proceeding with the econometric estimation as described hereafter.

The econometric estimation of the BEER approach comprises five stages:

\footnotetext{
${ }^{17}$ Recall that small letters denote variables transformed into logarithms.
} 
1) Estimating the statistical long-run relationship between the real exchange rate, the fundamentals and short-run variables (single equation). This is tantamount to estimating real exchange rate determination models;

2) Calculating the actual misalignment. Short-term variables are set to zero and actual values of fundamentals identified in step 1) are substituted into the estimated relationship. The actual misalignment is given as the difference between the fitted and the actual value of the real exchange rate;

3) Identifying long-run or sustainable values for the fundamentals. (1) The long-term value of the fundamentals can be obtained by decomposing the series into permanent and transitory components (e.g. HP filter, Beveridge-Nelson decomposition). (2) Subjective evaluation of the long-term value is also possible (see Baffes et al., 1999);

4) Calculating total misalignment. Long-term values of fundamentals are substituted into the estimated relationship relating the real exchange rate to the fundamentals, and short-term variables are set to zero again. Total misalignment is the difference between the fitted and the actual value of the real exchange rate. Total misalignment depends on the short-term effect and on the departure of fundamentals from their long-term value;

5) Deducing the nominal equilibrium exchange rate. The observed nominal exchange rate is adjusted for total misalignment (the nominal equilibrium exchange rate equals the observed nominal exchange rate minus misalignment) ${ }^{18}$; and

6) Alternatively, steps three and four may be replaced by a single step that consists in decomposing the fitted estimated long-term relationship into permanent and transitory components using the Gonzalo-Granger method. This version of the BEER can be referred to as the Permanent Equilibrium Exchange Rate (PEER).

It should be noted that the list of the theoretical models presented above is not exhaustive. Theoretical approaches labeled with the acronyms CHEER and ITMEER

18 Note that this is a highly simplified approach to deducing the nominal equilibrium exchange rate because it does not account for dynamic effects of a nominal adjustment. A sizeable change in the nominal exchange rate that would correct for real misalignments in period $t$ may move the real exchange rate away from equilibrium because of the nominal adjustment's effects on domestic (and foreign) prices. Such an effect could be considered by examining nominal exchange rate passthrough (Darvas, 2001) or by using a structural model of the economy. 
are left aside, as they are either not very useful or not used for developing countries (for a recent survey, see e.g. MacDonald, 2000, and Driver and Westaway, 2004). Furthermore, general equilibrium models applied to small, open economies (see Edwards, 1994) are also ignored in this paper, mainly because they use the internal real exchange rate, and thus cannot provide too much guidance on the external real exchange rate and thus the nominal exchange rate.

\section{The Connection Between Different Approaches}

Thus far, we have presented the major models employed while estimating equilibrium real exchange rates. They can be structured as follows: PPP can be used in the very long run, i.e. in a secular context. The B-S effect, both in levels (PPP adjusted for differences in productivities) and dynamics (convergence towards the PPP level in the event of rapid growth) provides good guidance in the long run. Beside this nontradable price channel, a trend appreciation of the tradable price-deflated real exchange rate can also occur in the long run for the reasons developed earlier. FEER and medium-term NATREX ought to secure medium-term current account sustainability. The long-term NATREX, which considers adjustments of the capital and net foreign debt stocks toward their steady state level, is expected to hold over a longer horizon. BEER can be used in the medium and the longer run, as BEER specifications usually include elements of the trend appreciation. This is depicted in chart 2. 


\section{Chart 2 Time Hierarchy of the Different Approaches}

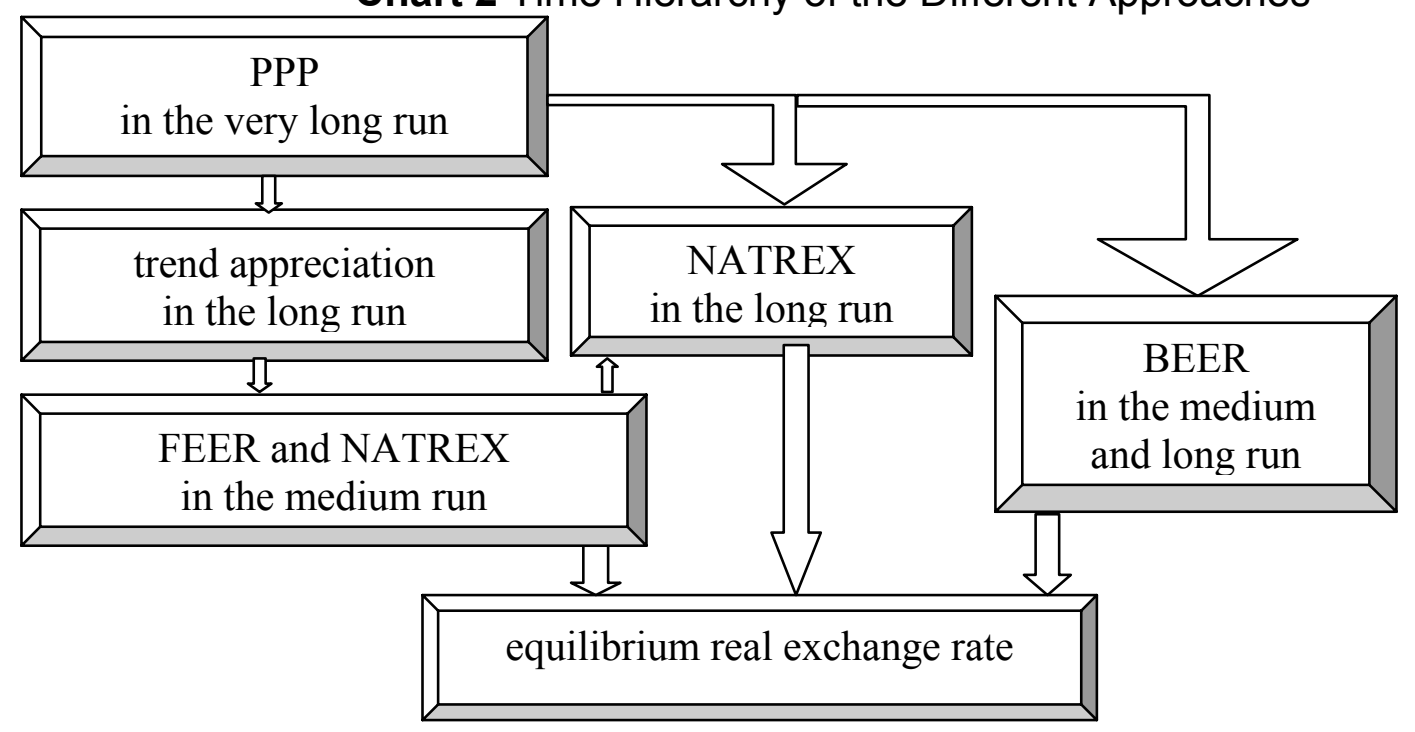

Source: Author.

However, for a better understanding, it seems useful to go into more detail and to present the equilibrium real exchange rate also graphically.

In chart 3, the gray corridor represents what may be called the PPP zone. For countries at comparable levels of development, the level of the real exchange rate should be equal to 1, i.e. the price levels in the home and foreign countries should be equal when expressed in the same currency unit $\left(E P^{*}=\mathrm{P}\right.$, that is, absolute PPP holds). Nonetheless, because of differences in e.g. the tax system and wage policies and because of trade barriers and other market imperfections, the equilibrium real exchange rate fluctuates in a band of $\pm \mu$ around 1 . Also, differentiated goods allow for pricing-tomarket practices, which may shift the PPP ratio (with the band around it) away from 1 even in the long run.

When countries at different stages of development are considered, the less developed country's real exchange rate is usually undervalued when using the PPP concept and, consequently, it is higher than $1 .{ }^{19}$ But this is an equilibrium undervaluation in PPP terms. At the same time, the real exchange rate is in equilibrium when taking into account the difference in the levels of dual productivity between countries. Point $A$ represents this situation. 
For these two cases, the absence of major changes in relative economic development, especially in relative dual productivity levels, would imply no major changes in the level of the equilibrium real exchange rate. PPP was difficult to verify even for such cases using standard time series econometric techniques to shorter time spans of 20 to 30 years. The use of secular time series and large panels appeared to show that real exchange rates are mean reverting, i.e. they return to their long-term value. The typical half-life, i.e. the time needed for the deviation vis-à-vis equilibrium to diminish by half, ranges from three to five years in the long time series and panel literature (Rogoff, 1996). However, a more plausible explanation to the PPP puzzle is about to emerge from the literature. Using threshold autoregressive (TAR) models, it is possible to show that within a band around equilibrium, such as shown in chart 3 , the real exchange rate exhibits nonstationarity, i.e. it follows a stochastic trend because transaction costs are high enough to prohibit goods arbitrage. However, when the real exchange rate moves beyond a threshold over which profits to be realized from goods arbitrage exceed transaction costs, the real exchange rate tends to return to the PPP corridor, ${ }^{20}$, which may be different for individual countries. Typically, nonlinear adjustments towards the band are found to happen much faster when compared with the typical half-life of three to five years. ${ }^{21}$

If one country experiences higher economic growth, and especially rapid increases in dual productivity that cause the price level to rise compared with those in the other countries, its equilibrium real exchange rate appreciates systematically. This reflects a successful catching-up with the other countries if this country starts from a lessdeveloped stage. Alternatively, if it starts from a similar stage of development, it can also grow apart from the rest of the world. In chart 3, the equilibrium real exchange rate appreciates until it reaches, through points $B$ and $C$, the PPP corridor of $1 \pm \mu$. The equilibrium appreciation itself is also a corridor because of transaction costs.

\footnotetext{
${ }^{19}$ The exchange rate is expressed as home currency units over one unit of foreign currency.

20 The speed with which the real exchange rate returns to the band may be modeled in different ways. The TAR model assumes abrupt adjustment back to the band, whereas smooth transition autoregressive (STAR) and self-exciting threshold autoregressive (SETAR) models allow for smoother adjustment toward the band of inaction.

${ }^{21}$ For an overview, see Sarno and Taylor (2002).
} 
However, it may be that the real exchange rate is not in equilibrium when considering dual productivity levels. For instance, point $A$ " shows the situation of the real exchange rate when it is undervalued not only in PPP terms but also when accounting for differences in dual productivity levels. This implies an initial undervaluation of the domestic currency that could call for a quick real appreciation towards levels given by productivity levels. By contrast, $A^{\prime}$ refers to the position in which the real exchange rate can be viewed as overvalued when differences in dual productivity levels are accounted for. As a consequence, the actual real appreciation should be lower than the equilibrium trend appreciation in line with productivity advances so as to compensate for this misalignment and to ensure that the real exchange rate returns into the "equilibrium corridor."

During periods of rapid changes in relative economic development levels, the equilibrium real exchange rate may exhibit a trending behavior over a period of 15 to 30 years. For such a period, PPP cannot be used as a yardstick. But it may be indicative in periods over which relative economic performances equalize (Froot and Rogoff, 1994; Froot et al. 1995).

But 15 to 30 years is still far too long to interpret the equilibrium real exchange rate for policy purposes. The FEER approach provides a medium-term definition of the equilibrium real exchange rate which is compatible with current account sustainability. This implies that even during a period of trend appreciation, the equilibrium real exchange rate can depreciate or appreciate compared to the trend because of external imbalances.

Accordingly, not only the observed real exchange rate, but also the equilibrium real exchange rate can fluctuate within the band, and the latter can even exit the corridor so as to take account of the external position of the given economy. The reason for this is that productivity increases consider current account developments and net foreign indebtedness only implicitly by referring to competitiveness in the tradable sector. This is possibly not always sufficient to secure current account sustainability in the medium term. And that is why the BEER including these variables and especially the FEER approaches can explicitly tackle this issue in the medium run. It may be that in spite of 
the fact that the equilibrium real exchange rate appreciates in the longer run, it has to depreciate in the medium run so as to bring back the current account to its long-term value, which ensures a viable path for the foreign debt.

\section{Chart 3. Trend Appreciation of the Equilibrium Real Exchange Rate}

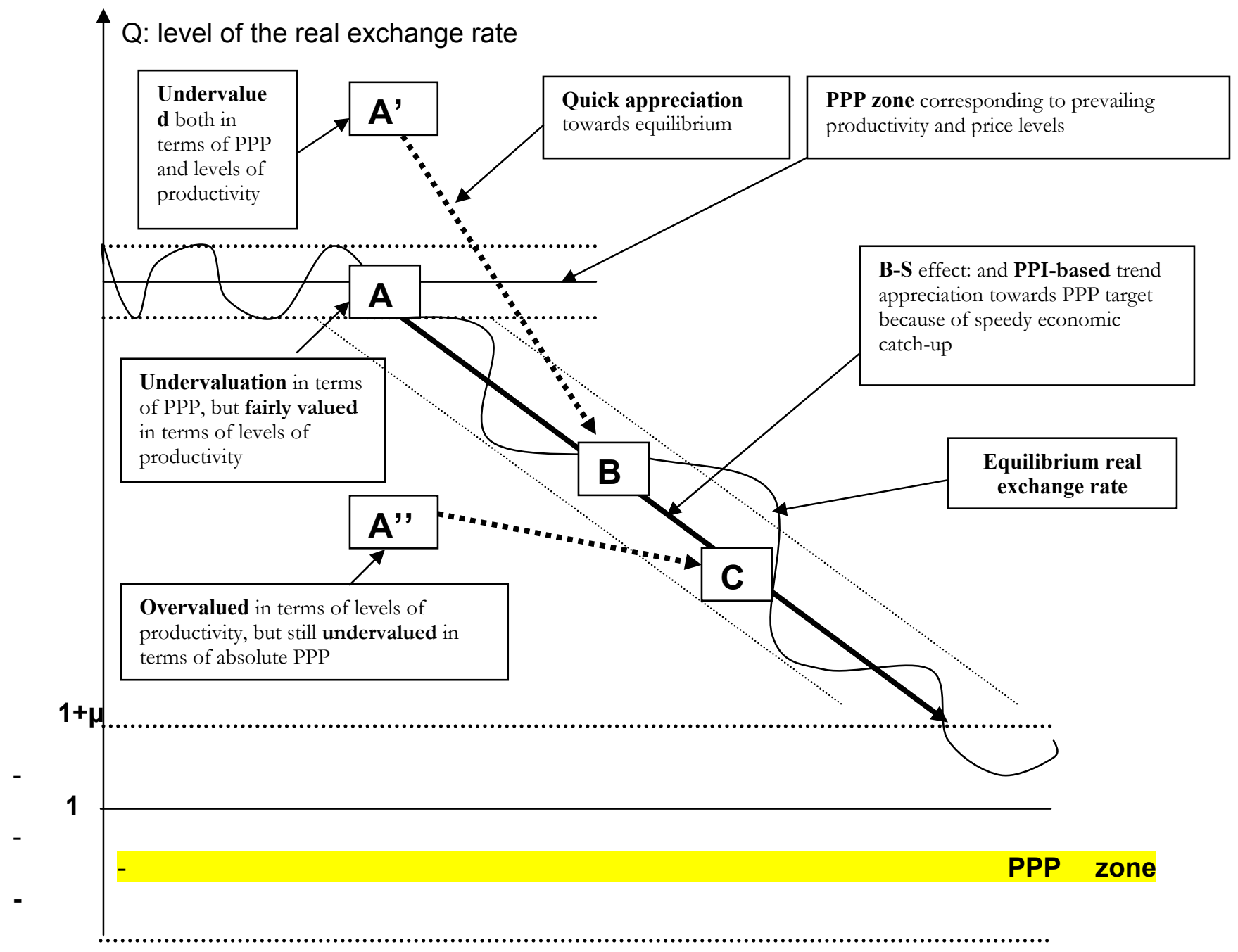

$1-\mu$

Source: author

Purchasing Power Parity: 30-100 years 


\section{Surveying the Empirical Literature}

Whereas the empirical literature related to real exchange rates in CEE acceding countries was limited to a relatively small number of contributions up to the late 1990s, quite a bit of ink has been spilled on the subject over the past few years. In this section, we attempt to overview this literature in a structured way.

In accordance with chart 3, absolute and relative PPP constitute the starting point of any analysis aimed at investigating equilibrium real exchange rates in acceding countries. As shown in table 1, the nominal exchange rate implied by PPP (given by the ratio of the domestic and German price levels) is far lower than the actual nominal exchange rate in eight acceding economies in 1996, 1999 and 2002. This means indeed that the real exchange rate is considerably undervalued (as it is higher than 1), as is the nominal exchange rate. This holds true vis-à-vis the Deutsche mark and subsequently the euro.

Table 1 PPP and the Nominal and Real Exchange Rates in 1996, 1999 and 2002

\begin{tabular}{|c|c|c|c|c|c|c|c|c|c|}
\hline & $\begin{array}{c}1996 \\
\text { PPP } \\
(1) \\
\end{array}$ & $\begin{array}{c}\text { NER } \\
(2)\end{array}$ & $\begin{array}{c}\text { RER } \\
(2) /(1)\end{array}$ & $\begin{array}{c}1999 \\
\text { PPP } \\
(1) \\
\end{array}$ & $\begin{array}{l}\text { NER } \\
(2) \\
\end{array}$ & $\begin{array}{c}\text { RER } \\
(2) /(1)\end{array}$ & $\begin{array}{c}2002 \\
\text { PPP } \\
\text { (1) }\end{array}$ & $\begin{array}{c}\text { NER } \\
(2)\end{array}$ & $\begin{array}{c}\text { RER } \\
(2) /(1)\end{array}$ \\
\hline Czech & & & & & & & & & \\
\hline Republic & 5.76 & 18.04 & 3.13 & 13.85 & 34.6 & 2.5 & 14.88 & 32.7 & 2.2 \\
\hline Estonia & --- & --- & & 6.35 & 14.78 & 2.33 & 7.63 & 16.61 & 2.18 \\
\hline Hungary & 35.76 & 101.4 & 2.84 & 100.66 & 237.2 & 2.36 & 118.3 & 257.9 & 2.18 \\
\hline Latvia & --- & --- & & 0.25 & 0.59 & 2.36 & 0.25 & 0.62 & 2.48 \\
\hline Lithuania & --- & --- & & 1.55 & 4 & 2.58 & 1.5 & 3.68 & 2.45 \\
\hline Poland & 0.67 & 1.77 & 2.64 & 1.81 & 4 & 2.21 & 2.04 & 4.1 & 2.01 \\
\hline Slovakia & 6.01 & 20.37 & 3.39 & 13.87 & 41.36 & 2.98 & 16.95 & 45.33 & 2.67 \\
\hline Slovenia & 47.29 & 89.97 & 1.9 & 118.87 & 182 & 1.53 & 143.83 & 240 & 1.67 \\
\hline
\end{tabular}

Source: Author's own calculations based on data obtained from NewCronos/Eurostat.

Note: PPP is the domestic to German price level ratio. Data on absolute price levels were obtained from NewCronos/Eurostat.

NER stands for the nominal exchange rate against the Deutsche mark in 1996 and against the euro in 1999 and 2002.

RER is the real exchange rate and is obtained as NER/PPP.

Table 1 in fact indicates that PPP does not hold true in levels. But it also indicates that the real exchange rate decreased somewhat from 1996 to 2002. Applying ocular econometrics to charts 4 and 5 also reveals real appreciation of the CPI-based real exchange rate for five acceding countries, to a differing extent though, throughout the 1993 to 2002 period. Therefore, the majority of empirical studies consider the B-S effect when investigating the real equilibrium exchange rate. However, as depicted in charts 4 
and 5, the PPI-deflated real exchange rate also witnessed a strong appreciation over the period considered. And this implies that the B-S effect is bound to fail to explain the entirety of the real appreciation.

Chart 4. CPI- and PPI-Based Real Effective Exchange Rates, 1993 to 2002
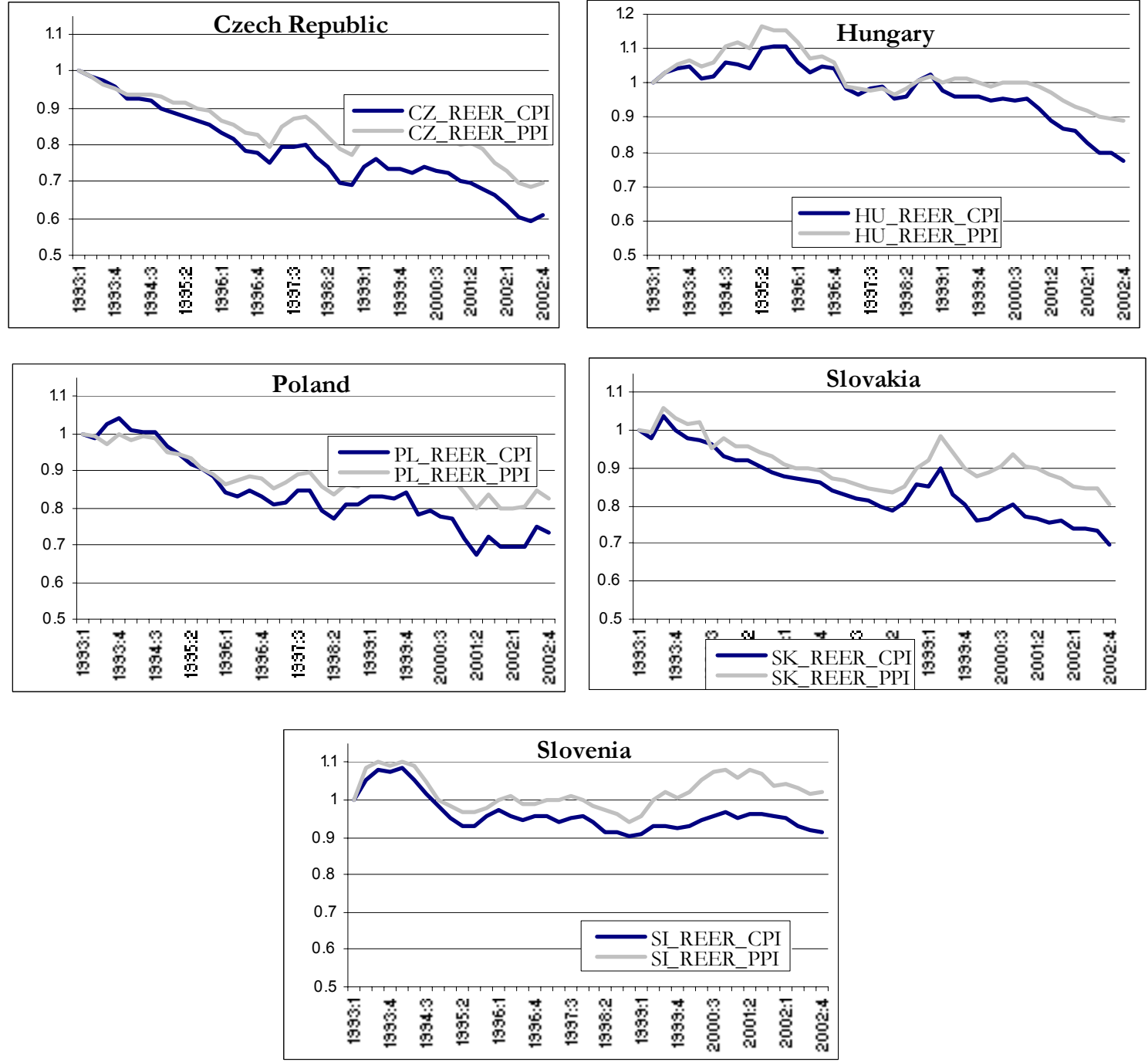

Source: Author's own calculations based on data obtained from the OECD's Main Economic Indicators databes. 
Chart 5. CPI- and PPI-Based Real Exchange Rates vis-à-vis the Deutsche Mark, 1993 to 2002
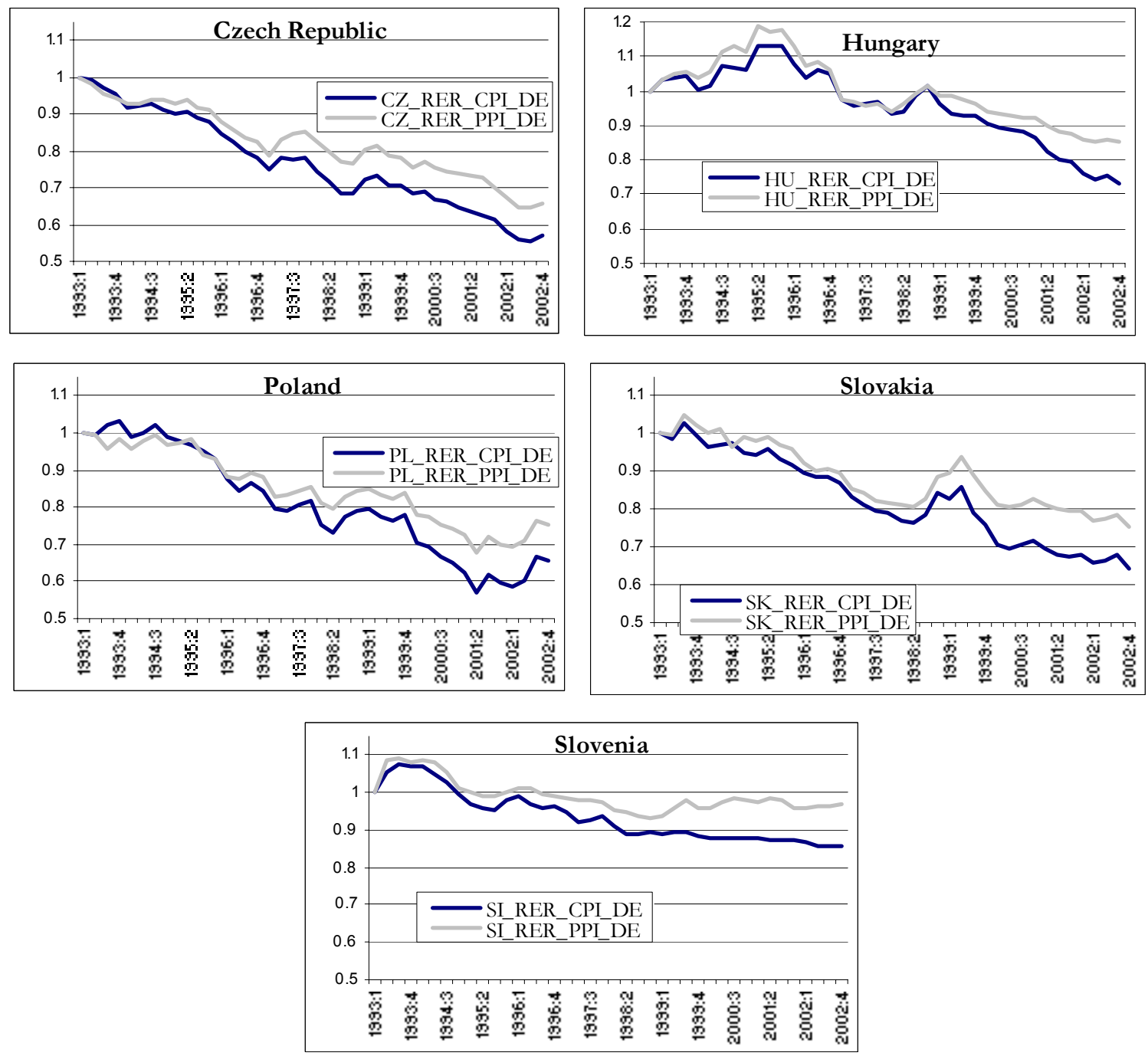

Source: Author's own calculations based on data obtained from the OECD's Main Economic Indicators databes.

There are several criteria according to which the literature could be classified, namely the theoretical background and the econometric technique employed. The first criterion is related to the theoretical background underlying the empirical investigation. A first strand of the literature focuses on the simple B-S model. A second string of papers uses the BEER as a background. In general, while analyzing the B-S effect and especially the impact of productivity increases on prices and the real exchange rate, one has to bear in mind that the effect of productivity growth on the real exchange rate can be treated in different ways. 
1) The most complete approach to the B-S model is to disentangle the two transmission mechanisms. In a first step, the relationship linking the dual productivity and the relative price of nontradable goods is looked at in the home country $\left(\left(\mathrm{a}^{\mathrm{T}}-\mathrm{a}^{\mathrm{NT}}\right) \rightarrow\left(\mathrm{p}^{\mathrm{NT}}-\mathrm{p}^{\mathrm{T}}\right)\right)$, where " $a$ " stands for productivity. This can be referred to as the internal transmission mechanism). The second step considers the link between the dual productivity differential and the difference in the home and foreign relative price of nontradable goods (relative price differential henceforth) $\left(\left(\mathrm{a}^{\mathrm{T}}-\mathrm{a}^{\mathrm{NT}}\right)-\left(\mathrm{a}^{\mathrm{T} *}-\mathrm{a}^{\mathrm{NT}}\right) \rightarrow\left(\mathrm{p}^{\mathrm{NT}}-\mathrm{p}^{\mathrm{T}}\right)-\left(\mathrm{p}^{\mathrm{NT} *}-\mathrm{p}^{\mathrm{T} *}\right)\right)$. It should be noted that usually no distinction is made between market and regulated nontradable prices. This could yield substantially biased estimates. The third and final stage of the analysis consists in investigating the relationship between the relative price differential and the real exchange rate $\left(\left(\mathrm{p}^{\mathrm{NT}}-\mathrm{p}^{\mathrm{T}}\right)-\left(\mathrm{p}^{\mathrm{NT} *}-\mathrm{p}^{\mathrm{T} *}\right) \rightarrow \mathrm{RER}\right)$. Steps 2 and 3 can be referred to as the external transmission mechanism. However, the drawback of this approach is that only one channel, i.e. market-based nontradable prices (see chart 1), through which productivity may have an impact on the real exchange rate is investigated. Therefore, the estimated coefficient for $\left(\mathrm{p}^{\mathrm{NT}}-\mathrm{p}^{\mathrm{T}}\right)-\left(\mathrm{p}^{\mathrm{NT} *}-\mathrm{p}^{\mathrm{T*}}\right) \rightarrow$ RER is likely to be biased.

2) The second approach is limited to the exploration of the relationship $\left(\mathrm{a}^{\mathrm{T}}-\mathrm{a}^{\mathrm{NT}}\right) \rightarrow\left(\mathrm{p}^{\mathrm{NT}}-\mathrm{p}^{\mathrm{T}}\right)$. Underlying this approach is the consideration that it suffices to make sure that relative prices are connected to dual productivity. Estimating the productivity-driven relative price of nontradable goods separately, and thus overall inflation for the foreign country, enables us to derive the inflation differential associated with the dual productivity differential. This in turn gives the extent of the real appreciation that could be justified by productivity gains.

3) The third approach is to link the dual productivity differential to the real exchange rate $\left(\left(a^{\mathrm{T}}-\mathrm{a}^{\mathrm{NT}}\right)-\left(\mathrm{a}^{\mathrm{T} *}-\mathrm{a}^{\mathrm{NT}}\right) \rightarrow \mathrm{RER}\right)$. A slightly modified version is to regress the real exchange rate on the home country's dual productivity $\left(\left(a^{\mathrm{T}}-\mathrm{a}^{\mathrm{NT}}\right) \rightarrow \mathrm{RER}\right)$. Although the overwhelming majority of studies interpret this relationship as the B-S effect by assuming the two transmission mechanisms described in approach 1 to be at work, it also incorporates the impact of productivity increases on the real exchange rate of the 
open sector as described previously. It should be noted that this approach, developed in Section 3.2 appears, on economic grounds, to be the most reliable.

4) The fourth approach consists in analyzing the link between the relative price differential and the real exchange rate $\left(\left(\mathrm{p}^{\mathrm{NT}}-\mathrm{p}^{\mathrm{T}}\right)-\left(\mathrm{p}^{\mathrm{NT*}}-\mathrm{p}^{\mathrm{T*}}\right) \rightarrow \mathrm{RER}\right)$. Hence, by omitting the link between dual productivity and the relative price of nontradables, it is tacitly assumed that dual productivity impacts properly on relative prices in the domestic economy as well as in the foreign country. It is worth mentioning that although the relationship $\left(\mathrm{p}^{\mathrm{NT}}-\mathrm{p}^{\mathrm{T}}\right)-\left(\mathrm{p}^{\mathrm{NT}}-\mathrm{p}^{\mathrm{T} *}\right) \rightarrow$ RER is often considered an alternative to $\left(a^{\mathrm{T}}-\mathrm{a}^{\mathrm{NT}}\right)-\left(\mathrm{a}^{\mathrm{T} *}-\mathrm{a}^{\mathrm{NT} *}\right) \rightarrow$ RER, given that the relative price differential is taken as proxies for the dual productivity differential, it does not stand for the same relationship, because productivity may also impact on tradable prices and the nominal exchange rate in the latter case. And most importantly, in the event that the relationship $\left(\mathrm{p}^{\mathrm{NT}}-\mathrm{p}^{\mathrm{T}}\right)-\left(\mathrm{p}^{\mathrm{NT} *}-\mathrm{p}^{\mathrm{T} *}\right) \rightarrow$ RER is found to be significant, it might well be a spurious one. If the coefficient is much higher than the share of market-driven nontradable prices in $\mathrm{CPI}$, the estimated coefficient clearly reflects the positive inflation differential for tradable goods and other items such as regulated prices.

It deserves mention that while the first approach is mainly used when investigating the simple B-S model, the other three approaches can be employed, in principle, to both the simple B-S framework and the BEER approach.

Regarding estimations based on the FEER approach, two strands can be identified. The first avenue is the use of multinational macro models where the equilibrium real and nominal exchange rates are deduced for the set of countries included in the macro model. The real exchange rate of the home country is assumed to affect economic variables in other economies. However, it might be argued that developments in small economies such as the acceding countries are likely to have no impact whatsoever on the outside world. This is why the second avenue is to rely on a single-country structural model (which might of course be a module of a larger international macro model). Hence, interactions between the home and foreign economies are not taken into 
account. In addition to large macro models, one can also use partial models aimed at describing only the foreign trade of the home economy.

Now let us turn to the issue of the statistical techniques used (displayed in chart 2) to estimate the real exchange rate. The first and simplest approach is descriptive statistics, which is applied only to the simple B-S model and basically consists in computing yearly average growth rates for dual productivity (or the dual productivity differential) and the relative price of nontradables (or the relative price differential). Alternatively, data can be analyzed graphically to see whether the real exchange rate and the relative price differential are in line with the dual productivity differential.

Table 2. Overview of Major Differences in the Estimation Methods

\begin{tabular}{|c|c|c|c|}
\hline $\begin{array}{l}\text { Simple B-S } \\
\text { model }\end{array}$ & $\begin{array}{l}\left(a^{\mathrm{T}}-\mathrm{a}^{\mathrm{NT}}\right) \rightarrow\left(\mathrm{p}^{\mathrm{NT}}-\mathrm{p}^{\mathrm{T}}\right) \\
\left(\mathrm{a}^{\mathrm{T}}-\mathrm{a}^{\mathrm{NT}}\right)-\left(\mathrm{a}^{\mathrm{T}}-\mathrm{a}^{\mathrm{NT} *}\right) \rightarrow\left(\mathrm{p}^{\mathrm{NT}}-\mathrm{p}^{\mathrm{T}}\right)-\left(\mathrm{p}^{\mathrm{NT} *}-\mathrm{p}^{\mathrm{T} *}\right) \\
\left(\mathrm{p}^{\mathrm{NT}}-\mathrm{p}^{\mathrm{T}}\right)-\left(\mathrm{p}^{\mathrm{NT} *}-\mathrm{p}^{\mathrm{T} *}\right) \rightarrow \mathrm{RER} \\
\left(\mathrm{a}^{\mathrm{T}}-\mathrm{a}^{\mathrm{NT}}\right)-\left(\mathrm{a}^{\mathrm{T} *}-\mathrm{a}^{\mathrm{NT}}\right) \rightarrow \text { RER }\end{array}$ & $\begin{array}{l}\text { Descriptive statistics } \\
\text { Time series } \\
\text { Panel } \\
\text { Cross-section }\end{array}$ & $\begin{array}{l}\text { None. } \\
\text { Actual }\end{array}$ \\
\hline BEER & $\begin{array}{l}\left(a^{\mathrm{T}}-\mathrm{a}^{\mathrm{NT}}\right) \rightarrow\left(\mathrm{p}^{\mathrm{NT}}-\mathrm{p}^{\mathrm{T}}\right) \\
\left(\mathrm{a}^{\mathrm{T}}-\mathrm{a}^{\mathrm{NT}}\right)-\left(\mathrm{a}^{\mathrm{T} *}-\mathrm{a}^{\mathrm{NT}}\right) \rightarrow \mathrm{RER} \\
\left(\mathrm{a}^{\mathrm{T}}-\mathrm{a}^{\mathrm{NT}}\right) \rightarrow \mathrm{RER} \\
\left(\mathrm{p}^{\mathrm{NT}}-\mathrm{p}^{\mathrm{T}}\right)-\left(\mathrm{p}^{\mathrm{NT} *}-\mathrm{p}^{\mathrm{T} *}\right) \rightarrow \mathrm{RER}\end{array}$ & $\begin{array}{l}\text { Time series } \\
\text { Panel: in-sample, out-of-sample }\end{array}$ & $\begin{array}{c}\text { None } \\
\text { Actual } \\
\text { Total }\end{array}$ \\
\hline FEER & $\begin{array}{l}\text { Multi-country model } \\
\text { Single-country model } \\
\text { Full-scale macromodel } \\
\text { Model of foreign trade }\end{array}$ & Structural models -4 steps & Total \\
\hline NATREX & & $\begin{array}{l}\text { Single equation } \\
\text { Structural model }\end{array}$ & Total \\
\hline
\end{tabular}

Source: Author.

It is common practice to use time series analysis both for the simple and the extended version of the B-S model. How it is used is described in detail in the section discussing BEER. Another way to estimate the simple and extended B-S model consists in employing panel estimation methods. Since the philosophy underneath the application of panel methods differs to some extent from that of the use of time series, we shall describe it more in detail below. The underlying idea is that the countries included in the panel should behave relatively similarly in the long run. This implies that the real exchange rate is assumed to react quite similarly to changes in its fundamentals in 
every country of the panel. The estimation of the relationship between the real exchange rate and its fundamentals yields average coefficients for the whole panel. If long-term homogeneity holds true for the panel, then the estimated average coefficients are expected to properly reflect the long-run behavior of the real exchange rate of individual countries and can thus provide a better estimate than what we could obtain by means of time series techniques.

The equilibrium real exchange rate can be derived the same way as for time series. First, the actual misalignment is determined. Second, total misalignment is obtained based on the long-term values of the fundamentals.

It is necessary to mention two types of panel estimations, namely in-sample and out-ofsample panel estimations. Underneath the in-sample approach lies the concept that the equilibrium real exchange rate is assessed for the countries included in the sample and for the period used for the estimation. By contrast, out-of-sample means that the empirical relationship linking the real exchange rate to its fundamentals is estimated using a given set of countries, but the equilibrium exchange rate will be computed for countries not included in the sample and/or for a different period ${ }^{22}$ by substituting the corresponding fundamentals series into the estimated equation.

Regarding the calculation of misalignment, the following patterns emerge from the literature:

1) Some papers simply do not compute misalignment. The sole aim of these papers is to show the empirical linkage through which the real exchange rate is connected with its fundamentals (real exchange rate determination, as in step 1 of BEER and panel estimations), i.e. to estimate real exchange rate determination.

2) Others calculate only actual misalignment. This is particularly the case in time-series and panel estimations.

\footnotetext{
${ }^{22}$ E.g. the panel includes countries A, B, C,..., M for 1960-90, and the equilibrium exchange rate is
} assessed for the case of countries $\mathrm{N}$ and $\mathrm{L}$ for the period 1995-2003. 
3) Finally, another part of the BEER and panel literature also aims at identifying total misalignment. It should be noted that the FEER approach always produces total misalignment.

\subsection{The Simple Balassa-Samuelson Framework}

\subsubsection{Studies Based on Descriptive Statistics}

Kovács and Simon (1998) were among the first to give an estimate on the size of the B$S$ effect in Hungary. They use yearly data for the period 1991-96 obtained from national accounts and proceed to compute yearly changes in labor productivity both for the open and the sheltered sectors. The open sector is defined in terms of manufacturing whereas the sheltered sector contains the remaining sectors with the exception of agriculture, mining, electricity, public services, education, health and social services. The productivity differential between the open and sheltered sectors they obtain is then compared with the corresponding differential of a basket of foreign economies, corresponding roughly to Hungary's effective trading basket. They assume a proportionate relationship between dual productivity and the relative price of nontradable goods for Hungary as well as for the foreign basket. That is, a $1 \%$ change in dual productivity should translate into a $1 \%$ change in the relative price of nontradables. How large the impact of the increase in dual productivity is depends in the end on the share of nontradable goods in the price basket $(1-\alpha)$ as given in equation (3) $\left(p=\alpha \cdot p^{T}+(1-\alpha) \cdot p^{N T}\right)$. The higher this share is, the larger the impact on overall inflation and the larger the real appreciation attributable to the B-S effect is. Kovács and Simon (1998) employ the share of nontradables extracted from the national accounts (share of nontradable sectors in GDP) as well as that drawn from the CPI basket (share of nontradable goods in the price basket). The inflation due to productivity gains is calculated both for Hungary and for the foreign basket. The results indicate that the inflation differential due to the B-S effect is of the order of $2.9 \%$ to $3.1 \%$ when weights from national accounts are used and is $1.6 \%$ using weights obtained from the CPI.

Kovács (2001) updates the yearly dataset used in Kovács and Simon (1998). Using the same methodology, the author comes to the conclusion that the average yearly inflation 
differential and the real appreciation of the Hungarian forint consistent with the B-S effect was in the range of $0.8 \%$ to $2.2 \%$ over the period $1991-99$.

Rother (2000) focuses on whether the B-S effect is at work in Slovenia. His analysis is based on quarterly sectoral data over the period 1993-98. For the calculation of dual productivity, the open sector consists of manufacturing whilst the sheltered sector is composed of the rest except agriculture, which is excluded from the analysis. Figures for dual productivity are calculated for each year. This is then graphically compared with annual changes in the relative price of nontradable goods: If annual changes in dual productivity are roughly the same as those for the relative price of nontradables, this is viewed as a piece of evidence in favor of the B-S effect. This exercise is also performed for three other CEE countries, namely the Czech Republic, Estonia and Slovakia (for the periods 1994 to 1998, 1993 to 1997 and 1994 to 1998, respectively). Rother concludes that the B-S effect seems to hold in Slovenia and the Czech Republic, and to a much lesser extent in Estonia and Slovakia. Rother (2000) estimates that the rate of inflation due to the B-S effect ranges from $2.5 \%$ to $3 \%$ in Slovenia over the period under study. He considers a foreign benchmark composed of Austria, France, Germany and Italy, for which $1 \%$ is taken as the size of the B-S effect-driven inflation, a figure provided in Alberola and Tyrväinen (1998). The author concludes that the inflation differential and the real appreciation associated with the B-S effect amount to $1.5 \%$ to $2 \%(2.5 \%$ to $3 \%$ minus $1 \%)$. However, the conclusions can be mitigated because of the short time span used.

For a number of European countries, Sinn and Reutter (2001) attempt to determine the productivity-driven inflation conditional on the absence of deflation in the lowestproductivity economy, namely in Germany. In so doing, average yearly labor productivity figures for dual productivity are calculated based on national accounts data. The results suggest that this inflation rate would have been as high as $2.88 \%, 3.38 \%$, $4.06 \%, 4.16 \%$ and $6.86 \%$ for the Czech Republic, Slovenia, Estonia, Poland and Hungary, respectively, for the periods 1994 to 1998, 1996 to 1999, 1994 to 1998, 1995 to 1998 and 1995 to 1998 . Beside the use of very short time periods, one criticism that can be addressed is that the results are hard to compare due to different time periods, 
especially vis-à-vis the benchmark country, i.e. Germany, for which the time series covers the period 1979 to 1991.

Rosati (2002) engages in a similar exercise and computes yearly averages for dual productivity (based on average labor productivity) for the Czech Republic, Estonia, Hungary, Poland and Slovenia. The share of the nontradable sector in GDP, defined as the sectors excluding industry and, in a second step, also agriculture, is subsequently applied to these growth rates. Although the period under study is different, i.e. 1993 to 1999, results are roughly in line with those of Sinn and Reutter (2001). The domestic inflation implied by productivity gains amounts to $1.1 \%$ to $1.2 \%$ in the Czech Republic, $2.2 \%$ in Estonia, $3.9 \%$ to $4.3 \%$ in Hungary, $3.6 \%$ to $4.2 \%$ in Poland and $2.1 \%$ in Slovenia.

Backé et al. (2003) provide estimates concerning the average annual impact of dual productivity on overall inflation. In this study, inflation is defined in terms of the implicit GDP deflator (and not as consumer price inflation). Using annual national accounts data, average yearly changes in dual labor productivity are calculated for the Czech Republic, Hungary, Poland and Slovenia, with manufacturing being considered as the open sector and the rest representing the sheltered sector. The results are portrayed in table 3. Because this calculation is based on equation (7), the average labor productivity in the open sector is multiplied by the $\delta / \gamma$ coefficient, which is higher than unity: This may partly explain the high figures for some of the countries compared to the rest of the literature. The difference is considerable between the results for the Czech Republic, on the one hand, and Hungary, Poland and Slovenia, on the other. This is mainly because during the period under consideration, the change in the productivity differential was markedly lower in the Czech Republic than in the remaining countries.

Table 3. Average Annual Change in Overall Inflation Attributable to Changes in Dual Productivity, 1992 to 2000 (in \%)

\begin{tabular}{|c|rrrr|}
\hline$\%$ & Czech Republic & Hungary & Poland & Slovenia \\
\hline 1992-2000 & 0.79 & 5.58 & 9.43 & 3.48 \\
1995-2000 & 0.35 & 3.84 & 9.76 & 3.88 \\
Source: Backé et al. (2003, p. 61, table 3). \\
\hline
\end{tabular}


In a study commissioned by five CEE central banks, Kovács (2002) investigates the importance of the B-S effect for inflation and real exchange rates in the Czech Republic, Hungary, Poland, Slovakia and Slovenia. Different parts of the paper were written in the respective central banks, so that the results reported for different countries are not (fully) comparable. For instance, the paper does not contain productivity-based estimates for Poland and Slovakia. Nonetheless, the results for Hungary and Slovenia are comparable, and those for the Czech Republic can be translated into interpretable figures. The part on Hungary is based on the dataset used in Kovács (2001) updated until 2001. The productivity-driven inflation differential vis-à-vis Germany turns out to be $1.9 \%$ per annum on average over the period 1992-2001. For Slovenia, it is found that the corresponding figure is as low as $0.7 \%$ a year (the open sector is manufacturing; the sheltered sector is the rest, but energy, public services and agriculture are not considered). However, whereas the impact of dual productivity was close to $0 \%$ a year during 1991-96, it has been on an accelerating path since then (1.4\% per annum). For the Czech Republic, the paper gives an indicative figure of $2.44 \%$ for dual productivity from 1994 to 2001. Hence, assuming that the average share of nontradable goods was $30 \%$ during the period under investigation, we obtain $0.7 \%$ for the magnitude of the inflation differential due to productivity gains in the Czech Republic. However, the inflation differential against Germany will be even lower if we assume positive B-S inflation in Germany.

Burgess et al. (2003) seek to determine the B-S effect-induced inflation differential in three Baltic countries vis-à-vis Germany and the euro area. Using yearly observations from 1997 to 2001, GDP per worker and total factor productivity (TFP) figures are compared to those in the euro area. The period averages multiplied by the share of market services in CPI yields an inflation differential of $0.6 \%$ and $0.5 \%$ for Estonia, $0.7 \%$ and $0.5 \%$ for Latvia and $0.5 \%$ and $0.3 \%$ for Lithuania. When the difference between average labor productivity between manufacturing and services is considered, the corresponding figures are $0.2 \%, 0.0 \%$ and $0.6 \%$ for Estonia, Latvia and Lithuania, respectively. 


\subsubsection{Time Series Studies}

Golinelli and Orsi (2002) explore different facets of inflation in three acceding countries, notably in the Czech Republic, Hungary and Poland. The estimated inflation model contains three blocs, of which one aims at having a closer look at the relationship between the dual productivity differential and the CPI-deflated real exchange rate. Labor productivity series are based on monthly industrial production data. Hence, industry is considered the open sector whereas productivity changes in the sheltered sector are set to zero. Then, the difference between the domestic country's productivity and that of the euro area is constructed. Using the Johansen cointegration technique, robust cointegration relationships are established and estimated between the dual productivity differential and the real exchange rate, indicating that changes in the real exchange rate are linked to changes in labor productivity during the 1993-2000 period for the Czech Republic and the 1991-2000 period for Hungary and Poland. In a second step, the authors proceed to calculate the extent to which dual productivity might have contributed to overall inflation. They come up with $0.6 \%$ to $3.7 \%$ for Hungary, $4.4 \%$ to $5.8 \%$ for Poland and $3.3 \%$ to $5.3 \%$ for the Czech Republic.

Jazbec (2002) also uses the Johansen cointegration technique to shed light on whether inflation and real exchange rate movements are due to changes in dual productivity in the case of Slovenia. The study employs quarterly national accounts data for the period from the first quarter of 1993 to the second quarter of 2001 and constructs dual labor productivity as follows. The open sector includes industry; the sheltered sector contains the rest. Agriculture is excluded. The econometric tests show that dual productivity in Slovenia and the real exchange rate, based on the CPI and against the Deutsche mark have a long-term relationship. However, dual productivity is not compared with that of a foreign benchmark country. Furthermore, Slovenian CPI inflation (and not the relative price of nontradables) is regressed on dual productivity. The author reaches the conclusion that consumer price inflation is driven by productivity developments. The size of the B-S effect is not estimated.

Lommatzsch and Tober (2002a) examined five acceding countries. The objective of the paper is to analyze the link between dual productivity and the relative price of 
nontradables in the Czech Republic, Estonia, Hungary, Poland and Slovenia. For this purpose, the Engle-Granger cointegration technique is employed. For Estonia, labor productivity is constructed using national accounts data. The open sector is defined as industry, and the sheltered sector only includes construction, trade and finance. Labor productivity in the remaining countries is based on industrial production. Therefore, as in Golinelli and Orsi (2002), productivity growth in the sheltered sector is set equal to zero. Dual productivity and the relative price of nontradables appear to be connected through a cointegrating vector in Estonia, Hungary and Slovenia, whereas no long-term relationship is found for Poland and the Czech Republic. The paper does not provide estimates for the size of the inflation attributable to the B-S effect.

Mihaljek and Klau (2003) set out to investigate a somewhat different set of acceding countries containing the Czech Republic, Hungary, Poland, Slovakia and Slovenia. Furthermore, Croatia is also included in the sample. The analysis rests on the use of labor productivity. The classification of the sectors into tradable and nontradable sectors seems unconventional, since beside manufacturing and mining, the sectors hotels, transport, storage and communication are also considered part of the open sector. The sheltered sector contains the remaining sectors, except agriculture and public administration. The period under investigation varies across countries (starting between 1992 and 1995 and ending in 2001 or the first quarter of 2002). The author examines the wage equalization process and finds that it seems to be violated only in Croatia and Slovakia. Therefore, the difference in sectoral wages (open/sheltered) between the home and the foreign countries is also included in the estimated specification along the lines of Alberola and Tyrväinen (1998). The authors motivate their analysis with equations (7) and (8) with $\delta / \gamma$ being set to 1 . The authors estimate the relationship between the inflation differential against the euro area (not the difference in relative prices) and the dual productivity differential using ordinary least squares (OLS) for levels and first differences. Also, the relative price of nontradables in the home country is regressed on dual productivity. Finally, period averages for the domestic productivity differential and the difference in productivity differentials are multiplied by the corresponding estimated coefficients to derive domestic inflation and the inflation differential vis-à-vis the euro area that can be imputed to the B-S effect. The estimates 
reported in table 4 below show that the derived home inflation is generally higher than the inflation differential due to the B-S effect. However, the inflation differential appears to be higher than domestic inflation for the Czech Republic and Slovenia. This is surprising because the foreign benchmark, i.e. the euro area, is the same for all the estimations.

Table 4. The B-S Effect as Reported in Mihaljek and Klau (2003)

\begin{tabular}{|l|c|cc|}
\hline & & Domestic Inflation (\%) & Inflation Differential (\%) \\
\hline Croatia & $\mathbf{1 9 9 5 - 2 0 0 1}$ & 1.26 & 0.17 \\
Czech Republic & $\mathbf{1 9 9 3 - 2 0 0 1}$ & 0.32 & 0.98 \\
Hungary & $\mathbf{1 9 9 4 - 2 0 0 1}$ & 1.58 & 0.56 \\
Poland & $\mathbf{1 9 9 4 - 2 0 0 1}$ & 1.41 & 0.12 \\
Slovakia & $\mathbf{1 9 9 5 - 2 0 0 1}$ & 0.64 & 0.18 \\
Slovenia & $\mathbf{1 9 9 2 - 2 0 0 1}$ & 0.60 & 1.84 \\
\multicolumn{2}{|c|}{ Source: Mihaljek and Klau (2003, pp. 10-11, tables 3 and 4). } \\
\hline
\end{tabular}

Lojschová (2003) follows Mihaljek and Klau (2003) in that she regresses the inflation differential on the dual productivity differential. But contrary to Mihaljek (2002) and the rest of the literature, Lojschová's study employs quarterly sectoral TFP from 1996 to 2002 for the Czech Republic, Hungary, Poland and Slovakia. It should be noted that it is the only paper that properly tests equation (7) in first differences and using total factor productivity. However, $\delta / \gamma$ is set to 1 . With manufacturing representing the open sector and services and construction representing the sheltered sector, the author specifies two equations in addition to the standard equation. The first one includes the differential between domestic and foreign price inflation, whereas the second one contains the difference between foreign and domestic sectoral wage differences, as introduced by Alberola and Tyrväinen (1998) and used in Mihaljek (2002). The first modification is meant to allow for PPP not to hold for tradable goods, whereas the second specification considers the case when wages do not equalize across sectors. Estimations are performed on time series in first differences by means of OLS and then using pooled and fixed-effect panel OLS for the four countries. Results suggest that the introduction of the tradable inflation differential sharply reduces the size of the coefficients of TFP, whereas the wage terms are found significant only for the case of Slovakia. These results provide strong evidence for the fact that overall inflation is driven less by productivity-driven service price inflation than other factors and that wages tend to 
equalize in all countries but Slovakia. At the beginning of the article, the author shows that Hungary and Poland exhibit much larger annual changes in dual productivity than the Czech Republic and Slovakia. Maybe as a consequence, the coefficients for dual productivity are found to be much lower for Hungary and Poland than for the Czech Republic and Slovakia. However, the author construes these coefficients as the average annual inflation due to dual productivity and argues that productivity-driven inflation is highest in Slovakia, followed by the Czech Republic, whereas Hungary and Poland have inflation rates close to zero. It should be borne in mind, however, that as absolute values of average productivity changes are not considered, the author's interpretation is fairly misleading. ${ }^{23}$

Égert (2002a, b) investigates the case of five acceding economies. The papers make use of monthly and quarterly data for the Czech Republic, Hungary, Poland, Slovakia and Slovenia. Labor productivity is calculated using industrial production, and therefore changes in productivity are considered to be zero in the nontradable sector. This zeroproductivity assumption holds in the event that changes in the productivity of the nontradable sector are alike in the home and foreign country. Otherwise, the results may be biased. Employing the Johansen (Égert, 2002a, b) and panel cointegration (Égert, 2002b) techniques, the author uncovers that changes in dual productivity lead to changes in the relative price of nontradable goods. However, because of the low share of nontradable items in the CPI basket, the impact of productivity improvements on overall inflation remains limited. The average inflation differential against Germany due to the B-S effect is then assessed based on descriptive statistics using the share of nontradables in the $\mathrm{CPI}$ and partly estimated coefficients. The results are as follows: $0 \%$ to $0.4 \%$ for the Czech Republic, $0.9 \%$ to $1.9 \%$ for Hungary, $0.8 \%$ to $2.4 \%$ for Poland, $0.4 \%$ to $-0.1 \%$ for Slovakia and finally $-0.2 \%$ to $0.7 \%$ for Slovenia. Although long-term relationships between the relative price differentials and the CPI-based real exchange rate could be established, the coefficients are considerably higher than the share of nontradables in the CPI would justify. It is argued that the appreciation of the real

\footnotetext{
${ }^{23}$ For instance, Darvas (2001, p. 26) shows that the estimated coefficient of the dual productivity variable is smaller for Hungary than for the other countries because dual productivity rose faster in Hungary than elsewhere.
} 
exchange rate is only partially explained by the B-S effect either because of the absence of productivity growth or due to the incomplete spillover of productivity gains into overall inflation.

Égert (2003) studies the case of Estonia over the period from the first quarter of 1993 to the first quarter of 2002 based on a fifteen-sector breakdown for GDP and a five-digit level CPI disaggregation with over 260 items. The analysis reveals that all hypotheses of the B-S model are fulfilled for Estonia and that dual productivity has an important influence on nontradable prices. However, it is also shown that econometric results are sensitive to how sectors are classified into the open and closed sectors (that might partly explain the results in Mihaljek and Klau, 2003). Furthermore, it turns out that some sectors should be classified differently in Estonia than would be common practice. Dual productivity is connected to the relative price of market nontradables obtained by eliminating regulated nontradable prices. The size of the productivity-driven inflation is estimated at $4 \%$ to $5 \%$ at the outset and at $0.3 \%$ to $1 \%$ at the end of the period. It is argued that the potential long-term inflation rate is around $1 \%$ to $2 \%$. The inflation differential due to the B-S effect is calculated both against Estonia's four major western European trading partners, namely Finland, Sweden, Germany and the U.K., and vis-àvis Germany alone, and it is estimated at $0.2 \%$ to $1 \%$. Finally, when assessing the equilibrium real exchange rate, the author stresses the need for using fully comparable real exchange rates adjusted for regulated prices and differing weights in the CPI across countries. At the end of the period, the majority of the real appreciation is found to be consistent with the B-S effect.

\subsubsection{Panel Studies}

Halpern and Wyplosz (2001), a study commissioned by the UNECE, covers 12 transition economies (the CEECs, the Baltic atates and the CIS) over an unbalanced period from 1991 to 1996-98. The paper attempts to disentangle the link between dual productivity and the relative price of nontradables and is therefore structured as follows:

1) First, the wage equalization process between the open (industry) and closed sectors (the remaining sectors excluding agriculture and construction) is analyzed. Wages tend to equalize in all countries but the CIS. 
2) Second, the reasons for sectoral labor productivity increases are considered. The explanatory variables, namely sectoral investment and FDI, are found to have a strong impact on sectoral productivity.

3) Third, gross sectoral wages are investigated. The econometric analysis reveals that sectoral productivity, unemployment and the number of employees largely explain gross wages.

4) Fourth, the authors consider whether gross and net real wages are connected with one another.

5) Fifth, sectoral GDP is regressed on a number of supply- and demand-side variables.

6) Sixth, given that the hypotheses of the B-S model appear to be satisfied, more (econometric) attention is devoted to exploring the relationship between dual productivity and the relative price of nontradables defined as CPI over PPI. Indeed, productivity in the open sector and in the closed sector (taken separately), GDP per capita measured in purchasing power standards and the size of the inflation rate turn out to be significant for relative prices.

7) The last stage of the analysis is the substitution of average annual productivity growth rates, both in the open and the closed sector for all countries, into the estimated equation, which yields an average annual nontradable inflation rate of $2.9 \%$ to $3.1 \%$. According to Kovács (2002), this would imply an overall inflation rate of $1.2 \%(2.9 \%$ to $3.1 \%$ multiplied by the share of nontradable items in the CPI assumed to be $40 \%$ ).

Flek et al. (2002) analyze the case of the Czech Republic. This is done in a panel framework based on an unbalanced panel composed of eight EU countries, namely Belgium, Denmark, Finland, France, Germany, Italy, the Netherlands, the U.K. and the Czech Republic. The period covered spans from 1986-92 to 1993-99 for the EU countries and from 1994-2001 for the Czech Republic. Based on annual data drawn from national accounts, and using manufacturing for the open sector and somewhat interestingly only construction for the closed sector, the relative price ratio determined using corresponding sectoral deflators is regressed first on dual productivity, and 
second on labor productivity in the open and closed sectors separately. The impact of dual productivity on the relative price of nontradables is found to amount to roughly 0.6. Finally, the influence of dual productivity growth is quantified using period average productivity figures and the share of tradable and nontradable sectors in GDP. It is noteworthy that there is a mismatch between sectors used to compute dual productivity and relative prices and those employed to derive the share of tradable goods and nontradable goods in GDP. The outcome is that in the Czech Republic, the domestic inflation brought about by the B-S effect ranged from $0.05 \%$ to $0.29 \%$ from 1994 to 2001 , and the inflation differential against Germany amounted to $-0.22 \%$ to $-0.04 \%$.

Égert et al. (2003) implements the exercise done in Égert (2002b) for a larger sample including nine transition economies and with better data drawn from national accounts. After verifying the basic assumptions to the B-S model (wage equalization, relationship between productivity and real wages in the open sector), Pedroni panel cointegration tests are conducted and the panel FMOLS is employed. They confirm, once again, that dual productivity differentials are strongly reflected in nontradable prices, especially when calculated on the basis of GDP deflators. The impact on consumer price inflation and consequently on the appreciation of the CPI-based real exchange rate is, however, limited on the grounds of the relatively small share of nontradable goods in the CPI basket (see figures in table 6). By contrast, tradable prices measured by means of the PPI contributed considerably to the real appreciation of the CPI-based real exchange rate. One possible reason for this is that productivity gains might also affect tradable prices through improved product quality and thus higher prices. At the same time, regulated prices were an important source of inflation and their presence might have biased the estimations.

Table 5 provides an overview of the studies on the variables, time period, country groups and the tested relationship. Table 6 summarizes the currently available estimates of the inflation differential and the implied appreciation of the real exchange rate that could be associated with productivity-fueled nontradable price inflation. It should be noted that these figures can be viewed as the inflation differential if the inflation differential were set to zero, so that tradable inflation in the home country would be equal to that in the foreign economy. 
These figures can be compared with the average appreciation of the real exchange rate in the respective countries over the period from 1993 to 2001. In accordance with Backé et al. (2003), Golinelli and Orsi (2002), Rosati (2002), Rother (2000) and Sinn and Reutter (2001), the real appreciation of the Slovene tolar is more than fully covered by the B-S effect-driven inflation differentials. At the same time, in the case of Hungary and Poland, the observed appreciation of the real exchange rate seems in line with productivity increases. For the Czech Republic and Estonia, appreciation appears twice as high as the one given by the B-S effect.

In contrast to the studies mentioned in the above paragraph, Burgess et al. (2003), Égert (2002a, b, 2003), Égert et al. (2003), Flek et al. (2002), Halpern and Wyplosz (2001), Kovács (2001), Kovács and Simon (1998), Kovács (2002) and Mihaljek and Klau (2003) suggest that even in Hungary and Poland only a fraction of the real appreciation could be explained by the inflation differential implied by productivity-driven nontradable inflation. Moreover, for the remaining countries, the real appreciation remains largely unexplained by the standard B-S effect. 
Table 5a. Studies Using the Simple Balassa-Samuelson Framework

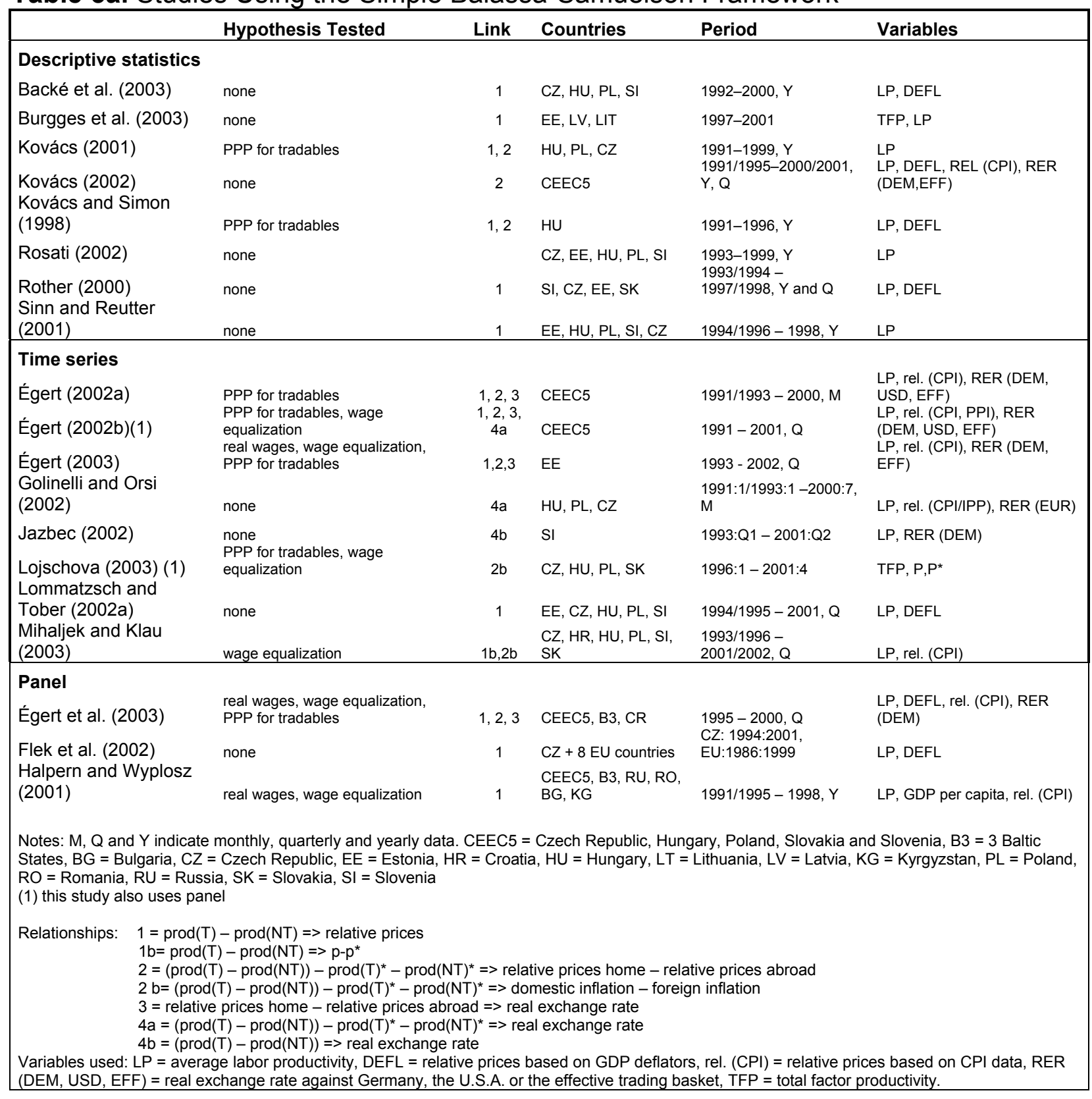


Table 5b. Studies Using the Simple Balassa-Samuelson Framework: Methods

\begin{tabular}{|ll|}
\hline & Econometric Technique \\
\hline Égert (2002a) & \\
Égert (2002b) & Johansen cointegration \\
Égert (2003) & Johansen cointegration \\
Golinelli and Orsi (2002) & Johansen cointegration \\
Jazbec (2002) & Johansen cointegration \\
Lojschova (2003) & Johansen cointegration \\
Lommatzsch and Tober (2002a) & Engle and Granger cointegration \\
Mihaljek and Klau (2003) & OLS, in levels and first differences \\
\hline Panel & \\
Égert (2002b) & panel FMOLS; Pedroni panel cointegration \\
Égert et al. (2003) & panel FMOLS; Pedroni panel cointegration \\
Flek et al. (2002) & fixed-effect OLS \\
Halpern and Wyplosz (2001) & GLS \\
Lojschova (2003) & pooled and fixed effect OLS \\
Note: FMOLS = fully modified OLS, GLS = generalized least squares
\end{tabular}

Table 5c. Inflation Differential and the Real Appreciation of the Exchange Rate Implied by the Balassa-Samuelson Effect vis-à-vis Germany or the Euro Area

\begin{tabular}{|c|c|c|c|c|c|c|c|c|}
\hline (in \%) & Czech R. & Estonia & Hungary & Latvia & Lithuania & Poland & Slovakia & Slovenia \\
\hline Backé et al. (2003); a & 0.00 & & 4.10 & & & 9.00 & & 3.10 \\
\hline Golinelli and Orsi (2002); a & 3.70 & & 1.55 & & & 4.50 & & \\
\hline Rosati (2002); a & 0.55 & 1.60 & 3.50 & & & 3.75 & & 1.60 \\
\hline Rother (2000); a & & & & & & & & 2.15 \\
\hline Sinn and Reutter (2001); a & 2.30 & 2.80 & 6.30 & & & 3.60 & & 2.80 \\
\hline Average & 1.64 & 2.20 & 3.86 & & & 5.21 & & 2.41 \\
\hline Burgess et al. (2003) & & 0.43 & & 0.40 & 0.47 & & & \\
\hline Égert (2002a) & 0.20 & & 1.50 & & & 1.35 & -0.10 & 0.60 \\
\hline Égert (2002b) & 0.20 & & 1.40 & & & 1.85 & -0.70 & -0.50 \\
\hline Égert (2003) & & 0.65 & & & & & & \\
\hline Égert et al. (2003) & -0.20 & 0.10 & 0.75 & -0.30 & -0.10 & 1.60 & 1.50 & 0.70 \\
\hline Felk et al. (2002) & -0.29 & & & & & & & \\
\hline $\begin{array}{l}\text { Halpern and Wyplosz (2001); } \\
\text { a }\end{array}$ & 0.60 & 0.60 & 0.60 & 0.60 & 0.60 & 0.60 & 0.60 & 0.60 \\
\hline Kovács (2001) & & & 1.50 & & & & & \\
\hline Kovács and Simon (1998) & & & 1.60 & & & & & \\
\hline Kovács (2002) & 0.10 & & 1.90 & & & & & 0.70 \\
\hline Mihaljek and Klau (2003); a & -0.30 & & 1.00 & & & 0.80 & 0.00 & 0.00 \\
\hline Average & 0.04 & 0.45 & 1.28 & 0.23 & 0.32 & 1.24 & 0.26 & 0.35 \\
\hline $\begin{array}{l}\text { Average real appreciation } \\
\text { 1993-2001 }\end{array}$ & $\sim 5.00$ & $\sim 10.00$ & $\sim 3.00$ & $\sim 10.00$ & $\sim 10.00$ & $\sim 5.00$ & $\sim 4.00$ & $\sim 1.50$ \\
\hline
\end{tabular}




\subsubsection{Studies Based on Cross-Section Data}

The cross-section analysis is useful to determine where a given country is situated in chart 3 , i.e. whether a country's real exchange rate is undervalued (point $A^{\prime}$ ), fairly valued (point $A$ ) or overvalued (point A") in terms of its relative productivity level. To see this, the relative price level of the home country vis-à-vis a benchmark economy (the reciprocal of the real exchange rate in levels as defined in footnote 4) is to be regressed on the dual productivity level in the home country relative to that in the foreign benchmark. However, in practice, GDP per capita expressed in PPP terms is used, which is only a proxy for productivity. ${ }^{24}$ Table 6 a summarizes the available studies and reveals that the slope coefficient varies between 0.5 and 1.0 (with the exception of Coudert and Couharde, 2002).

Some studies go one step further and calculate fitted values of the relative price level of transition countries. The fitted value is then compared with the value observed for each country. De Broeck and Sløk (2001) calculate confidence intervals around the fitted values. The confidence intervals turn out to be rather large. In 1993, the real exchange rate in levels (relative price level) was undervalued in terms of productivity levels in the three Baltic states, the Czech Republic and Slovakia. At the same time, Hungary, Poland and Slovenia were located within the confidence intervals. By 1999, the three Baltic states had moved inside the confidence intervals, implying the correction of undervaluation, whereas the Czech Republic and Slovakia remained undervalued and Hungary, Poland and Slovenia did not move from within the band. Using the regression of De Broeck and Sløk (2001) for 2001, Burgess et al. (2003) find the three Baltic states to be fairly valued (they were within the confidence intervals).

Coudert and Couharde (2002), Randveer and Rell (2002) and Čihák and Holub (2001, 2003) also perform the same exercise but without confidence intervals. Therefore, their results are not fully comparable with those of De Broeck and Sløk (2001) and Burgess et al. (2003). Still, these results broadly confirm previous findings. According to 
Randveer and Rell (2002), the real exchange rate in Estonia was undervalued in 1993 but was fairly valued in 1999. Coudert and Couharde (2002) show that the real exchange rate of the Czech Republic and Slovakia were substantially undervalued in 2000. The real exchange rates of Estonia, Hungary and Slovenia, while also undervalued, were very close to the fitted values (regression line). Latvia, Lithuania and Poland appeared to have overvalued real exchange rates that were, however, also very close to the regression line. For 1996 and 1999, Čihák and Holub $(2001,2003)$ report similar results for the Czech Republic, Hungary, Poland, Slovakia and Slovenia.

Čihák and Holub $(2001,2003)$ show that the Czech relative price level is significantly lower than what the equation linking the relative price level and GDP per capita would imply. However, when the authors account for other factors, such as government activity and changes in the terms of trade, the relative price level of the Czech Republic turns out to be in line with its GDP per capita.

${ }^{24}$ First, it is a very rough proxy for dual labor productivity. Second, it can be a biased proxy for labor productivity if the labor market participation rates are very different in the home and the foreign economies. 
Table 6a. Studies Based on Cross-Section Regression

\begin{tabular}{|c|c|c|c|c|c|}
\hline & Countries & Coefficient & Year & Benchmark & $\mathbf{R 2}$ \\
\hline \multicolumn{6}{|l|}{ Out-of-sample } \\
\hline DeBroeck and Sløk (2001) & 149 & 0.41 & 1996 & US & 0.63 \\
\hline Maeso-Fernandez et al. (2003) & 24 (OECD) & 0.50 & 2002 & EU-15 & 0.65 \\
\hline Maeso-Fernandez et al. (2003) (1) & 25 (OECD) & 0.48 & 2002 & EU-15 & 0.36 \\
\hline Pelkmans et al. (2000) & 29 (OECD) & 0.89 & 1996 & Germany & 0.88 \\
\hline \multicolumn{6}{|l|}{ In-sample } \\
\hline Randveer and Rell (2002) & 52 & 0.69 & 1996 & Austria & 0.83 \\
\hline Coudert and Couharde (2002) & $120(2)$ & 0.25 & 2000 & EU-15 & 0.24 \\
\hline Čihák and Holub (2001) & 22 & 1.00 & 1999 & Germany & 0.91 \\
\hline Čihák and Holub (2003) & $21-33$ & $0.88-1.00$ & 1993, 1996, 1999 & Germany & $0.88-0.93$ \\
\hline Čihák and Holub (2003) & $103-106$ & $0.56-0.62$ & 1998 & Germany & $0.70-0.79$ \\
\hline Čihák and Holub (2003) & $22-30$ & $0.86-0.94$ & 1999, 2001 & EU-15 & $0.79-0.87$ \\
\hline \multicolumn{6}{|c|}{$\begin{array}{l}\text { Notes: The coefficient is the slope coefficient from the regression: } \\
\text { RelativePriceLevel = } a+b^{\star} \text { GDPperCAPITA; out-of-sample means that the sample excludes transition economies; conversely, in- } \\
\text { sample implies the inclusion of transition economies; R2 stands for the goodness-of-fit of the regression. } \\
\text { (1) GDP per workers in PPP terms is employed. The other studies apply GDP per capita in PPP terms. } \\
\text { (2) Only those countries are included whose GDP per capita is lower than that of the euro area }\end{array}$} \\
\hline
\end{tabular}

Table 6b Undervaluation and Overvaluation in Terms of Relative Productivity Levels

\begin{tabular}{|lrccc|}
\hline & Year & Undervalued & Fairly Valued & Overvalued \\
\hline DeBroeck and Sløk (2001) & 1993 & CZ, EE, LV, LT, SK & HU, PL, SI & \\
& 1999 & CZ, SK & HU, EE, LV, LT, PL, SI & \\
\hline Burgess et al. (2003) (1) & 1993 & EE, LV, LT & \\
& 2001 & & EE, LV, LT & \\
\hline Randveer and Rell (2002) & 1993 & EE & EE & \\
& $1996-1999$ & & LV, LT, PL \\
\hline Coudert and Couharde (2002) & 2000 & CZ, EE, HU, SI, SK & PL \\
\hline Čihák and Holub (2001, 2003) & 1996,1999 & CZ, HU, SI, SK & \\
\hline (1) They use estimates of DeBroeck and Sløk (2001) &
\end{tabular}

Cross-section data can be used not only to investigate levels but also to analyze inflation rates. Pelkmans et al. (2000) is an example for this. The authors proceed in two steps to derive an inflation rate that they link to the B-S effect. First, they run a regression between the relative price level and the GDP per capita for a set of 29 OECD countries for the year 1999. Second, the harmonized consumer price index of the euro area countries is regressed on the relative price level of the same set of countries. In addition, the core inflation rates are also regressed on the relative price level. The authors argue that the GDP per capita influences the relative price level, which in turn determines the rate of inflation. Observed GDP per capita figures of ten transition countries of Central and Eastern Europe are substituted into the first equation. The relative price level obtained this way is then used to derive the inflation rate implied by the second equation. The ten resulting inflation rates average $3.8 \%$ (equation based on 
the HICP) and $4.2 \%$ (equation based on core inflation). ${ }^{25}$ The average inflation rate thus derived for the transition economies is interpreted as the inflation rate that can be imputed to the B-S effect. The main problem with this approach is that it assumes that the catching-up economies used in the two estimated equations - Ireland, Portugal, Spain and Greece - had higher dual productivity growth rates than countries with higher GDP per capita, which in turn explains the higher inflation rates. However, with the exception of Ireland, the changes in dual productivity in those countries were in fact below the EU average during the 1990s (Lommatzsch and Tober, 2003). ${ }^{26}$ Therefore, higher inflation rates cannot be linked to larger increases in dual productivity levels for these countries, which strongly mitigates the paper's results.

Čihák and Holub (2001) attempt to link the relative price structure to the relative price level of a given economy. The relative price structure is calculated as a weighted relative standard deviation of the relative price level of individual goods in the home country vis-à-vis the benchmark economy Germany. ${ }^{27} \mathrm{~A}$ cross-section regression performed for 22 European OECD and selected transition economies and for 1996 shows that the higher the relative price level, the lower the relative price coefficient. On the basis of the cross-section regression, the authors then calculate what relative price level would be implied if the transition economies were to reach the relative price structure of the least developed EU Member States, namely Greece, Portugal and Spain. For the Czech Republic, these calculations reveal an increase of $20 \%$ to $35 \%$ in the relative price level.

${ }^{25}$ Country-specific results are not reported in the paper.

${ }^{26}$ Only Ireland experienced high growth in dual productivity in the late 1990s. Although the annual growth in average economy-wide labor productivity was over $3 \%$ in Greece, dual productivity was close to $1 \%$ per annum. More striking is the fact that average annual economic growth rates of above $3 \%$ in Spain and Portugal were not accompanied by corresponding changes in dual productivity $(1 \%$ in Spain and about $-2 \%$ in Portugal)

$27 R E L=\frac{\sqrt{\sum_{i=1}^{n} w_{i}\left(P_{i}-\bar{P}\right)^{2}}}{\bar{P}}$, where $\mathrm{n}$ is the number of individual prices, and $P_{i}$ and $\bar{P}$ stand for the relative price of individual items vis-à-vis Germany and the overall relative price level vis-à-vis Germany, respectively. 
Also, in separate cross-section regressions, prices of 31 commodity groups are regressed on GDP per capita for 1996 using data for the same set of countries. Then, the authors use the derived coefficients for each commodity group to see the extent to which relative price levels of these commodity groups and thus the overall relative price level vis-à-vis Germany would change if the GDP per capita were to increase from a level of $55 \%$ in 1999 to a level of $65 \%$ relative to that in Germany. The result is in line with the earlier finding of an increase of $20 \%$ to $35 \%$. Taking a horizon of ten years, the inflation rate implied by changes in relative prices would range from $1.7 \%$ to $2.7 \%$ a year in the Czech Republic.

Čihák and Holub (2003) update the estimates of Čihák and Holub (2001) using data for 1999 and complete it with estimates back to the 1980s (1980, 1985, 1990 and 1993). The results appear to be fairly robust. The authors establish several convergence scenarios for the Czech Republic based on which they argue that the relative price level would increase by $2.5 \%$ to $3.6 \%$ a year. This approach could be viewed as much broader than the usual B-S framework. First, it not only considers relative price adjustments of market-based nontradables but it also includes the whole gamut of prices, i.e. durable and semidurable goods, foods and regulated services. Second, these price adjustments are linked to productivity gains only in an indirect way.

\subsection{BEER and PEER Studies}

\subsubsection{Time Series Studies}

\subsubsection{Conventional BEER Studies}

In a country study of Slovakia, the IMF (1998) sets out to estimate the equilibrium real exchange rate for Slovakia. The ingredients of the empirical relationship are the real exchange rate (the CPI-based, PPI-based, unit labor cost-based real exchange rates as well as the internal real exchange rate are considered), the share of public consumption and investment in GDP, the openness ratio, $(\mathrm{X}+\mathrm{M}) / \mathrm{GDP}$, and real wages used as a proxy for productivity. In addition, M2 over GDP is also included to explain short-term fluctuations in the real exchange rate. The equations are estimated using OLS over the period from January 1990 to between February and June 1997 (with monthly data). According to step 2 of BEER, the short-term dynamic (M2) is set to zero and the actual 
values of the long-term fundamentals are substituted into the model. After determining the actual misalignment of the Slovak koruna, the paper comes to the conclusion that the currency was not overvalued during the period under study. This finding dissents from the general view that the large current account deficit was brought about by real overvaluation.

Avallone and Lahrèche-Révil (1999) analyze the equilibrium real exchange rate for the case of Hungary. A single equation including the CPI-based real exchange rate, public and private consumption in GDP, terms of trade and GDP per capita as a proxy for productivity growth is estimated with the help of the Johansen cointegration technique over the period covering the first quarter of 1985 to the second quarter of 1997 . The fitted values of the estimated equation are then compared with the actual real exchange rate (actual misalignment) that shows the absence of overvaluation over the whole period studied.

Beguna (2002) is one of the rare studies that analyzes the case of Latvia based on the Engle-Granger framework. The author regresses the CPI-based real effective exchange rate on the following variables: (1) the ratio of central government expenditures to GDP, (2) terms of trade, (3) total trade to GDP, and (4) net FDI. Long-term values for fundamentals are obtained as five-quarter moving averages, and 1997 is chosen as the base year, i.e. the actual and estimated equilibrium exchange rates are set to be equal in 1997. The total misalignment derived for the period spanning 1994 to 2001 reveals only very small deviations from equilibrium. For instance, an overvaluation of as little as 2\% appears from 1999 to end-2001.

Darvas (2001) investigates the exchange rate pass-through in the Czech Republic, Hungary, Poland and Slovenia. The exchange rate pass-through equation includes the adjustment of the real exchange rate toward its long-run value. Therefore, the author estimates a single equation of the real exchange rate vis-à-vis the Deutsche mark and based on core inflation series that exclude food, energy and administered items for the period running from the first quarter of 1993 to the first quarter of 2000. Two alternative measures of labor productivity are considered: (1) GDP per worker, and (2) the dual labor productivity differential. The other candidate fundamental variables considered in 
the paper are terms of trade, net foreign assets to GDP, FDI to GDP, the difference between net foreign assets to GDP and FDI to GDP, the share of government expenditures in GDP and the German real interest rate. The final specifications are different across countries. Although the dual labor productivity differential enters the long-run relationship in all countries, it is the dual labor productivity differential that is found significant in Hungary and Slovenia whereas GDP per worker appears to work better for the Czech Republic and Poland. In addition, the terms of trade and FDI are included in the equation for the Czech Republic, and net foreign assets for Hungary. For Poland and Slovenia, only the German real interest rate is included beside the productivity variable, which is also used for the Czech Republic and Hungary. It turns out that an increase in the foreign real interest rate leads to an appreciation of the real exchange rate in the Czech Republic and Slovenia and to a real depreciation in Hungary and Poland. The unit root tests carried out on the residuals of the equations conform that the variables are cointegrated for the Czech Republic, Poland and Slovenia. In the case of Hungary, there is much less evidence for the presence of a cointegating vector. The author does not calculate real misalignments.

Frait and Komárek (1999) draw on the NATREX model and estimate a reduced-form equation using the autoregressive distributed lag (ARDL) approach to identify a cointegrating vector for the Czech Republic. This long-term relationship contains the following variables: the CPI-based real exchange rate on the one hand, and an array of fundamentals, i.e. the terms of trade, real GDP growth approximating productivity, the world interest rate and the saving-to-GDP ratio. The equation is used to derive total misalignment. This is done by the substitution of the long-term value of fundamentals into the equation that indicates a slight overvaluation prior to the 1997 crisis, an undervaluation afterwards and a renewed overvaluation during 1998.

Filipozzi (2000) investigates the equilibrium real exchange rate of the Estonian kroon. It is possible to estimate a well-specified long-term relationship connecting the real effective exchange rate with the dual productivity differential, the share of investment in GDP, the trade balance over GDP and the nominal effective exchange rate. Filipozzi determines the extent of total misalignment by setting up several scenarios for the longrun values of the fundamentals for the period spanning the second quarter of 1993 to 
the second quarter of 1999. The results show that whereas the kroon was overvalued by $25 \%$ to $30 \%$ at the very outset, it appears only slightly overvalued by $5 \%$ at the end of the period.

Kemme and Teng (2000) set out to estimate the equilibrium exchange rate for Poland. An Engle-Granger-type cointegration relationship is tested for, using monthly data for the period from December 1990 to May 1999. Because monthly data were used, the following variables were introduced into the tested equation: (1) government expenditure over industrial production as a proxy for changes in the structure of aggregate demand, i.e. between private and public consumption, (2) capital inflows, (3) the current account, (4) the ratio of wages to producer prices to proxy the dual productivity differential and thus the B-S effect, and (5) the ratio of total trade to industrial production as a proxy for economic openness. Capital inflows are then dropped, as they prove to be insignificant. The difference between the estimated equilibrium real exchange rate deflated by the CPI, PPI, profits and wages, and the actual real exchange rate, i.e. the actual misalignment, indicates that the Polish currency was fairly valued or even slightly undervalued until the mid-1990s and then started to become overvalued in real terms. In mid-1999, misalignment was in a range of $2 \%$ to $10 \%$, depending on the real exchange rate used, i.e. CPI-based, PPI-based, profit-based or wage-deflated. The misalignment appears smallest when using the CPI and is highest for the profit-based real exchange rate.

Randveer and Rell (2002) also cover Estonia. The data used span a somewhat different period than in Filipozzi (2000), i.e. the first quarter of 1994 to the fourth quarter of 2000. From a long list of possible long-term fundamentals, the dual labor productivity differential and the terms of trade seem to explain the real effective exchange rate of the kroon. The paper follows the five-step BEER analysis and computes total misalignment. The HP filter is implemented to uncover the long-term trend of fundamentals. The total misalignment obtained in this way is adjusted with the use of a base year where the real effective exchange rate is supposed to be at equilibrium. For this purpose, the relationship between the price level and the income level is estimated for a panel composed of 52 OECD and transition countries taken together. It is assumed that the estimated coefficient of the income level (the price level is regressed on the income 
level) is the long-term value for all countries, as already explained. Then, the income level from 1994 to 2000 is substituted into the equation. The fitted value of the price level is subsequently compared with the actual price level. It turns out that the only year when the fitted value equals the actual value is 1996 . Given this, total misalignment is "shifted" upwards so that misalignment is zero for 1996. The adjusted misalignment indicates an overvaluation of the kroon of roughly 30\% in early 1994 and an overvaluation of approximately $4 \%$ to $5 \%$ in 2000 . In 1999, there seems to be an undervaluation of $0 \%$ to $3 \%$, which contrasts slightly with Filipozzi (2000). Finally, causality is tested for between the estimated misalignment on the one hand and exports, imports and investment on the other, which leads to the conclusion that misalignment might predict exports and investment.

Hinnosar et al. (2003) aim at assessing the BEER approaches for the case of Estonia using quarterly time series from 1995 to end-2002. The authors regress the real effective exchange rate on the dual labor productivity differential, net foreign assets and terms of trade. Two measures for labor productivity are used. The first considers agriculture and manufacturing as the open sector and the remaining sectors as the sheltered one, whereas the second also classifies hotels, restaurants, transport, storage and communication as belonging to the open sector. Altogether, twelve different specifications are tested using the Johansen cointegration technique, five of which are found to be properly specified in econometric terms. The first two include the real exchange rate and the two productivity measures; the third comprises a dummy variable to capture outliers when using the first productivity measures. These specifications are indeed in line with the B-S model. By contrast, the two last specifications include, in addition to the alternative productivity measures, terms of trade and net foreign assets over GDP. Subsequently, applying HP-filtered series to the equations yields five misalignment series that reveal the following: From 1995 to 1998, the Estonian kroon was either undervalued or fairly valued, but in 1999, after the Russian crisis, it became clearly overvalued by about $4 \%$. Then, the currency returned to equilibrium and appeared to be fairly valued in the fourth quarter of 2002 .

Based on the Engle-Granger cointegration technique, Bitans (2002) investigates the case of Latvia for 1994 to 2001. The author finds it difficult to detect a long-term 
relationship using the real effective exchange rate and the real exchange rate against the Baltic states and other transition economies. By contrast, the real exchange rate visà-vis Latvia's Western trading partners turn out to be connected to the dual productivity differential, openness and government expenditures over GDP. An increase in the dual productivity differential leads to a real appreciation whereas a rise in openness and government expenditure brings about real depreciation. The total misalignment measure does not actually reveal any major deviation from the equilibrium exchange rate in 2001. Bitans and Tillers (2003) update these results. They use the Johansen cointegration technique and show that the real exchange rate vis-à-vis Latvia's Western trading partners (Germany, U.K., Denmark, Finland, Sweden and the Netherlands) is connected to net foreign assets, GDP per capita, terms of trade and the real interest differential. Similarly to Bitans (2002), no real misalignment is found from 2001 onwards. Kazaks (2000) also analyzes Latvia using an error correction model. The real effective exchange rate calculated on the basis of the CPI is found to be linked to labor productivity in industry in Latvia, the openness ratio, the unemployment rate and money velocity. The estimation is based on monthly data running from March 1993 to June 1998. Actual misalignment calculations show no misalignment in 1998.

Similarly, Vetlov (2002) examines the case of Lithuania. Using the Engle-Granger technique over the period 1994 to 2001 , in addition to the dual productivity differential and openness, oil prices are also connected to the PPI-based real effective exchange rate. A rise in the dual productivity differential and oil prices cause the real exchange rate to appreciate whilst an increase in openness works in the opposite direction. The author then applies the HP-filtered values of the fundamentals to derive total misalignment, which reveals an undervaluation of about $7 \%$ at end-2001. Alternatively, eight different scenarios are considered to assess long-term values of the fundamentals, seven of which show an undervaluation ranging from $0 \%$ to $15 \%$. By contrast, if the openness ratio is assumed to be $120 \%$, an overvaluation of about $20 \%$ is found in the second quarter of 2001.

Rawdanowicz (2003) makes use of quarterly data covering the first quarter of 1995 to the second quarter of 2002 to assess the Polish zloty's equilibrium exchange rate. The 
variables included in the long-term relationship to the real effective exchange rate are the dual productivity differential against the EU-12 (based on industrial production), the terms of trade for Poland and the real interest rate differential. The fitted values of the long-term relationship and the actual real effective exchange rate are graphically presented for 1997 to 2000, showing the actual misalignment. The zloty seems undervalued in 1997 and overvalued by $1 \%$ to $10 \%$ in 1998 and 2001, and fairly valued in 2002. We note that the paper reports no details on the tests.

\subsubsection{BEER Studies Based on Differing Theoretical Backgrounds}

The studies below adopt different approaches than the conventional BEER for their theoretical backdrop. However, given the similarity in the estimation technique with BEER, they are presented here.

Continuing along the lines of Alberola et al. (1999), Alberola (2003) seeks to connect the real effective exchange rate to the labor productivity in manufacturing relative to that in the foreign country and to net foreign assets, which are represented by cumulated current account balances. The Johansen cointegration technique is used to detect possible long-term relationships for the Czech Republic, Hungary and Poland over the first quarter of 1993 to the fourth quarter of 2002. Whereas an increase in the dual productivity differential yields an appreciation of the real effective exchange rate in all cases, an increasingly negative net foreign asset position leads to depreciation in Hungary and Poland while it results in an appreciation in the Czech Republic, which is contrary to what theory would suggest. The equilibrium real exchange rate is derived by applying the Gonzalo-Granger decomposition to the cointegration vectors. Results suggest an overvaluation of roughly $10 \%$ in 2001 followed by a sizeable undervaluation of $10 \%$ in 2002 for Poland. An increasing overvaluation is detected at the end of the period in the Czech Republic (10\%) and Poland (12\%).

Rahn (2003) follows the approach introduced in Alberola et al. (1999) and used in Alberola (2003) in that the real exchange rate is regressed on the difference in relative prices taken as a proxy for the dual labor productivity differential and net foreign assets proxied with cumulated current account balances for eight CEE acceding and two accession countries, namely the Czech Republic, Estonia, Hungary, Latvia, Lithuania, 
Poland, Slovakia and Slovenia, and Bulgaria and Romania. The Johansen cointegration test is applied to determine whether the real effective exchange rate is linked to the relative price and the cumulated current account variables throughout the period from the first quarter of 1990 or 1993 to the first quarter of 2002. Cointegration is found only for the Czech Republic, Estonia, Hungary, Poland and Slovenia, implying that misalignment cannot be assessed for the remainder of the countries. In all cases, increasing net foreign assets are found to lead to real appreciation. The PEER approach is employed to obtain total misalignment in effective terms. The equilibrium real exchange rate and thus the misalignment vis-à-vis the euro is derived from the equilibrium real effective exchange rate by means of an algebraic transformation also used in Alberola et al. (1999). It turns out that the currencies of the Czech Republic, Estonia and Poland were overvalued by $10 \%$ to $15 \%$ against the euro, and somewhat less in effective terms in the first quarter of 2002. The Hungarian forint seems to be close to fairly valued in effective terms, but is $3 \%$ to $9 \%$ overvalued vis-à-vis the euro, whereas the Slovene tolar is found to be slightly undervalued, both against the effective benchmark and the euro.

Alonso-Gamo et al. (2002) seek to determine the total misalignment of the Lithuanian litas. Based on quarterly data stretching from the first quarter of 1994 to the third quarter of 2001, a cointegration relationship is estimated including the real effective exchange rate, the CPI-to-PPI ratio as a proxy for the relative price of nontradable goods relative to that of the trading partners, and net foreign assets over GDP. The estimated longterm relationship is subsequently decomposed into permanent and transitory components, with the permanent component being the equilibrium real exchange rate. The estimated equilibrium real exchange rate turns out to appreciate broadly hand in hand with the actual real exchange rate. The total misalignment determined based on the HP filter indicates an overvaluation of roughly $10 \%$ in 1994 and from 1999 to 2000 and an undervaluation of the order of 10\% from 1995 to 1998 and of 5\% in 2001.

Burgess et al. (2003) examine the case of the three Baltic states using the same framework as Alberola et al. (1999). For the period 1994 to 2002, a cointegration relationship is sought between the real effective exchange rate, on the one hand, and the CPI-to-PPI ratio and net foreign assets, on the other hand. Contrary to Rahn (2003), 
Burgess et al. could establish cointegration for all countries based on the Johansen cointegration framework. Also, increasing foreign liabilities lead to a real appreciation of the currencies. Furthermore, the result that an increase in foreign liabilities leads to an appreciation of the real exchange rate is in contradiction not only with Rahn (2003) but also with Hinnosar et al. (2003) and partly with Alberola (2003). Total misalignment indicates an undervaluation of about 3\% in Estonia and an undervaluation of the Latvian and Lithuanian currencies of $6 \%$ in the first quarter of 2002. Note, however, that the confidence intervals around the estimate for Latvia make it difficult to conclude whether or not there is an over- or undervaluation. Burgess et al. (2003) determine a B-S effect close to zero for the three Baltic countries (Section 5.1.1), and then estimates a BEER model on the basis of the CPI-to-PPI ratio as a proxy for the dual productivity differential. The BEER estimates could not detect any major real misalignment. This is an interesting outcome because it would imply that the substantial real appreciation of the currencies is captured by net foreign assets.

Égert and Lahrèche-Révil (2003) aim at estimating the equilibrium real and nominal exchange rates for five selected Central and Eastern European transition economies, notably for the Czech Republic, Hungary, Poland, Slovakia and Slovenia. For this purpose, the FEER and BEER are combined. Three equations are estimated, the first for the internal balance (defined as the relative price of nontradable goods) and the second for the external balance (defined as the long-run sustainability of the current account). The third equation links the real effective exchange rate to the internal and external balances. Long-term equilibrium values for relative prices are determined using the dual productivity differential and private consumption, whereas the current account is regressed on terms of trade and the openness ratio. Long-run values for external and internal balances are subsequently substituted into the third equation. Comparing the fitted values of the third equation and the observable real effective exchange rates leads us to the observation that whilst the Hungarian and Slovenian currencies were not overvalued during the period from the first quarter of 1992 to the second quarter of 2001, the Czech, Polish and Slovak currencies turn out to be overvalued by approximately $15 \%, 15 \%$ and $8 \%$ at the end of the period under study. However, the 
base year problem arises: the rule for the choice of the base year is that the current account should have been in balance for that particular year, i.e. covered by FDI.

Lommatzsch and Tober (2002a) build on the observation that the real exchange rate based on the PPI appreciated almost as much as the CPI-deflated real exchange rate in the majority of acceding countries, especially in the Czech Republic, Hungary and Poland. They argue that this real appreciation might be an equilibrium phenomenon. The reason for this is the huge increase in export revenues brought about by changes in the composition of GDP, i.e. the shift in production towards goods of higher quality and improved technology. To test their conjecture, the authors first estimate export and import equations. The export equation includes labor productivity in industry, foreign output and export prices, while the import equation consists of final domestic demand, the fiscal position and oil prices. Next, a single equation is estimated for the PPI-based real exchange rate vis-à-vis Germany, which contains variables from the trade equations, net foreign assets and the real interest differential. The actual misalignment is subsequently determined the standard way. In every case, the first year is chosen as the base year. It appears that the Hungarian forint was fairly valued during the sample period from the fourth quarter of 1995 to the fourth quarter of 2001, except for a short undervaluation period during the Russian crisis. By contrast, the real exchange rate in Poland turns out to be overvalued for most of the time, with the overvaluation reaching $10 \%$ at the end of the period. The Czech Republic seems to be a special case in that two different specifications give very different results. The first specification indicates the absence of an overvaluation, whereas the second specification suggests a huge overvaluation of the Czech koruna.

The theoretical underpinning in Rubaszek (2003a) is close to that of the FEER. The approach, which is labeled the Balance of Payment Equilibrium Exchange Rate (BPEER), rests on the balance of payment identity. The following fundamentals with an impact on the PPI-deflated real effective exchange rate are identified: domestic and foreign demand, proxied by domestic and foreign output, net foreign assets and the real interest rate differential towards the U.S.A. Nonetheless, the empirical assessment of the equilibrium real exchange rate has a lot in common with BEER. First, a cointegration relationship is estimated for the aforementioned fundamentals and the real effective 
exchange rate is determined based on the Johansen technique and using the fully modified ordinary least squares (FMOLS) estimator, which relies on the single-equation approach. The fitted values of the equation are rather similar to the actual real exchange rate. Second, long-term values of fundamentals obtained using the HP filter are employed in the estimated equation to derive the total misalignment. From 2001 until early 2002 , the zloty appears to be strongly overvalued by up to $16 \%$. However, by the end of 2002, the real exchange rate had converged to equilibrium and real misalignment dropped below $4 \%$.

\subsubsection{Panel Studies}

\subsubsection{Conventional Panel Studies}

In perhaps one of the most cited papers on equilibrium real exchange rates in transition economies, Halpern and Wyplosz (1997) speculate that in the early years of transition, real exchange rates were well beneath their equilibrium value. Therefore, the real exchange rate is expected to appreciate (to correct this "undershooting") until the equilibrium level is reached. Moreover, even if real exchange rates are close to their equilibrium value, there is still room for appreciation, since the equilibrium rate itself is expected to appreciate, mainly due to higher inflation rates. Yet, higher overall inflation can be explained by the B-S effect, the improvement in the quality of tradable goods and relative wage adjustments. To prove both conjectures, the authors first estimate a real dollar wage equation, i.e. relative wage adjustment including GDP per capita as a proxy for productivity, school enrollment, the share of agriculture in GDP and government consumption. This estimate is based on pooled time series for 80 countries at approximately the same level of development. Five observations are included for each country (1970, 1975, 1980, 1985 and 1990). Results suggest that GDP per capita, school enrollment and government consumption are positively related to dollar wages, while the agriculture-to-industry ratio and inflation have negative signs. They then determine the equilibrium dollar wage by substituting the corresponding time series (1990-96) for transition countries into the estimated equation and compare it with actual dollar wages. The results are based on the implicit assumption that the wage and price levels are closely linked with each other. However, if this is not the case, the dollar 
wage equation cannot be used as a proxy for the real exchange rate.$^{28}$ Results support the undershooting theory for all countries except Hungary and Slovenia. It is shown that by 1996 , the real exchange rate had moved near its equilibrium level in Croatia, the Czech Republic, Poland, Slovenia and Hungary.

Begg et al. (1999) update the database used in Halpern and Wyplosz (1997): the number of countries is extended to 85 and the period is augmented with the observation for 1995. Additional variables such as the dependency ratio, the openness ratio, net foreign assets of the banking sector and of the economy, credit to the private sector and a number of regional dummies for OECD countries; former Soviet Bloc countries and CIS countries are added. They estimate the equilibrium dollar wage for 12 transition countries for the period from 1990 to 1997: in some countries, the equilibrium dollar wage does not seem to appreciate any more in 1996 and 1997. On the one hand, the currencies of the Baltic states and the Czech and Slovak Republics were substantially undervalued in real terms in the early 1990s but converged rapidly to their equilibrium value. On the other hand, the currencies of Hungary, Poland and Slovenia are fairly close to overvaluation from 1996 onward.

Krajnyák and Zettelmeyer (1998) follow in the footsteps of Halpern and Wyplosz (1997) in that they also estimate the equilibrium dollar wage using a large panel including 85 countries, of which 15 are transition economies. The database contains six annual observations for each country between 1990 and 1995. Likewise, the variables which are expected to capture real exchange rate movements are GDP per capita, school enrollment and the share of agriculture in GDP. In addition, a score of other variables is used to describe institutional settings, such as an indicator for government interventions, the fiscal regime, property rights and economic freedom. The results show that in the early 1990s, the equilibrium dollar wage appreciated in Bulgaria, the Czech Republic, Estonia, Hungary, Poland, Romania and Slovakia. At the same time, the observed dollar wage, which was undervalued at the beginning, converged to its equilibrium value.

${ }^{28}$ This is also valid for Begg et al. (1999) and Krajnyák and Zettelmeyer (1998). 
De Broeck and Sløk's (2001) paper covers two groups of transition countries. The one we are interested in is that of EU acceding and accession countries, i.e. the three Baltic states, Bulgaria, the Czech Republic, Hungary, Poland, Romania, Slovakia and Slovenia. Data are gathered on a yearly basis over the period 1991 to 1998 . Using the pooled mean group estimator (PMGE), the CPI-based real effective exchange rate is regressed on the dual productivity differential vis-à-vis the export-weighted average dual productivity of 18 OECD countries. The productivity variable turns out to be significant. In addition, other variables are introduced to control for short- and long-term fluctuations caused by other fundamental factors. The openness and government balance variables are also found to impact on the real exchange rate. The more open the country is, the stronger the push towards depreciation is, and the higher the government deficit is, the larger the depreciation in real terms is. The terms of trade and fuel and nonfuel prices become insignificant in their estimates. The authors substitute the growth of the dual productivity differential in 1999 to the estimated equations and point out that, on average, the dual productivity differential contributed 1 percentage point to the inflation differential in this particular year.

Coricelli and Jazbec (2001) develop a two-stage model for real exchange rate determination that describes the pre- and posttransition periods. Subsequently, with the help of an unbalanced panel (1990/1995 to 1998) composed of 19 transition economies, the authors establish a relationship between the internal real exchange rate (the relative price of tradables in terms of nontradables - the reciprocal of the internal real exchange rate presented in section 2), on the one hand and dual productivity, the share of nontradable consumption in total private consumption, real government consumption over GDP (demand-side variables), employment in industry to employment in services, the EBRD's reform variable and a series of dummies standing for structural changes on the other hand. The variables are found to explain movements in the relative price of tradable goods. Nonetheless, the extent of their influence varies across countries. In the acceding countries, dual productivity accounts for nearly $50 \%$ of the relative price of tradable goods whereas the rest can be ascribed to the remaining demand-side and structural variables. 
Dobrinsky (2003) is one of the rare papers that uses TFP based on capital stock estimates obtained with the aid of the permanent inventory method to explain changes in the real exchange rate. However, as capital stock is only estimated for the economy as a whole, no sectoral TFP is available. The author runs a panel regression between the CPI-deflated real effective exchange rate on the one hand, and the difference in productivities across the home and foreign country, augmenting the equation with some demand variable (GDP per capita measured in terms of PPP), M1 to GDP and dummy variables accounting for different exchange rate regimes on the other hand. Results obtained for 1993-99 indicate that TFP and the demand-side variable contribute importantly to explaining the appreciation of the real exchange rate of the 11 transition countries included in the panel.

In Kim and Korhonen (2002), the econometric estimation of the single equation, which is composed of the real exchange rate based on the CPI on the one hand and GDP per capita approximating productivity, the share of investment and public consumption in GDP and finally the openness ratio, $(\mathrm{X}+\mathrm{M}) / \mathrm{GDP}$, on the other hand, is performed for two groups of nonacceding economies. The first group consists of 29 countries and is used to estimate a real exchange rate equation against the U.S. dollar for the period from 1975 to 1999. The second group contains 19 economies whose real effective exchange rate is taken into consideration for the period from 1980 to 1999. In both cases, one part of the panel is composed of industrialized economies whereas the second part rests on emerging countries. This choice is explained by the fact that acceding countries exhibit similar features compared with both types of economies (they have a trade pattern similar to that of developed countries and GDP per capita figures roughly as high as those in emerging countries). It should be mentioned that this is one of the rare papers in which the homogeneity condition among panel members is put to the test, and it turns out to hold. This is crucial, since heterogeneity within the panel would invalidate the estimation results. The macroeconomic series of the Czech Republic, Hungary, Poland, Slovakia and Slovenia are then applied to the estimated equations. The graphic illustration shows that each country's actual real exchange rate is close to the estimated equilibrium real exchange rate against the U.S. dollar (within a range of $\pm 5 \%$ ) in 1999 . The exception is Slovenia, where the currency appears to be overvalued by 
approximately $20 \%$ in 1999 . The charts tell a different story about the effective real exchange rate. In 1999, the Polish and Slovak currencies are neither overvalued nor undervalued, whereas the Czech koruna is found to be undervalued by $10 \%$ and the Hungarian forint is overvalued by $40 \%$. There are no results for Slovenia. The huge Hungarian overvaluation casts some doubt on the robustness of the results. This finding is all the more implausible in that the extent of the overvaluation, which was already $10 \%$ in 1994, widened from then on despite important macroeconomic adjustments in the mid-1990s.

Instead of the basic two-sector (nontradables/tradables) two-input (capital/labor) B-S model, Fischer (2002) uses a three-sector (nontradables/exports/imports) and four-input (capital/labor/two-skills) model. In this model, not only productivity but also investment demand can have an impact on nontradable prices. In a panel framework for eight to ten transition economies, the author then estimates the impact of productivity in industry, agriculture and services, total and public consumption and terms of trade, and the influence of the real interest differential on the CPI-based real exchange rate. In alternative specifications, these variables appear to explain changes in the real exchange rate well. The author shows that $50 \%$ of the changes in the real exchange rate can be ascribed to productivity (half of which can be attributed to productivity in industry, and the other half to productivity in agriculture), $25 \%$ to consumption and $25 \%$ to the real interest differential. Fischer (2002) stresses that the indicated impact of productivity on real appreciation may be overestimated, given that investment demand also exerts an influence on nontradable prices. However, it should also be borne in mind that only part of the real appreciation comes through nontradable price channels, which mitigates the aforesaid results.

As opposed to the aforementioned panel studies, MacDonald and Wójcik (2002) set out to estimate the B-S effect extended with demand-side variables for a small panel composed of four acceding countries (the Czech Republic, Hungary, Slovakia and Slovenia). The authors report that the dual productivity differential and the difference in productivity of the domestic and foreign open sector significantly cause both the internal real exchange rate (relative price of nontradable goods in the home country) and the effective real exchange rate to appreciate. The magnitude of coefficients turns out to be 
different from that in other studies. There are two grounds for this. First, the productivity variable is calculated differently, with Austria being used as the foreign benchmark country. Second, the effective real exchange rate is regressed not on an effective productivity variable but rather on the dual productivity differential vis-à-vis Austria. The estimations also lend weak empirical support to what one might call the demand-side effect, i.e. the impact of total and private consumption on the real exchange rate. The authors document that productivity changes in the distribution sector and regulated prices also exert an influence on the real exchange rate. They argue that regulated prices may have weakened the effect of productivity on the real exchange rate.

Crespo-Cuaresma et al. (2003) investigate the monetary model for the case of five acceding countries (the Czech Republic, Hungary, Poland, Slovakia and Slovenia) and one accession country (Romania) from 1994 to 2002. Using monthly data, the nominal exchange rate vis-à-vis the euro is regressed on the following variables: industrial production as a proxy for real output, the monetary aggregate $M 2$, the nominal deposit interest rate and the relative price of nontradables proxied by the CPI/PPI ratio, which is meant to capture the B-S effect. It should be noted that in the monetary model augmented with the B-S effect, an increase in the relative price differential makes the nominal exchange rate appreciate. In the paper, all the variables are compared with the euro area based on the so-called synthetic euro. The econometric estimations rely on an extensive set of panel methods, such as panel FMOLS, DOLS (dynamic ordinary least squares) and PMGE (the pooled mean group estimator), and show that the explanatory variables are correctly signed. Next, the fitted values of the model are construed as the equilibrium exchange rate and are compared with the actual exchange rate. It appears that the Czech currency is overvalued from 2001 onwards and that overvaluation reached $16 \%$ in the last quarter of 2002 . Similarly, the Polish zloty is found to be overvalued by $3 \%$ at end-2002, and the Slovene tolar is overvalued by $20.8 \%$. By contrast, the Hungarian forint and the Slovak koruna turn out to be undervalued by $5.6 \%$ and $1.3 \%$ at the end of the period. Although using the monetary model allows the authors to directly derive nominal exchange rates, it is primarily a model for exchange rate determination and is thus difficult to relate to equilibrium 
exchange rates such as those discussed in previous sections of this article.$^{29}$ Also, the monetary model requires de facto floating exchange rates, which may not have been the case in four countries of the sample, namely Hungary, Poland, Slovakia and Slovenia, during a sizeable part of the period under study. Finally, introducing the B-S effect is based on the assumption that PPP holds for tradable goods, which apparently is not the case in at least four countries of the sample as shown in chart 5.

\subsubsection{Studies Incorporating Foreign Debt or Multiple Models}

Coudert (1999) seeks to estimate the equation containing the U.S. dollar-based, CPIdeflated real exchange rate on the one hand and the dual productivity differential and the foreign indebtedness ratio on the other. The relative price of nontradables and GDP per capita are used as a proxy for productivity. The panel is based on annual data for the period between 1977 and 1997 for a set of 16 emerging market economies in Asia, Latin America and Europe, including Hungary as the only acceding country. The results lend strong support to the fact that the stock of debt compared to GDP has a significant impact on real exchange rate movements in those countries. Furthermore, the results for Hungary also suggest the absence of sustained under- or overvaluation periods during the whole period in general and during the period covering the 1990s in particular.

Covering 12 CEECs and the period 1990-98, Maurin (2001) considers the real exchange rate deflated by the $\mathrm{CPI}$, on the one hand, and dual productivity, public consumption, real domestic interest rate and external debt, on the other hand. Assuming that progress in nontradable productivity equals zero, dual productivity is given by productivity advances in the open sector. Proxies for productivity are per capita GDP and the relative price of nontradables, that is, consumer prices compared to producer prices. Public consumption and external debt are expressed in terms of GDP. The key finding of the paper is that public consumption and external debt are correctly signed with positive and negative signs, respectively. The productivity coefficients are almost never significant whatever the proxy may be. We note that Maurin (2001) does not assess the equilibrium real exchange rate.

${ }^{29}$ This is why this paper is not included in Table 11. 
Csajbók (2003) summarizes the results of the research project conducted at the Hungarian central bank aimed at estimating the equilibrium real exchange rate for Hungary based on four different theoretical approaches. The equilibrium real exchange rate is assessed using the NATREX, BEER, FEER and Macroeconomic Balance (MB) approaches. Remarkably, the NATREX model is not only estimated in its reduced form but also structurally as in Detken et al. (2002). The results of the different approaches suggest a possible overvaluation at end-2002.

Égert and Lommatzsch (2003) have two goals in mind. First, they provide some theoretical underpinning for the PPI-based real exchange rate and go for testing it by regressing not only the $\mathrm{CPI}$-deflated but also the $\mathrm{PPI}$-deflated real exchange rate on a set of variables, also including the foreign-debt-to-GDP ratio. The results are fairly similar for the CPI- and PPI-based real exchange rates, lending support to the formulated hypothesis. Second, they seek to assess in a systematic manner the sensitivity of the usual BEER estimates to different time series and panel cointegration techniques. It appears that the results are sensitive to the different estimation methods, the estimated equations and the size of the panel. Hence, a range is obtained for the equilibrium real exchange rate and the real misalignment, which may be rather large. What appears from the high number of estimated misalignments is that the Czech, Polish and Slovak currencies are likely to have been overvalued in the last quarter of 2002 whereas the Slovene tolar was slightly undervalued in that period. In the case of Hungary, results based on time series and panel estimates appear a little conflicting but overall they indicate an ovevaluation in the fourth quarter of 2002. 
Table 7. Studies Using the BEER Approach

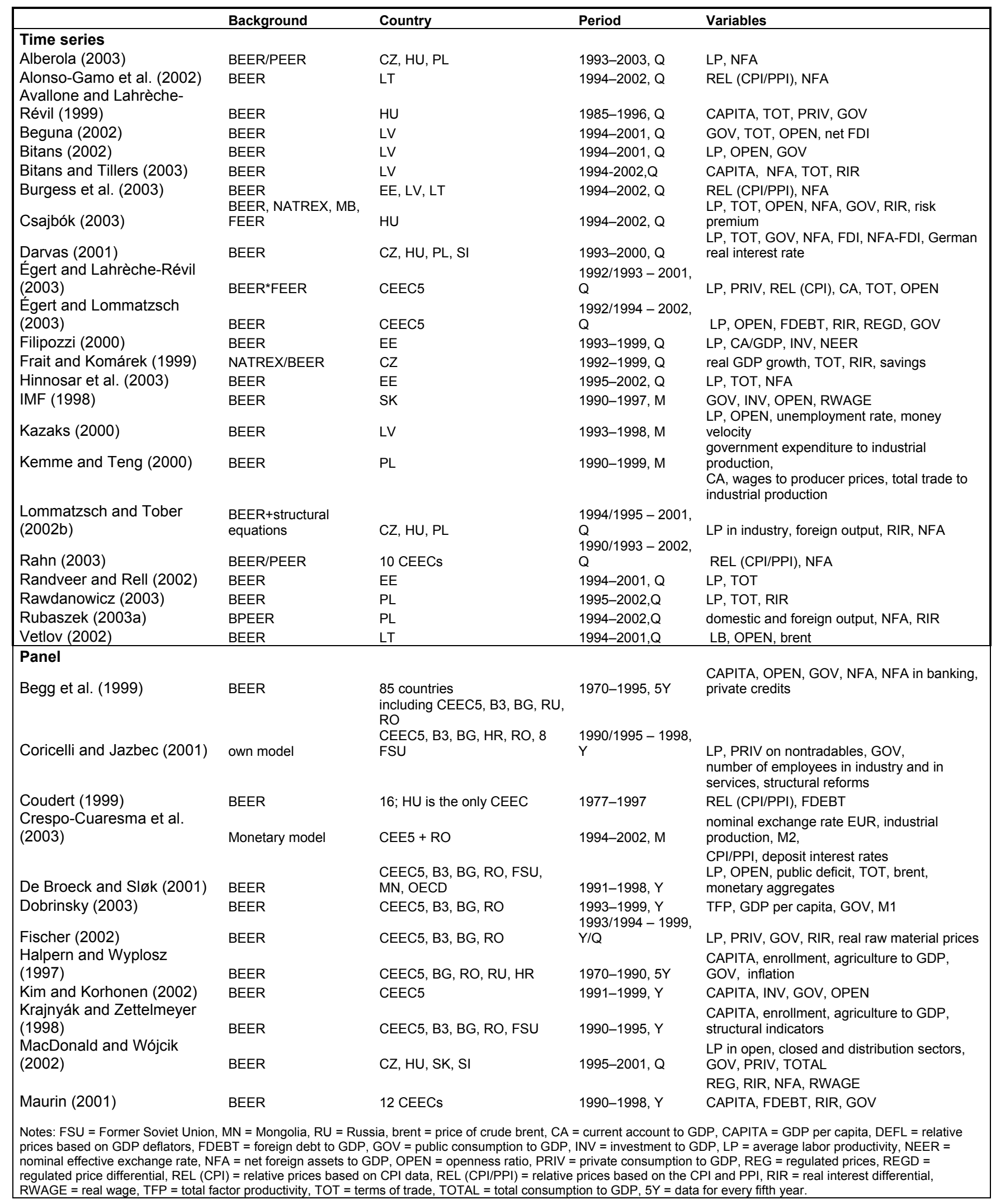




\subsection{Structural Models and the FEER}

Šmídková (1998) uses the Czech module of the NIGEM model of the London-based National Institute for Economic and Social Research (NIESR) estimated upon quarterly data over the period of 1992 to 1996. Based on the FEER approach presented earlier in this paper, the author establishes two scenarios and determines two bands of overvaluation. These results suggest that the Czech koruna is overvalued compared to its estimated level by a band of between $0.4 \%$ to $6.8 \%$ and $-1.4 \%$ to $5.4 \%$ in 1996 .

Also using the NIGEM model, Šmídková et al. (2002) take a look at four other acceding countries besides the Czech economy, namely Estonia, Hungary, Poland and Slovenia. The trade equation of the NIGEM model is estimated for 1994 to 1999 on quarterly data and explicitly accounts for the trade liberalization that occurred in the five CEECs, the external indebtedness and the impact of FDI. It is argued that the initial level of external indebtedness has an influence on the equilibrium exchange rate, i.e. there is more room for equilibrium appreciation if the level of external debt is less important. By setting a target value of $60 \%$ over GDP to be reached by 2022 , and implementing a sensitivity analysis, two estimated equilibrium real exchange rate corridors based on different assumptions are obtained for each single country. It turns out that the real effective exchange rate of the Czech koruna, well in the middle of the corridor in 1996, approached the stronger side of the corridor in late 1998 and remained very close to it until 2001, when it broke out. In 2002 it was clearly overvalued by some $8 \%$ to $9 \%$. Likewise, in Hungary, the real exchange rate was within the corridors until 2001 when it exited on the stronger edge and appeared overvalued by about $6 \%$ in mid-2002. The Polish currency exited the band in 2000 , indicating misalignment, but remained only slightly overvalued until end-2001 and became misaligned by approximately $10 \%$ to $12 \%$ in 2002. Similarly, the Estonian kroon appears to have become overvalued from 1999 onwards; the maximum overvaluation occurred in 2002 with an estimated $13 \%$ to $14 \%$. By contrast, no misalignment is found for the case of Slovenia, given that the tolar remained within the corridors. Note also that the Slovenian currency is situated closer to the weaker side of the corridor, indicating that the danger of an overvaluation is clearly more limited than that of an undervaluation. 
Coudert and Couharde (2002) provide estimates on whether the currencies of five acceding economies, namely the Czech Republic, Estonia, Hungary, Poland and Slovenia, are under- or overvalued in 2000 and 2001 in effective terms and against the euro. Derived as indicated in the description of the FEER in Section 3, the estimates are based on the NIGEM model, considering the possible impact of acceding countries on the outside world. Also, sensitivity analysis is carried out to check the robustness of the results. Of the misalignments, only the Polish misalignment stands out, as it exhibits overvaluations of $7 \%$ in 2000 and $3 \%$ in 2001 . The other economies seem to have fairly valued currencies. It is worth noting that for the long-term current account target, estimates of Doisy and Hervé (2003) are used, which in turn are based on the Macroeconomic Balance approach.

Rubaszek (2003b) seeks to determine the FEER for the zloty/euro rate. In doing so, he uses a small model for Polish trade to derive trade elasticities. The target value for the current account deficit used in the paper is $3.6 \%$ of GDP, which is obtained by setting the foreign debt-to-GDP ratio to $39 \%$. Under the baseline scenario that includes a USD/EUR value of 1.13 , the author comes to the conclusion that the Polish zloty was overvalued by approximately $9 \%$ in the last quarter of 2002 and that it appears fairly valued in mid-2003.

Csajbók and Kovács (2002) examine possible misalignments for Hungary using the Hungarian module of NIGEM. The module is disconnected from the rest of the international model, as it seems a plausible assumption that given its small size, developments in the Hungarian economy will hardly affect foreign economies. Without providing precise figures, the authors point out that the FEER indicates the presence of overvaluation. In addition to this analysis, one big merit of the paper is that it illustrates possible changes in the FEER and the real exchange rate prior to and after euro adoption. In this context, they argue that prior to euro adoption, the FEER is likely to appreciate owing to the B-S effect and a one-off reduction of the risk premium. In contrast, because of the expected fiscal consolidation, the observed real exchange rate is expected to depreciate. In the post-euro adoption period, the risk premium and the trade channel are strong candidates to affect both the FEER and the real exchange rate. The risk premium channel is composed of a reduction in the risk premium and an 
increase of actual compared with potential output. The risk premium channel would appreciate the FEER. Unchanged in the short term, the FEER would appreciate in the longer run on the grounds of higher trade and growth brought about by EMU (trade channel).

Hinnosar et al. (2003) attempt to apply the FEER approach to Estonia. They find that the FEER model cannot be reasonably assessed mainly because of the lack of a longrun relationship between foreign trade and the real effective exchange rate. However, the paper fails to compare these outcomes with what is found in other papers based on the NIGEM model. Estonia is also included in the NIGEM model, and thus import and export elasticities are available. It might be of use to explain how these estimates in the NIGEM are derived.

\section{What Have We Learned from the Literature?}

\subsection{Trend Appreciation of the Real Exchange Rate}

The real exchange rate of the acceding countries has experienced strong appreciation from the outset of the transition process, although the extent of the appreciation has been very different across individual countries. It is a widely held view that this appreciation is largely due to the B-S effect and thus has not resulted in an overvaluation of the currencies. A first strand of papers (e.g. Sinn and Reutter, 2000; Rother, 2002; Golinelli and Orsi, 2002; Jazbec, 2002) supports this view. However, another string of papers, as shown in table $5 \mathrm{c}$, has recently shown that, at best, half of this appreciation can be ascribed to the B-S effect (see Kovács, 2001, 2002; Flek et al., 2002; Égert, 2002a, b; Égert et al., 2003, and Mihaljek and Klau, 2003) ${ }^{30}$. The main reason for this finding is that PPP does not hold for the open sector, since the PPIbased real exchange rate (used as a proxy for the real exchange rate in the open

${ }^{30}$ Curiously enough, even the first strand of papers finds a very low inflation differential for the Czech Republic that could be attributed to the B-S effect. This is because increases in overall and dual productivity in the Czech Republic were among the lowest in the transition countries. However, another explanation for this outcome may lie in statistical problems: The Czech Statistical Office may have considerably underestimated output in the Czech Republic (Filer and Hanousek, 2000). This is all the more possible as the Czech Republic was the biggest net FDI receiver among the transition economies not only in terms of FDI per capita but also regarding the absolute stock of FDI cumulated from 1991 to 2003, which amounts to nearly USD 42 billion (EBRD, 2003). 
sector) has also appreciated, though to a lesser extent than the CPI-based real exchange rate. The B-S effect is expected to explain the difference between the overall inflation-deflated (CPI) and the tradable price-based (PPI) real exchange rates. ${ }^{31}$

The equilibrium appreciation of the real exchange rate, and thus the underlying inflation differential vis-à-vis Germany and the euro area that is imputable to the B-S effect, is found to amount to up to $2.0 \%$ in Hungary and Poland and is much lower in the other countries. ${ }^{32}$ In the Czech Republic and Latvia, it is close to zero. ${ }^{33}$ This finding has important implications: The B-S effect, i.e. productivity-driven market service inflation, is likely to be no barrier to meeting the Maastricht criterion on price stability, defined as the average inflation rate (measured in terms of the harmonized CPI) of the three bestperforming EU countries in terms of price stability plus $1.5 \% .{ }^{34}$ However, this does not mean that the fulfillment of the criterion would pose no problem for tradable price inflation, and especially regulated price inflation may be of importance in this respect. Furthermore, it is interesting to see that catching-up EU countries such as Greece, Portugal and Spain recorded very low changes in dual productivity during the 1990s despite above-average economic growth coupled with above-average inflation rates. This may imply that mechanisms other than the B-S effect could be at work and bring about changes in relative price levels.

${ }^{31}$ When using the CPI and the PPI, this only holds if overall inflation is composed of tradable goods and market-based services, and if the tradable component of the PPI corresponds to that of the CPI.

32 Kovács (2003) argues that the B-S effect is not likely to exceed $2 \%$ per annum even in the longer run. Kozamernik (2003) makes model-based projections and concludes that the yearly inflation rate imputable to the B-S effect would range from $1 \%$ to $1.5 \%$ in Slovenia $(0.4 \%$ to $0.9 \%$ in terms of an inflation differential vis-à-vis Germany).

33 One should not forget that these figures are based on past data. However, one may argue that the maximum value of $2 \%$ may be an upper limit even in the future. One reason for this is that productivity increases in the open sector may slow down as the acceding countries' productivity levels approach EU productivity levels. Also, productivity gains in the sheltered sector may pick up. Although the share of (market) services in the acceding countries' national and harmonized CPI $(20 \%$ to $35 \%)$ is still lower than what we can observe in the EU $(40 \%$ to $45 \%)$, it may only increase progressively with higher real income per capita, and would not exacerbate the B-S effect's impact on the CPI.

34 This is in contrast with the long held view, advocated by Szapáry (2000) among others, that acceding countries would not be able to fulfill the Maastricht criterion on price stability because of the B-S effect. 
Notwithstanding the fact that the B-S effect can explain only part of the real appreciation of the transition countries' currencies, the currencies are not necessarily overvalued because:

1) The real exchange rate may have been over- or undervalued at the outset of transition. If it had been fairly valued, the actual real exchange rate would have appreciated faster than the equilibrium real exchange rate. Consequently, it would be overvalued by now. But Halpern and Wyplosz (1997) and Krajnyák and Zettelmeyer (1998) reported a strong undervaluation at the beginning of the transition period. This means that the "excess" appreciation of the actual real exchange rate (the difference between the appreciation of the actual and equilibrium real exchange rate) has only been a "corrective" convergence towards its equilibrium level.

2) There is a more compelling reason why the equilibrium real exchange rate could appreciate despite the low B-S effect. In transition economies, the adoption of new technology and higher productivity leads to higher supply capacities to produce goods of better quality. Due to improvements in the quality of goods and marketing, and because of a change in preferences towards domestic goods, pricing strategies result in higher tradable prices. It is hardly possible to filter these changes out of inflation, which brings about a real appreciation via a positive inflation differential in tradable goods. In addition, the real exchange rate based on tradable prices may also appreciate because of the adoption of new technologies and driven by expected productivity gains linked to capital inflows related to productive foreign investment. Note, however, that if expected productivity gains do not materialize, the real appreciation will not be an equilibrium phenomenon ex post.

3) Real appreciation induced by an increase in regulated prices of nontradable goods might also be viewed as an equilibrium phenomenon in as far as increases in regulated prices imply an approach towards the market-based service price level and do not lead to a deterioration of competitiveness.

4) Moreover, real exchange rates based on the CPI are not fully consistent. Using the same weights for tradable and nontradable goods in the CPI would result in a slightly higher appreciation. Beside the quality issue, price indices in transition 
economies are subject to other sources of upward biases (Filer and Hanousek, 2001a, 2001b), which may also overstate the "true" appreciation.

5) Tradable prices also contain market-determined nontradable components and elements of regulated items. ${ }^{35}$ Thus, part of the appreciation of the PPI-based real exchange rate could be attributed indirectly to the B-S effect and to increases in regulated prices. A trend increase in disposable income per capita results in an increased demand for nontradable goods of higher value. The distribution sector may also play a role here, as advocated in MacDonald and Ricci (2001) and as shown in MacDonald and Wójcik (2002). Lee and Tang (2003), however, mitigate the role the distribution sector may play in the real appreciation.

\subsection{Small BEER and Big FEER}

\subsubsection{Is there Misalignment out There?}

The difficulty we encounter with BEER and FEER is that very recent estimates are needed to assess the extent of misalignment of the real and the nominal exchange rate for ERM II entry. Of the few estimates at our disposal, some are already outdated referring to e.g. 1997 or 1998). Another problem is that some of the countries are rather poorly covered. For instance, there are only a few estimates available for Latvia, Lithuania, Slovakia and Slovenia.

For the Czech Republic, the equilibrium exchange rate seems to be overvalued in 2001 and 2002 , for the estimated real misalignment ranges from $0 \%$ to $+20 \%$. Poland also exhibits signs of a misalignment in 2001 and early 2002, which might have been reversed by the strong depreciation of the nominal exchange rate. In the case of Hungary, most estimates find no misalignment prior to the abandonment of the crawling peg. Since then, the nominal exchange rate has appreciated by more than $10 \%$ coupled with a positive inflation differential vis-à-vis its trading partners; this may have resulted

\footnotetext{
${ }^{35}$ Adjustments in regulated prices are predominantly increases in nonmarket-based nontradable prices. For regulated items partly represent inputs for tradable goods, those adjustments contribute to an increase in tradable prices. For homogeneous goods that eventually enter international competition either because they are exported or because they are subject to import competition, an increase in their nonmarket-market and market-based nontradable component may lead to a loss in competitiveness and thus could not be viewed as an equilibrium phenomenon.
} 
in an above-equilibrium appreciation of the forint. This is widely acknowledged by available estimates. Although the Estonian kroon shows little sign of over- or undervaluation in 2000 and 2001, recent estimates for 2002 are more mixed on whether the real exchange rate is fairly valued or overvalued. 
Table 8. The Magnitude of Real Misalignment

\begin{tabular}{|c|c|c|c|c|c|c|c|}
\hline Country & Author(s) & Year & Misalignment & Country & Author(s) & Year & Misalignment \\
\hline \multicolumn{4}{|c|}{ Czech Republic } & \multicolumn{4}{|l|}{ Latvia } \\
\hline & Šmídková (1998) & 1996 & Eff: $-1 \%-+5 \%$ & & Kazaks (2000) & 1998 & Eff: NM \\
\hline & Begg et al. (1999) & 1997 & Eff: NM & & Beguna (2002) & 2001 & Eff:-2\% \\
\hline & Frait-Komárek (1999) & 1998 & Slightly + & & Bitans (2002) & 2001 & Eff(EU): NM \\
\hline & Kim and Korhonen (2002) & 1999 & Eff: $-10 \%$ & & Burgess et al. (2003) & 2002:Q1 & Eff:-6\% \\
\hline & Coudert and Couharde (2002) & 2001 & EUR: $-3 /+1 \%$ & & Bitans and Tillers (2003) & 2002:Q4 & $E f f(E U): N M$ \\
\hline & Lommatzsch and Tober (2002b) & 2001 & Eff: $0 \% /+15 \%$ & Lithuania & & & \\
\hline & Égert and Lahrèche-Révil (2003) & 2001:Q2 & Eff: $+15 \%$ & & Vetlov (2002) & 2001 & Eff: $-7 \%$ \\
\hline & Šmídková et al.(2002) & 2002 & Eff. $+8-9 \%$ & & Alonso-Gamo et al. (2002) & 2002 & Eff:-5\% \\
\hline & \multirow[t]{2}{*}{ Rahn (2003) } & 2002:Q1 & Eff. $+9.7 /+11 \%$ & & Burgess et al. (2003) & 2002:Q1 & Eff:-6\% \\
\hline & & 2002:Q1 & EUR $+13.7 /+14.7 \%$ & \multicolumn{4}{|l|}{ Poland } \\
\hline & Alberola (2003) & 2002:q4 & Eff:+10\% & & Begg et al. (1999) & 1997 & Slightly $+?$ \\
\hline & Égert and Lommatzsch (2003) & 2002:Q4 & EUR:+10-20\% & & Kim and Korhonen (2002) & 1999 & Eff: NM \\
\hline \multirow[t]{10}{*}{ Estonia } & & & & & Kemme and Teng (2000) & 1999 & Eff. $+2 /+10 \%$ \\
\hline & Begg et al. (1999) & 1997 & Eff: NM & & Lommatzsch and Tober (2002b) & 2001 & Eff: $+10 \%$ \\
\hline & Filipozzi (2000) & 1999 & Eff: $+5 \%$ & & Coudert and Couharde (2002) & 2001 & EUR: $+3 /+5 \%$ \\
\hline & Randveer and Rell (2002) & 2000 & Eff: NM & & Égert and Lahrèche-Révil (2003) & 2001 Q2 & Eff: $+11 \%$ \\
\hline & Coudert and Couharde (2002) & 2001 & Eff: NM & & Rawdanowicz (2003) & 2002 & Eff: NM \\
\hline & Šmídková et al.(2002) & 2002 & Eff. $+13-14 \%$ & & Šmídková et al. (2002) & 2002 & Eff. $+10-+12 \%$ \\
\hline & Hinnosar et al. (2003) & 2002 & Eff: NM & & Rahn (2003) & 2002:Q1 & Eff. $+8 \% /+13 \%$ \\
\hline & \multirow[t]{2}{*}{ Rahn (2003) } & 2002:Q1 & Eff. $+5 /+7 \%$ & & & & EUR. $+13 \% /+17 \%$ \\
\hline & & 2002:Q1 & EUR. $+10 /+12 \%$ & & Alberola (2003) & 2001:Q2 & Eff: $+10 \%$ \\
\hline & Burgess et al. (2003) & 2002:Q1 & Eff:-3\% & & & 2002:Q4 & Eff: $-10 \%$ \\
\hline \multirow[t]{19}{*}{ Hungary } & & & & & Rubaszek (2003a) & 2001:Q2 & Eff: $+16 \%$ \\
\hline & Avallone and Lahrèche-Révil (1999) & 1997 & Eff: NM & & & 2002:Q4 & Eff: $+4.3 \%$ \\
\hline & Begg et al. (1999) & 1997 & Eff: slightly + & & Rubaszek (2003b) & 2002:Q4 & EUR: $+9 \%$ \\
\hline & Coudert (1999) & 1997 & USD: NM & & & 2003:Q2 & EUR:NM \\
\hline & Kim and Korhonen (2002) & 1999 & Eff: $+40 \%$ & & Égert and Lommatzsch (2003) & 2002:Q4 & EUR: $+0-6 \%$ \\
\hline & Coudert and Couharde (2002) & 2001 & EUR: $+2 /+4 \%$ & Slovakia & & & \\
\hline & Lommatzsch and Tober (2002b) & 2001 & Eff: NM & & IMF (1998) & 1997 & Eff: NM \\
\hline & Égert and Lahrèche-Révil (2003) & 2001 Q2 & Eff: NM & & Begg et al. (1999) & 1997 & Eff: NM \\
\hline & Csajbók and Kovács (2002) & 2002 & Eff: overvalued & & Kim and Korhonen (2002) & 1999 & Eff: NM \\
\hline & Šmídková et al. (2002) & 2002 & Eff. $+6 \%$ & & Égert and Lahrèche (2003) & 2001 & EUR: $+10 \%$ \\
\hline & Csajbók (2003) & 2002 & Eff. $+3 /+10 \%$ & & Égert and Lommatzsch (2003) & 2002:Q4 & EUR: $+10 /+15 \%$ \\
\hline & \multirow[t]{2}{*}{ Rahn (2003) } & 2002:Q1 & Eff. $-3 \% /+5 \%$ & \multirow[t]{8}{*}{ Slovenia } & & & \\
\hline & & 2002:Q1 & EUR $+2.5 \% /+8.6 \%$ & & Begg et al. (1999) & 1997 & Slightly $+?$ \\
\hline & Alberola (2003) & 2002:Q4 & Eff: $+10 /+12 \%$ & & Coudert and Couharde (2002) & 2001 & EUR: $+1 /+2 \%$ \\
\hline & \multirow[t]{5}{*}{ Égert and Lommatzsch (2003) } & \multirow[t]{5}{*}{ 2002:Q4 } & \multirow[t]{5}{*}{ EUR: $+0 /+8 \%$} & & Égert and Lahrèche-Révil (2003) & 2001 Q2 & Eff: NM \\
\hline & & & & & Šmídková et al. (2002) & 2002 & Eff. NM \\
\hline & & & & & Rahn (2003) & 2002:Q1 & Eff. $-3 \%$ \\
\hline & & & & & & 2002:Q1 & EUR. $-6 \%$ \\
\hline & & & & & Égert and Lommatzsch (2003) & 2002:Q4 & EUR: $-20 \%$ \\
\hline
\end{tabular}


While these estimates might be suited to indicating whether or not a currency is overvalued, determining the precise size of a possible misalignment is a much harder task. In addition, a large number of available estimates refer to the real effective exchange rate. To obtain the equilibrium exchange rate vis-à-vis the euro, reliable information about the equilibrium USD/EUR cross rate is needed. This might also be subject to high uncertainty.

\subsubsection{Signs of the Estimated Coefficients}

The divergence in the estimated misalignment may be due to several factors. Results for the BEER approach may vary considerably depending on the period underlying the estimations. Across different papers, the whole gamut of fundamentals is used, and, as a corollary, the outcome is sensitive to which particular fundamentals are included in the estimated model. The use of different fundamentals may be a result of different theoretical frameworks or may simply reflect ad hoc choices. ${ }^{36}$

Table 9 reveals that an increase in the dual productivity (differential) leads always to an appreciation of the real exchange rate. Terms of trade and public consumption to GDP also appear to be positively connected to the real exchange rate but the evidence is less robust, though. Much more controversial are net foreign assets and openness. For instance, an increase in net foreign assets is found to bring about an appreciation of the real exchange rate in Alonso-Gamo et al. (2002), Lommatzsch and Tober (2002) and Burgess et al. (2003), whereas Hinnosar et al. (2003) and Rahn (2003) find the opposite effect for Estonia. This finding of Hinnosar et al.(2003) and Rahn(2003) is largely confirmed by Rahn for the Czech Republic, Hungary, Poland and Slovenia, and by Alberola (2003) for Hungary and Poland. By contrast, an increase in net foreign assets turns out to result in a real appreciation of the Czech currency. One reason why the sign on net foreign assets is so controversial is that capital inflows into productive sectors may have materialized in the form of productivity growth. Second, the sample period may be too short, so that real appreciation and net capital inflows occur simultaneously.

36 The fact that for the same country or for comparable panels, long-term relationships can be established, which include a different set of fundamentals, may also indicate that the real exchange rate may be linked to the fundamentals through multiple long-term relationships. 
This may be understood, for instance, in the framework of the NATREX model according to which net foreign assets are endogenous. If investment rises in the open sector, capital inflows reflected in a decline in net foreign assets causes the real exchange rate to appreciate in the medium-run. In the long run, when investment starts working in the open sector, the trade balance ameliorates, resulting an increase in net foreign assets, leads to the appreciation of the real exchange rate in the second phase.

The same controversy holds true for openness. While the IMF (1998), Begg et al. (1999), Beguna (2002) and Csajbók (2003) find that an increase in the openness ratio leads to a real appreciation of the exchange rate, estimates in Avallone and LahrècheRévil (1999), De Broeck and Sløk (2001), Bitans (2002), Kim and Korhonen (2002), Vetlov (2002), and Égert and Lommatzsch (2003) show the opposite to be the case. A negative sign (an increase in openness leads to a depreciation of the real exchange rate) reflects the traditional view according to which openness is an indicator of trade liberalization: Higher openness is associated with decreasing trade barriers, which raises imports more than exports. The deterioration in the trade balance makes the real exchange rate depreciate. However, an increase in openness can also represent improved supply capacities, which result in higher exports, and this can cause a real appreciation of the exchange rate. Nevertheless, this effect is expected to be captured by the productivity variables.

\subsubsection{Parameter Distortion}

The presence of an initial undervaluation would bias time-series and in-sample panel estimates of the equilibrium exchange rate because the slope coefficient estimated between the observed real exchange rate and the fundamentals would look different from the true slope coefficient linking the equilibrium real exchange rate to the fundamentals. This problem appears exacerbated in an in-sample panel setting if the initial undervaluations and the adjustment paths toward equilibrium are different across countries (Maeso-Fernandez et al., 2003).

But a more general problem, which does not apply only to transition economies, is that BEERs are models of real exchange rate determination in that they attempt to connect the observed real exchange rate to the fundamentals. Hence, empirically estimated 
coefficients are interpreted as equilibrium coefficients, which link the equilibrium exchange rate and the fundamentals, although they only represent the relationship between the observed real exchange rate and the fundamentals (the equilibrium relationship is assumed to equal the empirical long-term relationship). In this sense, real exchange rate determination models are used as models of equilibrium real exchange rates. As an outcome, the estimated coefficients from BEER models are likely to be biased and thus probably yield biased real misalignments, irrespective of whether or not they are based on time series or panels. However, this bias is likely to be larger for estimates based on time series as well as on small- and medium-size panels. As a consequence, the extent of a misalignment derived from the estimates might depend on how well the observed real exchange rate can be modeled using fundamentals. Furthermore, if no long-term relationship can be established between the observed real exchange rate and its fundamentals, this does not mean that there is no relationship between the equilibrium real exchange rate and the fundamental variables. 
Table 9. Signs of the Estimated Coefficients

\begin{tabular}{|c|c|c|c|c|c|c|c|c|c|c|c|c|}
\hline \multirow[b]{2}{*}{ Time series } & \multicolumn{4}{|l|}{ dependent variable } & \multicolumn{8}{|c|}{ explanatory variables } \\
\hline & & PROD & $\begin{array}{c}\text { CAPIT } \\
\text { A }\end{array}$ & NFA & OPEN & TOT & GOV & PRIV & RIR & INV & $\begin{array}{l}\text { FDEB } \\
\mathrm{T} \\
\end{array}$ & REGD \\
\hline Alberola (2003) & $\operatorname{REER}(\mathrm{CPI})$ & $+(\mathrm{LP})$ & & $+/-$ & & & & & & & & \\
\hline $\begin{array}{l}\text { Alonso-Gamo et al. (2002) } \\
\text { Avallone and Lahrèche-Révil } \\
\text { (1999) }\end{array}$ & $\begin{array}{l}\text { REER(CPI) } \\
\text { REER(CPI) }\end{array}$ & $+(\mathrm{CPI} / \mathrm{PPI})$ & + & - & - & + & + & + & & & & \\
\hline Beguna (2002) & REER(CPI) & & & & + & + & + & & & & & \\
\hline Bitans (2002) & REER(CPI,PPI) EU & $+(\mathrm{LP})$ & & & - & & - & & & & & \\
\hline Bitans and Tillers (2003) & REER(PPI) EU & & + & + & & - & & & & & & \\
\hline Burgess et al. (2003) & REER(CPI) & $+(\mathrm{CPI} / \mathrm{PPI})$ & & - & & & & & & & & \\
\hline Csajbók (2003) & $\operatorname{REER}(\mathrm{CPI})$ & $+(\mathrm{LP})$ & & + & + & + & + & & $\begin{array}{c}+ \\
+/-\end{array}$ & & & \\
\hline $\begin{array}{l}\text { Darvas (2001) } \\
\text { Égert and Lahrèche-Révil } \\
\text { (2003) } \\
\text { Égert and Lommatzsch } \\
\text { (2003) }\end{array}$ & $\begin{array}{l}\text { RER (DEM) } \\
\text { REER(CPI) } \\
\text { RER(CPI,PPI) } \\
\text { DEM,EUR }\end{array}$ & $\begin{array}{c}+(\mathrm{LP}) \\
+(\mathrm{CPI} / \mathrm{PPI}) \\
+(\mathrm{LP})\end{array}$ & & + & - & & & & (1) & & $+/-$ & + \\
\hline Filipozzi (2000) & $\operatorname{REER}(\mathrm{CPI})$ & $+(\mathrm{LP})$ & & & & & & & & + & & \\
\hline Frait and Komárek (1999) & $\operatorname{REER}(\mathrm{CPI})$ & + (real GDP) & & & & + & & & & & & \\
\hline Hinnosar et al. (2003) & $\operatorname{REER}(\mathrm{CPI})$ & $+(\mathrm{LP})$ & & + & & + & & & & & & \\
\hline IMF (1998) & REER(CPI, PPI) & $+($ RWAGE) & & & + & & - & & & - & & \\
\hline $\begin{array}{l}\text { Kazaks }(2000) \\
\text { Lommatzsch and Tober } \\
(2002 b)\end{array}$ & $\begin{array}{l}\text { REER(CPI) } \\
\text { REER(PPI) }\end{array}$ & $\begin{array}{l}+(\mathrm{LP}) \\
+(\mathrm{LP})\end{array}$ & & - & - & & & & + & & & \\
\hline Rahn (2003) & $\operatorname{REER}(\mathrm{CPI})$ & $+(\mathrm{CPI} / \mathrm{PPI})$ & & + & & & & & & & & \\
\hline Randveer and Rell (2002) & REER(CPI) & $+(\mathrm{LP})$ & & & & + & & & & & & \\
\hline Rawdanowicz (2003) & RER(CPI) EU & $+(\mathrm{LP})$ & & & & + & & & + & & & \\
\hline Rubaszek (2003a) & REER(PPI) & & & + & & & & & + & & & \\
\hline Vetlov (2002) & REER(PPI) & $+(\mathrm{LP})$ & & & - & & & & - & & & \\
\hline \multicolumn{13}{|l|}{ Panel } \\
\hline Begg et al. (1999) & & & + & & + & & + & & & & & \\
\hline Coricelli and Jazbec (2001) & $\mathrm{P}(\mathrm{t}) / \mathrm{P}(\mathrm{nt})$ & $+(\mathrm{LP})$ & & & & & + & $+(2)$ & & & & \\
\hline Coudert (1999) & RER(CPI) US & $+(\mathrm{CPI} / \mathrm{PPI})$ & & & & & & & & & - & \\
\hline De Broeck and Sløk (2001) & $\operatorname{REER}(\mathrm{CPI})$ & $+(\mathrm{LP})$ & & & - & & & & & & & \\
\hline $\begin{array}{l}\text { Dobrinsky (2003) } \\
\text { Égert and Lommatzsch } \\
\text { (2003) }\end{array}$ & $\begin{array}{l}\text { RER(CPI) EU } \\
\text { RER(CPI,PPI) EU }\end{array}$ & $\begin{array}{l}+(\mathrm{TFP}) \\
+(\mathrm{LP})\end{array}$ & + & & - & & + & & + & & $+/-$ & + \\
\hline Halpern and Wyplosz (1997) & $\begin{array}{l}\text { RER(CPI) US } \\
\text { REER(CPI); }\end{array}$ & $\begin{array}{c}+(\text { LP) } \\
+ \\
\text { (GDP/worker } \\
\quad)\end{array}$ & + & & & - & + & & $+/-$ & & & \\
\hline $\begin{array}{l}\text { Kim and Korhonen (2002) } \\
\text { Krajnyák and Zettelmeyer } \\
\text { (1998) } \\
\text { MacDonald and Wójcik } \\
\text { (2002) }\end{array}$ & $\begin{array}{l}\text { RER(CPI) US } \\
\text { RER(CPI) US } \\
\text { REER(CPI) }\end{array}$ & $+(\mathrm{LP})$ & $\begin{array}{l}+ \\
+\end{array}$ & $+/-$ & - & & + & & + & + & & $+(3)$ \\
\hline Maurin (2001) & REER(CPI) & & + & & & & + & & + & & - & \\
\hline $\begin{array}{l}\text { Note: }+(-) \text { means that an increa } \\
=\text { real effective exchange rate b } \\
\text { RER(CPI) U.S. = real exchange } \\
\text { the definition of the explanatory } \\
\text { (1) the foreign real interest rate } \\
\text { (2) the share of nontradable con } \\
\text { (3) regulated prices in the home }\end{array}$ & $\begin{array}{l}\text { e (decrease) in the given } \\
\text { sed on the CPI; REER(PI } \\
\text { ate against the EU, the e } \\
\text { ariables } \\
\text { umption in private consul } \\
\text { country }\end{array}$ & $\begin{array}{l}\text { ariables gives ris } \\
\text { ) = real effective } \\
\text { o and the U.S., } \\
\text { ption }\end{array}$ & $\begin{array}{l}\text { to an } \\
\text { xchan } \\
\text { specti }\end{array}$ & ely; $P($ & $\begin{array}{l}\text { ation (d } \\
\text { based o } \\
\text { /P(nt) }\end{array}$ & the & $\begin{array}{l}\text { ation) o } \\
\text { PPI; RE } \\
\text { ternal }\end{array}$ & eal e & ang & te. S & $\begin{array}{l}\text { e; REE } \\
\text { EUR; } \\
\text { e table }\end{array}$ & for \\
\hline
\end{tabular}




\subsection{Time Series versus Panel Estimates}

There is an apparent tradeoff between the use of time series and panel data. At best, time series span slightly more than ten years, assuming no structural or smooth changes in the estimated relationships, and thus provide roughly 40 to 50 quarterly observations, which - from a strictly econometric point of view - might be insufficient.

It may be argued that employing panel data may increase the number of observations. Typically, three types of panels are used in the literature: small panels including 6 to 9 countries, medium-size panels composed of 20 to 30 countries and large panels containing up to 80 or 90 countries. In addition, panels may or may not include the countries under investigation. Small panels are typically in-sample panels, whilst medium and large panels can be both in-sample and out-of-sample panels.

However, a number of problems still remain. In general, medium-size in-sample panel studies use a heterogeneous set of countries. From an econometric viewpoint, using panel data makes sense if homogeneity is verified for the countries. A typical panel employed e.g. in Coricelli and Jazbec (2001) or in Halpern and Wyplosz (2001) contains countries such as the Czech Republic and Slovenia on the one hand and Mongolia and Kyrgyzstan on the other. Yet only Kim and Korhonen (2002) and Csajbók (2003) test for homogeneity in the panel they use. It is then pretty difficult to interpret a common coefficient obtained for a set of economies which are so different.

The escape route leads either through smaller panels composed of more homogeneous countries (De Broeck and Sløk, 2001; Dobrinszky, 2001) or huge panels (Halpern and Wyplosz, 1997; Krajnyák and Zettelmeyer, 1998). The problem indicated for the case of time series estimates remains in small panels, i.e. estimates stand for the relationship between the observed real exchange rate, rather than the equilibrium real exchange rate, and a set of other variables. Moreover, in small panels based on annual data, the number of observations might drop significantly. The large panel setting assumes that market economies behave very similarly in the long term, and the estimated coefficients should reflect this long-term average behavior. Therefore, these estimates could be applied to all countries. However, Maeso-Fernandez et al. (2003) argue that out-of- 
sample estimations do not provide a country-specific constant, and this could affect the level of the derived equilibrium real exchange rate when applied to individual countries.

A related issue here is how appropriate the estimation methods are. As shown in table 10 , time series studies usually account for the nonstationary nature of the data and employ different cointegration techniques. In contrast to this is the observation that some of the panel studies do not consider nonstationarity and do not test for cointegration (see Halpern and Wyplosz, 1997; Coudert, 1999; and Corricelli and Jazbec, 2001; for fixed and random effect OLS and Begg et al., 1999; and Dobrinsky, 2003; for GLS). It is admittedly difficult to test for cointegration when the time series dimension of the panel is limited. However, this issue can be tackled by running the regression both in levels and in first differences (Krajnyák and Zettelmeyer, 1998, and Maurin, 2001) or by applying nonstationary panel techniques: De Broeck and Sløk (2001) and Kim and Korhonen (2002) use PMGE and MGE and consider a significant error correction adjustment parameter as evidence for cointegration. Crespo-Cuaresma et al. (2003) use a variety of estimation methods and systematically apply cointegration tests proposed by Kao (1999) to the residuals of the long-term relationships. Following a similar approach, Égert and Lommatzsch (2003) employ panel cointegration tests developed by Pedroni(1999). ${ }^{37}$

37 Although MacDonald and Wójcik (2002) use panel dynamic OLS, they do not report panel cointegration tests. Fischer (2002) reports coefficients on the basis of fixed-effect OLS, seemingly unrelated regression and PMGE but carries out Pedroni cointegration tests for the long-term relationship obtained using panel FMOLS. 
Table 10. Econometric Techniques Used in the BEER Studies

\begin{tabular}{|c|c|c|}
\hline & Inference & Cointegration Tests \\
\hline \multicolumn{3}{|l|}{ Time series } \\
\hline Alberola (2003) & FIML & Johansen's trace and max \\
\hline $\begin{array}{l}\text { Alonso-Gamo et al. (2002) } \\
\text { Avallone and Lahrèche-Révil } \\
\text { (1999) }\end{array}$ & $\begin{array}{l}\text { FIML } \\
\text { FIML }\end{array}$ & $\begin{array}{l}\text { Johansen's trace and max } \\
\text { Johansen's trace and max }\end{array}$ \\
\hline Beguna (2002) & OLS & error correction term \\
\hline Bitans (2002) & OLS & residual-based; error correction term \\
\hline Bitans and Tillers (2003) & FIML, OLS & Johansen's trace and max \\
\hline Burgess et al. (2003) & FIML & Johansen's trace \\
\hline Csajbók (2003) & OLS & residual-based unit root tests \\
\hline $\begin{array}{l}\text { Darvas (2001) } \\
\text { Égert and Lahrèche-Révil } \\
(2003)\end{array}$ & $\begin{array}{l}\text { OLS } \\
\text { FIML }\end{array}$ & $\begin{array}{l}\text { residual-based unit root tests } \\
\text { Johansen's trace } \\
\text { residual-based; bounds testing approach; Johansen's }\end{array}$ \\
\hline Égert and Lommatzsch (2003) & OLS, DOLS, ARDL, FIML & trace \\
\hline Filipozzi (2000) & FIML & Johansen's trace \\
\hline Frait and Komárek (1999) & ARDL & $\begin{array}{l}\text { error correction term } \\
\text { Johansen's trace: Cheung and Lai small sample }\end{array}$ \\
\hline Hinnosar et al. (2003) & FIML & adjustment \\
\hline IMF (1998) & OLS & none \\
\hline Kazaks (2000) & OLS & error correction model \\
\hline Kemme and Teng (2000) & OLS & error correction term \\
\hline Lommatzsch and Tober (2002b) & OLS & residual-based unit root tests \\
\hline Rahn (2003) & FIML & Johansen's trace and max \\
\hline Randveer and Rell (2002) & OLS & Johansen's trace; residual-based unit root tests \\
\hline Rawdanowicz (2003) & FIML & Johansen's trace \\
\hline Rubaszek (2003a) & FIML & Johansen's trace: Reimers small sample adjustment \\
\hline Vetlov (2002) & OLS & error correction term \\
\hline \multicolumn{3}{|l|}{ Panel } \\
\hline Begg et al. (1999) & GLS & none \\
\hline Coricelli and Jazbec (2001) & FE OLS & none \\
\hline Coudert (1999) & FE and RE OLS & none \\
\hline Crespo-Cuaresma et al. (2003) & FE OLS; FMOLS; DOLS; PMGE; MGE & Pedroni \\
\hline De Broeck and Sløk (2001) & FE OLS; PMGE & error correction term for PMGE \\
\hline Dobrinsky (2003) & GLS & none \\
\hline Égert and Lommatzsch (2003) & FE OLS, DOLS, PMGE, MGE & Pedroni \\
\hline Fischer (2002) & FE OLS; FE SUR; PMGE & Pedroni \\
\hline Halpern and Wyplosz (1997) & FE OLS & none \\
\hline $\begin{array}{l}\text { Kim and Korhonen (2002) } \\
\text { Krajnyák and Zettelmeyer } \\
\text { (1998) }\end{array}$ & $\begin{array}{l}\text { FMOLS; PMGE; MGE } \\
\text { FE and RE OLS: in levels and 1st } \\
\text { differences }\end{array}$ & $\begin{array}{l}\text { error correction term for PMGE } \\
\text { none }\end{array}$ \\
\hline MacDonald and Wójcik (2002) & DOLS & none \\
\hline Maurin (2001) & FE OLS: in levels and 1st differences & none \\
\hline
\end{tabular}




\subsection{Data and Measurement Problems}

It is true to say that the literature is burdened with a number of measurement and methodological difficulties.

Because an increase in the dual productivity differential is transmitted onto the real exchange rate not only through market-based nontradable inflation as assumed by the standard B-S effect, but also via multiple channels related to tradable prices, the relative price differential appears to be an extremely poor proxy for the dual productivity differential. In particular, the CPI-to-PPI ratio often used in the literature (see e.g. Coudert,1999; Alonso-Gamo et al., 2002; Burgess et al., 2003; Rahn, 2003) is even more affected by this problem given that the share of nontradable goods in CPI is very low in the CEECs and because of the presence of regulated prices in the CPI.

In principle, labor productivity is given as output per total hours worked. In practice, however, the output-per-employee ratio is used. If there is a shift in full-time employment towards part-time employment (or vice versa), the number of employees is a poor proxy for total hours worked.

The classification of sectors into open and closed sectors is also surrounded by a great deal of uncertainty:

1) Different classifications may be reflected in different dual productivity figures. For instance, in Mihaljek and Klau (2003), the open sector includes hotels and restaurants, and transport, storage and communication, which entails larger dual productivity in the Czech Republic than in all the other acceding countries. This is in sharp contrast with other studies and with the estimates of the Czech central bank (see Kovács, 2002; Flek et al., 2002). Égert (2003) also shows that results are sensitive to how the open and the closed sectors are defined, and points out that one-size-fits-all techniques are not appropriate (a given sector can be viewed as tradable in one country and as nontradable in another one). As the B-S model posits PPP to hold in the tradable sector, goods arbitrage - the mechanism ensuring PPP - should be potentially possible in the 
tradable sector. This, too, might be limited in the case of e.g. tourism or storage $\mathrm{e}^{38}$, since one cannot buy two nights in a five-star hotel, say, in Tallinn and sell them in Berlin or in Paris.

Table 11. Classification of Sectors into Open and Closed Sectors in Transition Economies

\begin{tabular}{|c|c|c|}
\hline & Open Sector & Closed Sector \\
\hline Alberola (2003) & manufacturing & not considered \\
\hline Backé et al. (2003) & manufacturing & rest \\
\hline $\begin{array}{l}\text { Coricelli and Jazbec } \\
(2001)\end{array}$ & industry + construction & rest, agriculture excluded \\
\hline $\begin{array}{l}\text { De Broeck and Sløk } \\
(2001)\end{array}$ & industry + construction & rest, agriculture excluded \\
\hline Dobrinsky (2003) & whole economy & \\
\hline Égert (2002a,b) & industry & not considered \\
\hline \multirow[t]{2}{*}{ Égert et al. (2003) } & industry & rest \\
\hline & industry and agriculture & rest \\
\hline Filipozzi (2000) & industry & rest, agriculture excluded \\
\hline Fischer (2002) & industry and agriculture & rest \\
\hline Flek et al. (2002) & manufacturing & construction \\
\hline Golinelli and Orsi (2002) & Industry & rest \\
\hline $\begin{array}{l}\text { Halpern and Wyplosz } \\
\text { (2001) }\end{array}$ & manufacturing / industry & services, agriculture and construction excluded \\
\hline \multirow[t]{2}{*}{ Hinnosar et al. (2003) } & manufacturing and agriculture & rest \\
\hline & $\begin{array}{l}\text { manufacturing, agriculture, hotels, restaurants, } \\
\text { telecom and transport }\end{array}$ & rest \\
\hline $\begin{array}{l}\text { Kovács (2001, 2002), } \\
\text { Kovács and Simon (1998) }\end{array}$ & manufacturing & services, agriculture and public services excluded \\
\hline Lojschova (2003) & manufacturing & services and construction \\
\hline $\begin{array}{l}\text { Lommatzsch and Tober } \\
(2002 a)\end{array}$ & Industry & construction, trade, finance \\
\hline $\begin{array}{l}\text { MacDonald and Wójcik } \\
(2002)\end{array}$ & agriculture, mining, manufacturing, transport, telecom & rest \\
\hline Mihaljek and Klau (2003) & mining, manufacturing, hotels, transport, telecom & rest, agriculture and public administration excluded \\
\hline Randveer and Rell (2002) & agriculture, manufacturing, hotels, transport & rest (mining) \\
\hline Rother (2000) & Manufacturing & rest, agriculture excluded \\
\hline Rosati (2002) & Industry / industry and agriculture & Rest \\
\hline Sinn and Reutter (2001) & manufacturing and agriculture & construction, energy, services \\
\hline
\end{tabular}

${ }^{38}$ One may argue that there is no need for goods arbitrage. It suffices that the given good/service is exported and that it is exposed to international price competition. In the case of tourism, it would mean that hotels in Tallinn, Paris and Berlin would closely monitor each others' prices. However, the trouble with this argument is that prices in tourism are largely determined by local factors such as labor costs and property prices. In addition, tourism is a highly differentiated good and prices may depend largely on preferences. Although one and the same package holiday to Estonia may actually cost the same for both customers in Germany and customers in Austria, there is no straightforward mechanism to equalize the price a customer in Germany, Austria or elsewhere would pay for one package holiday to Tallinn and another package holiday to Paris. 
2) Agriculture is also a very controversial issue. Some consider it a tradable sector while others do not. For instance, Fischer (2002) argues that half of the appreciation brought about by productivity gains can be attributed to productivity gains in agriculture. This is very questionable and is akin to saying that agriculture has a bellwether role during the catching-up process.

There is a more general statistical problem. Data definitions differ between individual acceding countries and between acceding and EU countries in spite of ongoing data harmonization. In fact, the harmonization process implies changes in data definitions over time. In addition, data revisions occur relatively often in acceding countries (the Czech Republic is a recent example), which might cast doubt on estimates derived using prerevision data. Finally, the same time series for the same country can exhibit differences depending on whether it is drawn from national statistics, from IMF or from OECD databases (Égert et al., 2003). Another problem to address in this context is that weights used to calculate effective exchange rates are adjusted to changes in foreign trade only with a considerable lag by certain institutions, which may bias not only the estimates but may also pose a problem when deriving the bilateral equilibrium exchange rate against the euro.

If indices such as the $\mathrm{CPI}$ or $\mathrm{PPI}$, on which the real exchange rate is usually based, or import and export price indices (for determining the terms of trade) are used, the question that has to be addressed is how to determine the year in which the exchange rate may be viewed as in equilibrium. One can rely on several methods:

1) The counterfactual approach is based on a subjective evaluation of the real exchange rate, the current account and other factors; the year during which those variables are believed to be in equilibrium is selected. A typical criterion is the year in which the current account is fully financed by FDI (Filipozzi, 2000; Randveer and Rell, 2002; Lommatzsch and Tober, 2002; Égert and Lahrèche-Révil, 2003). It is a question whether FDI linked to one-off privatization operations should be considered for this purpose or not. Clearly, the extent of the misalignment is likely to be sensitive to such judgments. 
2) The nominal exchange rate implied by PPP is adjusted for differences in the level of productivity, which can be proxied by GDP per capita to derive the equilibrium nominal exchange rate for a particular year (usually for 1996 and 1999, as nonextrapolated data on price and productivity levels are available only for those years): $\frac{P / P^{*}}{T F P / T F P^{*}}$ (see Brook and Hargreaves, 2001). A slightly more sophisticated version of this method is to use cross-section estimates when the relative price level or the real exchange rate gap is regressed on relative productivity, usually proxied by GDP per capita measured in PPP terms (De Broeck and Sløk, 2001; Randveer and Rell, 2002; Coudert and Couharde, 2002; Burgess et al., 2003; Čihák and Holub, 2001, 2003). Charts $6 \mathrm{a}$ and $6 \mathrm{~b}$ show, however, that the result of such an exercise may be sensitive to the country sample, the year analyzed and the benchmark country.

However, it is noteworthy that some studies simply take the fitted values of the estimated relationship based on indices and do not seek to address the issue of base year.

Apart from the base year problem, another tricky issue for the BEER approach is how to tackle long-term values for fundamentals. One strand of papers simply assumes that actual values correspond to long-term values (see Lommatzsch and Tober, 2002). Others employ statistical methods to extract the trend component of the series (Filippozi, 2000; Randveer and Rell, 2002). Finally, model-based fitted values are also useful for this purpose (e.g. Rubaszek, 2003; Égert and Lahrèche-Révil, 2003).

The FEER approach cannot escape these problems, either. Coudert and Couharde (2002) use in-sample panel estimates provided by Doisy and Hervé (2003) for seven transition economies to derive the long-term current account along the lines of the Macroeconomic Balance approach whereas Csajbók and Kovács (2002) consider the year 2000 as in equilibrium and use values for the current account from that year. Both methods rely heavily upon subjective expert evaluations. It should also be mentioned that the NIGEM model on whose basis FEER calculations are performed has a few shortcomings. First, it is a one-sector economy model. Second, some of the parameters 
are estimated using the panel of five acceding countries (the Czech Republic, Estonia, Hungary, Poland and Slovenia), whilst others are calibrated.

More generally, it is often the case that the home country variable is not taken in terms of the foreign country (see Jazbec, 2002). As the very concept of the real exchange rate is based on the comparison of the domestic and foreign economies, variables ought to be computed as the ratio of the home country variable to the foreign country variable (see MacDonald, 1997; Clark and McDonald, 1998).

\section{Concluding Remarks}

All in all, assessing equilibrium real exchange rates for acceding countries appears to be no easy task. There is a great deal of model uncertainty related to the theoretical background and to the fundamentals chosen, and an array of methodological and statistical problems also renders the mission very complicated. But why should this task be easy if similar difficulties are encountered when estimating the equilibrium exchange rate of the euro or the U.S. dollar? According to the European Central Bank (2002), estimates of the equilibrium USD/EUR parity vary considerably within a range of 1.03 to 1.45. Consistent with this finding is the large degree of uncertainty with regard to the equilibrium value of the euro Detken et al. (2002) detect when using alternative theoretical models and econometric techniques.

However, it appears that a systematic assessment of the equilibrium exchange rate is necessary or even inevitable for countries contemplating entry in ERM II and an eventual adoption of the euro. Csajbók (2003) sets a good example by showing estimation results for Hungary based on different theoretical approaches such as BEER, FEER, Macroeconomic Balance and NATREX. Because of possible caveats of each approach and given that some of the approaches are model-based (FEER) whereas others are typically assessed using econometric estimation methods, they should be applied simultaneously. In addition, it also seems useful to conduct a systematic sensitivity analysis of econometric estimates employing different econometric techniques currently used in the literature for a set of acceding countries and applied to one and the same dataset, as in Égert and Lommatzsch (2003). 
Thus, the answer to the question in the title of the paper, namely Can we have DEER with BEER without FEER, is that we cannot possibly have DEER with BEER without FEER - not even without NATREX. 


\section{References}

Alberola, E. 2003. Real Convergence, External Disequilibria and Equilibrium Exchange Rates in EU Acceding Countries. Banco de España. Mimeo.

Alberola, E. and T. Tyrväinen. 1998. Is There Scope for Inflation Differentials in EMU? Banco de España. Working Paper No. 9823.

Alberola, E., S. G. Cervero, H. Lopez and A. Ubide. 1999. Global Equilibrium Exchange Rates: Euro, Dollar, "Ins," "Outs," and Other Major Currencies in a Panel Cointegration Framework. IMF Working Paper No. 175.

Alonso-Gamo, P., S. Fabrizio, V. Kramarenko and Q. Wang. 2002. Lithuania: History and Future of the Currency Board Arrangement. IMF Working Paper No. 127.

Artus, J. 1978. Methods of assessing the long-run equilibrium value of an exchange rate. Journal of International Economics 8. 277-299.

Avallone, N. and A. Lahrèche-Révil. 1999. Le taux de change réel d'équilibre dans les pays en transition: le cas de la Hongrie. TEAM. University of Paris I - Sorbonne. Cahiers blancs 91.

Backé, P., J. Fidrmuc, T. Reininger and F. Schardax. 2003. Price dynamics in Central and Eastern European EU Accession Countries. Emerging Markets Finance and Trade 39(3). 42-78.

Baffes, J., I. A. Elbadawi and S. A. O'Connell. 1999. Single Equation of the Equilibrium Real Exchange Rate. In: Hinkle, L. and P. Montiel (eds.). Estimating Equilibrium Exchange Rates in Developing Countries. Washington D.C.: World Bank.

Balassa, B. 1964. The Purchasing-Power-Parity Doctrine: A Reappraisal. Journal of Political Economy 72(6). 584-596.

Bayoumi, T., P. Clark, S. Symansky and M. Taylor. 1994. The Robustness of Equilibrium Exchange Rate Calculations of Alternative Assumptions and Methodologies. In: Williamson, J. (ed.). Estimating Equilibrium Exchange Rates. Washington D.C.: Institute for International Economics. 19-60.

Begg, D., Halpern, L. and Ch. Wyplosz. 1999. Monetary and Exchange Rate Policies, EMU and Central and Eastern Europe. Forum Report on the Economic Policy Initiative 5. London: CEPR and New York, Prague: EastWest Institute.

Beguna, A. 2002. Competitiveness and the Equilibrium Exchange Rate in Latvia. EuroFaculty Working Paper in Economics 16. August. Riga: University of Latvia and EuroFaculty.

Bergstrand, J. H. 1991. Structural Determinants of Real Exchange Rates and National Price Levels: Some Empirical Evidence. American Economic Review 81(1). 325-334.

Bitans, M. 2002. Real Exchange Rate in Latvia: 1994-2001. Latvijas Banka Working Paper.

Bitans, M. and I. Tillers. 2003. Estimates of Equilibrium Exchange Rate in Latvia. Latvijas Banka. Analysis of the Real Exchange Rate in Latvia: 1994-2001. Latvijas Banka. Mimeo.

Boskin, M. J., E.R. Dulberger, R.J. Gordon, Z. Griliches and D.W. Jorgenson. 1996. Toward a More Accurate Measure of the Cost of Living. Final Report to the U.S. Senate Finance Committee from the Advisory Commission to Study the Consumer Price Index.

Brook, A. M. and D. Hargreaves. 2001. PPP-based Analysis of New Zealand's Equilibrium Exchange Rate. Reserve Bank of New Zealand Discussion Paper No. 1.

Burgess, R., Fabrizio, S. and Y. Xiao. 2003. Competitiveness in the Baltics in the Run-Up to EU Accession. IMF Country Report No. 114.

Cassel, G. 1916a. The Present Situation of the Foreign Exchanges. Economic Journal 26(101). 62-65.

Cassel, G. 1916b. The Present Situation of the Foreign Exchanges. Economic Journal 26(103). 219-323.

Cassel, G. 1918. Abnormal Deviations in International Exchanges. Economic Journal 28(112). 413-415. 
Čihák, M. and T. Holub. 2001. Convergence of Relative Prices and Inflation in Central and Eastern Europe. IMF Working Paper 124.

Čihák, M and T. Holub. 2003. Price Convergence to the EU: What Do the 1999 ICP Data Tell Us? Åská národní banka Working Paper Series No. 2.

Clark, P. and R. MacDonald. 1998. Exchange Rates and Economic Fundamentals: A Methodological Comparison of BEERs and FEERs. IMF Working Paper No. 67.

Clark, P. and R. MacDonald. 2000. Filtering the BEER - A Permanent and Transitory Decomposition. IMF Working Paper No. 144.

Coricelli, F. and B. Jazbec. 2001. Real Exchange Rate Dynamics in Transition Economies. CEPR Discussion Papers Series No. 2869.

Coudert, V. 1999. Comment définir un taux de change d'équilibre pour les pays émergents? Economie Internationale. $77.1^{\text {er }}$ trimestre. 45-65.

Coudert, V. and C. Couharde. 2002. Exchange Rate Regimes and Sustainable Parities for CEECs in the Run-up to EMU Membership. CEPII Working Paper No. 15.

Crespo-Cuaresma, J., Fidrmuc, J. and R. MacDonald. 2003. The Monetary Approach to the Exchange Rate in CEECs. BOFIT Discussion Paper No. 14.

Csajbók, A. 2003. The Equilibrium Real Exchange Rate in Hungary: Results from Alternative Approaches. Paper presented at the $2^{\text {nd }}$ Workshop on Macroecomic Policy Research. Magyar Nemzeti Bank. October 2-3.

Csajbók, A. and M. A. Kovács. 2002. FEER Enough? Magyar Nemzeti Bank. Mimeo.

Darvas, Zs. 2001. Exchange Rate Pass-Through and Real Exchange Rate in EU Candidate Countries. Economic Research Centre of the Deutsche Bundesbank Discussion Paper No. 10.

De Broeck, M. and T. Sløk. 2001. Interpreting Real Exchange Rate Movements in Transition Countries. IMF Working Paper No. 56.

Detken, C., A. Dieppe, J. Henry, C. Marin and F. Smets. 2002. Model Uncertainty and the Equilibrium Value of the Real Effective Euro Exchange Rate. ECB Working Paper No. 160.

Dobrinsky, R. 2003. Convergence in Per Capita Income Levels, Productivity Dynamics and Real Exchange Rates in the EU Acceding Countries. Empirica. 30(3). 305-334.

Doisy M. and A. Hervé. 2003. Les déficits courants des PECO: quelles implications pour leur entrée dans l'Union européenne et la zone euro? Economie Internationale. 93. $1^{\text {er }}$ trimestre. 59-88.

Driver, R. L. and P. F. Westaway. 2004. Concepts of Equilibrium Real Exchange Rates. Bank of England Working Paper (forthcoming).

EBRD. 2003. Transition Report 2003.

European Central Bank. 2002. Economic Fundamentals and the Exchange Rate of the Euro, Monthly Bulletin. January. 41-53.

Égert, B. 2002a. Estimating the Impact of the Balassa-Samuelson Effect on Inflation and the Real Exchange Rate During the Transition. Economic Systems 26(1). 1-16.

Égert, B. 2002b. Investigating the Balassa-Samuelson Hypothesis in the Transition: Do We Understand What We See? A Panel Study. Economics of Transition 10(2). 273-309.

Égert, B. 2003. Nominal and Real Convergence in Estonia: The Balassa-Samuelson (Dis)connection: Tradable Goods, Regulated Prices and Other Culprits. Eesti Pank Working Paper No. 4.

Égert, B. and A. Lahrèche-Révil. 2003. Estimating the Equilibrium Exchange Rate of the Central and Eastern European Acceding Countries: The Challenge of Euro Adoption. Weltwirtschaftliches Archiv. 139(4). 683-708. 
Égert, B. and K. Lommatzsch. 2003. Equilibrium Exchange Rates in Acceding Countries: How Large Is Our Confidence (Interval)? Oesterreichische Nationalbank. Focus on Transition No. 2.

Égert, B., I. Drine, K. Lommatzsch and Ch. Rault. 2003. The Balassa-Samuelson Effect in Central and Eastern Europe: Myth or Reality? Journal of Comparative Economics 31(3). 552-572.

Égert, B., D. Ritzberger-Grünwald and M. Silgoner. 2004. Inflation Differentials in Europe: Past Experience and Future Prospects. Oesterreichische Nationalbank. Monetary Policy and the Economy No. 1.

Filer, R. K. and J. Hanousek. 2000. Output Changes and Inflationary Bias in Transition. Economic Systems. 24(3). 285-294.

Filipozzi, F. 2000. Equilibrium Exchange Rate of the Estonian Kroon, Its Dynamics and Its Impacts of Deviations. Eesti PankWorking Paper No. 3.

Fischer, Ch. 2002. Real Currency Appreciation in Accession Countries: Balassa-Samuelson and Investment Demand. BOFIT Discussion Paper No. 8.

Flek, V., L. Marková and J. Podpiera. 2002. Sectoral Productivity and Real Exchange Rate Appreciation: Much Ado About Nothing? Åeská národní banka Working Paper Series No. 4.

Frait, J. and L. Komárek. 1999. Dlouhodobý rovnovážný re álný měnový kurz koruny a jeho determinanty. Åeská národní banka Monetary Policy Division Working Paper No. 9.

Froot, K. A. and K. Rogoff. 1994. Perspectives on PPP and Long-Run Real Exchange Rates. NBER Working Paper No. 4952.

Froot, K. A., M. Kim and K. Rogoff. 1995.: The Law of One Price Over 700 Years, NBER Working Paper No. 5132.

Golinelli, R. and R. Orsi. 2002. Modelling Inflation in EU Accession Countries: The Case of the Czech Republic, Hungary and Poland. In: Charemza, W. W. and K. Strzala. (eds.). East European Transition and EU Enlargement: A Quantitative Approach. Berlin: Springer Verlag. 267-290.

Gordon, R. J. 2000. The Boskin Commission Report and Its Aftermath. NBER Working Paper No. 7759.

Halpern, L. and Ch. Wyplosz. 1997. Equilibrium Exchange Rates in Transition Countries. IMF Staff Papers 44(4). 430-461.

Halpern, L. and Ch. Wyplosz. 2001. Economic Transformation and Real Exchange Rates in the 2000s: The Balassa-Samuelson Connection. UNO Economic Survey of Europe. 227-239.

Hanousek, J. and R. K. Filer. 2001a. Consumers' Opinion of Inflation Bias Due to Quality Improvements in Transition in the Czech Republic. CERGE-EI Working Paper 184.

Hanousek, J. and R. K. Filer. 2001b. Evaluating Imperfections and Biases in Price Indexes during Transition. CERGE-EI Working Paper No. 186.

Haskel, J. and H. Wolf. 2001. The Law of One Price: A Case Study. NBER Working Paper No. 8112.

Holub, T. and M. Čihák. 2003. Price convergence: What can the Balassa-Samuelson Model Tell Us? Åeská národní banka Working Paper Series No. 8.

Hinnosar, M., R. Juks, H. Kaadu and L. Uusküla. 2003. Estimating the Equilibrium Exchange Rate of the Estonian Kroon. Eesti Pank. Mimeo.

International Monetary Fund. 1998. Republic of Slovakia: Recent Economic Developments. IMF Staff Country Report No. 60.

Isard, P., H. Faruquee, G. R. Kincaid and M. Fetherston. 2001. Methodology for Current Account and Exchange Rate Assessments. IMF Occasional Papers No. 209.

Ito, T., P. Isard and S. Symansky. 1997. Economic Growth and Real Exchange Rate: An Overview of the Balassa-Samuelson Hypothesis in Asia. NBER Working Paper No. 5979. 
Jazbec, B. 2002. Balassa-Samuelson Effect in Transition Economies: The Case of Slovenia. William Davidson Working Paper No. 507.

Kao, C. 1999. Spurious Regression and Residual-Based Tests for Cointegration in Panel Data. Journal of Econometrics. 90(1). 1-44.

Karádi, P. 2003. Structural and Single Equation Estimation of the NATREX Equilibrium Real Exchange Rate of the Hungarian Forint. Magyar Nemzeti Bank. Mimeo.

Kazaks, M. 2000. Real exchange rate appreciation and loss of competitiveness. The case of Latvia. Presented at the Second Seminar of Managing Economic Transition in Eastern Europe. May 24, 2000. University College London. School of Slavonic and East European Studies.

Kemme, D. M. and W. Teng. 2000. Determinants of the Real Exchange Rate, Misalignment and Implications for Growth in Poland. Economic Systems 24(2). 171-205.

Kim, B. Y. and I. Korhonen. 2002. Equilibrium Exchange Rates in Transition Countries: Evidence from Dynamic Heterogeneous Panel Models. BOFIT Discussion Paper No. 15.

Kohler, M. 2000. The Balassa-Samuelson Effect and Monetary Targets. In: Mahadeva, L. and G. Sterne (eds.). Monetary Policy Frameworks in a Global Context. London and New York: Routledge. 354-389.

Kovács, M. A. 2001. The Equilibrium Exchange Rate in Hungary. MNB Background Study 3. Budapest.

Kovács, M. A. (ed.). 2002. On the Estimated Size of the Balassa-Samuelson Effect in Five Central and Eastern European Countries. Magyar Nemzeti Bank Working Paper No. 5.

Kovács, M. A. 2003. How Real Is the Fear? Investigating the Balassa-Samuelson Effect in CEC5 Countries in the Prospect of EMU Enlargement. Presented at "Monetary Strategies for Accession Countries". Budapest. 27 - 28 February.

Kovács, M. A. and A. Simon. 1998. Components of the Real Exchange Rate in Hungary. Magyar Nemzeti Bank Working Paper No. 3.

Kozamernik, D. 2003. Long-Run Growth and Price Convergence: Implications of a Two-Sector Neoclassical Growth Model and Application to the Slovenian Case. Prikazi in analize 11(2). Banka Slovenije.

Krajnyák, K. and J. Zettelmeyer. 1998. Competitiveness in Transition Economies: What Scope for Real Appreciation? IMF Staff Papers 45. 309-362.

Lee, J. and M. K. Tang. 2003. Does Productivity Growth Lead to Appreciation of the Real Exchange Rate? IMF Working Paper 154.

Lojschova, A. 2003. Estimating the Impact of the Balassa-Samuelson Effect in Transition Economies. Institute for Advanced Studies Working Paper No. 140.

Lommatzsch, K. and S. Tober. 2002a. Monetary Policy Aspects of the Enlargement of the Euro Area. Deutsche Bank Research Working Paper No. 4.

Lommatzsch, K. and S. Tober. 2002b. What Is behind the Real Appreciation of the Accession Countries' Currencies? An Investigation of the PPI-Based Real Exchange Rate. Presented at "Exchange Rate Strategies during the EU Enlargement." Budapest. 27 - 30 November.

Lommatzsch, K. and S. Tober. 2003. The inflation target of the ECB: Does the Balassa-Samuelson effect matter? DIW-Berlin. Mimeo.

MacDonald, R. 1997. What Determines Real Exchange Rates? The Long and Short of It. IMF Working Paper No. 21.

MacDonald, R. 1998. What Do We Really Know About Real Exchange Rates? Oesterreichische Nationalbank Working Paper No. 28.

MacDonald, R. 2000. Concepts to Calculate Equilibrium Exchange Rates: An Overview. Deutsche Bundesbank Discussion Paper No 3. 
MacDonald, R. and L. Ricci. 2001. PPP and the Balassa Samuelson Effect: The Role of the Distribution Sector. IMF Working Paper No. 38.

MacDonald, R. and C. Wójcik. 2002. Catching Up: The Role of Demand and Supply Side Effects on the Real Exchange Rate of Accession Countries. Oesterreichische Nationalbank. Focus on Transition 2. 3857.

Maeso-Fernandez, F., Ch. Osbat and B. Schnatz. 2003. Towards the Estimation of Equilibrium Exchange Rates for CEE Acceding Countries: Methodological Issues and a Panel Cointegration Perspective. European Central Bank Working Paper (forthcoming).

Maurin, L. 2001. Fundamental Determinants of RER for Transition Countries. In: Stierle, M. H. and T. Birringer (eds.). Economics of Transition: Theory, Experiences and EU-Enlargement. Berlin: Verlag für Wissenschaft und Forschung. 427-442.

Mihaljek, D. and M. Klau. 2003. The Balassa-Samuelson Effect in Central Europe: A Disaggregated Analysis. BIS Working Paper 143. Basel and Comparative Economic Studies (forthcoming).

Nurkse, R. 1945. Conditions of International Monetary Equilibrium. Essays in International Finance. Princeton: International Finance Section. Princeton University. Republished in the Theory of International Trade. Philadelphia: Blackiston. 1949. 3-34.

Pedroni, P. 1999. Critical Values for Cointegration Tests in Heterogeneous Panels with Multiple Regressors. Oxford Bulletin of Economics and Statistics. 61. Supplement 1. 653-670.

Pelkmans, J., Gros, D. and J. N. Perrer. 2000. Long-Run Economic Aspects of the European Union's Eastern Enlargement. The Netherlands Scientific Council for Government Policy Working Document 109.

Rahn, J. 2003. Bilateral Equilibrium Exchange Rates of the EU Accession Countries Against the Euro. BOFIT Discussion Paper No. 11.

Randveer, M. and M. Rell. 2002. The Relationship Between Competitiveness and Real Exchange Rate in Estonia. Eesti Pank Research Paper.

Rawdanowicz, Ł. W. 2003. Poland's Accession to EMU: Choosing the Exchange Rate Parity. CASE Studies\&Analyses 247. December 2002, and forthcoming in: De Souza, L.V. and B. Van Aarle (eds.). The Euro Area and the New EU Member States. New York: Palgrave Macmillan.

Rogoff, K. 1996. The Purchasing Power Parity Puzzle. Journal of Economic Literature. 34(2). 647-668.

Rosati, D. K. 2002. The Balassa-Samuelson Effect in the EU Candidate Countries. In: Roger, G. and A. Inotai (eds.). Trade, Integration and Transition. Budapest: The World Bank and Institute for World Economics. Hungarian Academy of Sciences. 58-77.

Rother, C. P. 2000. The Impact of Productivity Differentials on Inflation and the Real Exchange Rate: An Estimation of the Balassa-Samuelson Effect in Slovenia. IMF Country Report. Republic of Slovenia: Selected Issues 56. April. 26-39.

Rubaszek, M. 2003a. A Model of Balance of Payments Equilibrium Exchange Rate: Application to the Zloty. Narodowy Bank Polski. Mimeo.

Rubaszek, M. 2003b. The Optimal ERM II Central Parity for the Polish Zloty. Narodowy Bank Polski. Mimeo.

Saal, D. and D. Parker. 2001. Productivity and Price Performance in the Privatised Water and Sewerage Companies of England and Wales. Journal of Regulatory Economics 20(1). 61-90.

Samuelson, P. 1964. Theoretical Notes on Trade Problems. Review of Economics and Statistics 46(2). 145154.

Sarno, L. and M. P. Taylor. 2002. The Economics of Exchange Rates. Cambridge University Press.

Sinn, H. W. and M. Reutter. 2001. The Minimum Inflation Rate for Euroland. NBER Working Paper No. 8085. 
Stein, J. L. 1994. The Natural Real Exchange Rate of the US dollar and Determinants of Capital Flows. in J. Williamson (ed.). Estimating Equilibrium Exchange Rates. Institute for International Economics. 133176.

Stein, J. L. 1995. The Fundamental Determinants of the Real Exchange Rate of the U.S. Dollar Relative to Other G-7 Countries. IMF Working Paper No. 81.

Stein, J. L. 2002. The Equilibrium Real Exchange Rate of the Euro: An Evaluation of Research. CESifo Economic Studies. Zeitschrift für empirische Wirtschaftsforschung. 43(3). 349-381.

Stein, J. L. and G. C. Lim. 2002. Introduction to "Exchange rates in Europe and Australasia: Fundamental determinant, adjustments and policy implications." Australian Economic Papers 41(4). 329-341.

Šmídková, K. 1998. Estimating the FEER for the Czech Economy. Czech National Bank Institute of Economy Working Paper Series No. 87.

Šmídková, K., R. Barrell and D. Holland. 2002. Estimates of Fundamental Real Exchange Rates for the Five EU Pre-Accession Countries. Åeská národní banka Working Paper Series No. 3.

Szapáry, Gy. 2000. Maastricht and the Choice of Exchange Rate Regime in Transition Countries During the Run-up to EMU. Magyar Nemzeti Bank Working Paper No 7.

Vetlov, I. 2002. Analysis of the Real Exchange Rate and Competitiveness in Lithuania. Eesti Pank Research Paper.

Williamson, J. 1994. Estimates of FEERs. In: Williamson, J. (ed.). Estimating Equilibrium Exchange Rates. Washington D.C.: Institute for International Economics. 177-244.

Zavoico, B. 1995. A Brief Note on the Inflationary Process in Transition Economies. IMF. Mimeo. 


\section{DAVIDSON INSTITUTE WORKING PAPER SERIES - Most Recent Papers}

The entire Working Paper Series may be downloaded free of charge at: www.wdi.bus.umich.edu

CURRENT AS OF 2/26/04

\begin{tabular}{|c|c|c|}
\hline Publication & Authors & Date \\
\hline $\begin{array}{l}\text { No. 664: Assessing Equilibrium Exchange Rates in CEE Acceding } \\
\text { Countries: Can We Have DEER with BEER without FEER? }\end{array}$ & Balázs Égert & Feb. 2004 \\
\hline $\begin{array}{l}\text { No. 663: Modelling stock returns in the G-7 and in selected CEE } \\
\text { economies: A non-linear GARCH approach }\end{array}$ & Balázs Égert and Yosra Koubaa & Feb. 2004 \\
\hline $\begin{array}{l}\text { No. 662: Institutional Change and Product Composition: Does the Initial } \\
\text { Quality of Institutions Matter? }\end{array}$ & $\begin{array}{l}\text { Johannes Moenius and Daniel } \\
\text { Berkowitz }\end{array}$ & Feb. 2004 \\
\hline No. 661: Dual track liberalization: With and without losers & $\begin{array}{l}\text { Jiahua Che and Giovanni } \\
\text { Facchini }\end{array}$ & Feb. 2004 \\
\hline $\begin{array}{l}\text { No. 660: Who Is in Favor of Enlargement? Determinants of Support for } \\
\text { EU Membership in the Candidate Countries' Referenda }\end{array}$ & Orla Doyle and Jan Fidrmuc & Feb. 2004 \\
\hline No. 659: Creditor Moral Hazard in Sovereign Bond Markets & $\begin{array}{l}\text { Ayşe Y. Evrensel and Ali M. } \\
\text { Kutan }\end{array}$ & Feb. 2004 \\
\hline No. 658: Worsening of the Asian Financial Crisis: Who is to Blame? & $\begin{array}{l}\text { Brasukra G. Sudjana and Ali M. } \\
\text { Kutan }\end{array}$ & Feb. 2004 \\
\hline $\begin{array}{l}\text { No. 657: European Integration, Productivity Growth and Real } \\
\text { Convergence }\end{array}$ & Taner M. Yigit and Ali M. Kutan & Feb. 2004 \\
\hline $\begin{array}{l}\text { No. 656: The Impact of News, Oil Prices, and Global Market } \\
\text { Developments on Russian Financial Markets }\end{array}$ & Bernd Hayo and Ali M. Kutan & Feb. 2004 \\
\hline No. 655: Politics and Economic Reform in Malaysia & Bryan K. Ritchie & Feb. 2004 \\
\hline No. 654: The Evolution of Income Inequality in Rural China & $\begin{array}{l}\text { Dwayne Benjamin, Loren Brandt } \\
\text { and John Giles }\end{array}$ & Feb. 2004 \\
\hline $\begin{array}{l}\text { No. 653: The Sources of Real Exchange Fluctuations in } \\
\text { Developing Countries : an Econometric Investigation }\end{array}$ & Imed Drine and Christophe Rault & Feb. 2004 \\
\hline $\begin{array}{l}\text { No. 652: Ownership, Control and Corporate Performance After } \\
\text { Large-Scale Privatization }\end{array}$ & $\begin{array}{l}\text { Jan Hanousek, Evzen Kocenda } \\
\text { and Jan Svejnar }\end{array}$ & Feb. 2004 \\
\hline $\begin{array}{l}\text { No. 651: Czech Social Reform/Non-reform: Routes, Actors and } \\
\text { Problems }\end{array}$ & Jiri Vecernik & Feb. 2004 \\
\hline $\begin{array}{l}\text { No. 650: Financial Integration, Exchange Rate Regimes in CEECs, } \\
\text { and Joining the EMU: Just Do It... }\end{array}$ & Maurel Mathilde & Feb. 2004 \\
\hline $\begin{array}{l}\text { No. 649: Corporate Investments, Liquidity and Bank Financing: } \\
\text { Empirical Evidence from an Emerging Market }\end{array}$ & Arun Khanna & Feb. 2004 \\
\hline $\begin{array}{l}\text { No. 648: Financial Constraints in Investment - Foreign Versus } \\
\text { Domestic Firms. Panel Data Results From Estonia, 1995-1999. }\end{array}$ & $\begin{array}{l}\text { Tomasz Mickiewicz, Kate Bishop } \\
\text { and Urmas Varblane }\end{array}$ & Feb. 2004 \\
\hline $\begin{array}{l}\text { No. 647: Legal Minimum Wages and the Wages of Formal and Informal } \\
\text { Sector Workers in Costa Rica }\end{array}$ & $\begin{array}{l}\text { T. H. Gindling and Katherine } \\
\text { Terrell }\end{array}$ & Feb. 2004 \\
\hline $\begin{array}{l}\text { No. 646: Employment Expectations and Gross Flows by Type of Work } \\
\text { Contract }\end{array}$ & $\begin{array}{l}\text { Catalina Amuedo-Dorantes and } \\
\text { Miguel Á. Malo }\end{array}$ & Jan. 2004 \\
\hline $\begin{array}{l}\text { No. 645: Transition on the Shop Floor - The Restructuring of a Weaving } \\
\text { Mill, Hungary 1988-97 }\end{array}$ & János Köllő & Jan. 2004 \\
\hline $\begin{array}{l}\text { No. 644: Fighting "Low Equilibria" by Doubling the Minimum Wage? } \\
\text { Hungary's Experiment }\end{array}$ & Gábor Kertei and János Köllő & Jan. 2004 \\
\hline $\begin{array}{l}\text { No. 643: Mind the Break! Accounting for Changing Patterns of Growth } \\
\text { during Transition }\end{array}$ & Jan Fidrmuc and Ariane Tichit & Jan. 2004 \\
\hline No. 642: The Monetary Approach to Exchange Rates in the CEECs & $\begin{array}{l}\text { Jesús Crespo-Cuaresma, Jarko } \\
\text { Fidrmuc and Ronald MacDonald }\end{array}$ & Jan. 2004 \\
\hline $\begin{array}{l}\text { No. 641: Community Norms and Organizational Practices: The } \\
\text { Legitimization of Wage Arrears in Russia, 1992-1999 }\end{array}$ & $\begin{array}{l}\text { John S. Earle, Andrew Spicer and } \\
\text { Klara Sabirianova Peter }\end{array}$ & Jan. 2004 \\
\hline No. 640: Trust in Transition: Cross Country and Firm Evidence & $\begin{array}{l}\text { Martin Raiser, Alan Rousso, and } \\
\text { Franklin Steves }\end{array}$ & Jan. 2004 \\
\hline $\begin{array}{l}\text { No. 639: What Makes Small Firms Grow? Finance, Human Capital, } \\
\text { Technical Assistance, and the Business Environment in Romania }\end{array}$ & $\begin{array}{l}\text { J. David Brown, John S. Earle } \\
\text { and Dana Lup }\end{array}$ & Jan. 2004 \\
\hline
\end{tabular}

